\title{
Deep brain stimulation in movement disorders : the applications reconsidered
}

Citation for published version (APA):

Visser-Vandewalle, V. E. R. M. (2003). Deep brain stimulation in movement disorders : the applications reconsidered. [Doctoral Thesis, Maastricht University]. Universiteit Maastricht. https://doi.org/10.26481/dis.20040123vv

Document status and date:

Published: 01/01/2003

DOI:

10.26481/dis.20040123vv

Document Version:

Publisher's PDF, also known as Version of record

\section{Please check the document version of this publication:}

- A submitted manuscript is the version of the article upon submission and before peer-review. There can be important differences between the submitted version and the official published version of record.

People interested in the research are advised to contact the author for the final version of the publication, or visit the DOI to the publisher's website.

- The final author version and the galley proof are versions of the publication after peer review.

- The final published version features the final layout of the paper including the volume, issue and page numbers.

Link to publication

\footnotetext{
General rights rights.

- You may freely distribute the URL identifying the publication in the public portal. please follow below link for the End User Agreement:

www.umlib.nl/taverne-license

Take down policy

If you believe that this document breaches copyright please contact us at:

repository@maastrichtuniversity.nl

providing details and we will investigate your claim.
}

Copyright and moral rights for the publications made accessible in the public portal are retained by the authors and/or other copyright owners and it is a condition of accessing publications that users recognise and abide by the legal requirements associated with these

- Users may download and print one copy of any publication from the public portal for the purpose of private study or research.

- You may not further distribute the material or use it for any profit-making activity or commercial gain

If the publication is distributed under the terms of Article $25 \mathrm{fa}$ of the Dutch Copyright Act, indicated by the "Taverne" license above, 
Deep brain stimulation in movement disorders 


\section{Cover}

The background symbolizes the present: an MR-image after the bilateral implantation of electrodes in the subthalamic nucleus in a patient with Parkinson disease, which is currently the most frequent indication for DBS.

The figure in the foreground symbolizes the future: an illustration of the target the author has established for DBS in Tourette syndrome.

O V. Visser-Vandewalle, Maastricht 2003

ISBN 9090176543

Vormgeving en druk: Datawyse bv Mastricht 


\section{DEEP BRAIN STIMULATION IN MOVEMENT DISORDERS}

The applications reconsidered

\section{PROEFSCHRIFT}

ter verkrijging van de graad van doctor aan de Universiteit Maastricht, op gezag van de Rector Magnificus,

Prof, mr. G.P.M.F. Mols

volgens het besluit van het College van Decanen, in het openbaar te verdedigen

op vrijdag 23 januari 2004 om 14.00 uur

door

Veerle Visser-Vandewalle

geboren op 31 december 1964 te Sint-Niklaas, België 


\section{Promotores}

Prof. dr. E.A.M. Beuls

Prof. dr. D.A. Bosch (Academisch Medisch Centrum Amsterdam)

\section{Co-promotor}

Dr. G.H. Spincemaille

\section{Beoordelingscommissie}

Prof. dr. H.W.M. Steinbusch (voorzitter)

Prof. dr. M.A. van den Hout

Prof. dr. J. Troost

Prof, dr. E. Ch. Wolters (Vrije Universiteit medisch centrum Amsterdam)

This thesis is sponsored by an educational financial support from Medtronic B.V. and is for educational purposes only. The views expressed in this thesis are not necessarily those of Medtronic B.V. For any questions you might have concerning the therapies of Medtronic, please, contact the respective manufacturer. 
You see things, and you say "Why?"

But I dream things that never were, and $I$ say "Why not?"

Geonge Bemant Shat

Aan mijn ouders

Aan Ton

Aan Caspertje 



\title{
Contents
}

\author{
INTRODUCTION \\ 9
}

\section{CHAPTER 1}

15 Long-term motor effects of unilateral pallidal stimulation in advanced Parkinson disease: a study of 26 patients.

Visser-Vandewalle $V$, van der Linden $C$, Temel $Y$, ef al.

J Neurosurg 99: 701-707, 2003

\section{CHAPTER 2}

33 Long-term effects of bilateral subthalamic nucleus stimulation in advanced Parkinson disease: a four year follow-up study.

Visser-Vandewalle $V$, van der Linden $C$, Temel $Y$, et al.

$J$ Neurosurg (submitted)

\section{CHAPTER 3}

51 Bilateral high-frequency stimulation of the subthalamic nucleus in multiple system atrophy-parkinsonism. A report of four cases. Visser-Vandewalle V, Temel $Y$, Colle $H$, et al.

J Neurosurg 98: 882-887, 2003

\section{CHAPTER 4}

65 Surgery in Tourette syndrome. (Research Review)

Temel $Y$ and Visser-Vandewalle $V$

Mov Disord (In press) 


\section{CHAPTER 5}

87 Chronic bilateral thalamic stimulation: a new therapeutic approach in intractable Tourette syndrome. A report of three cases.

Visser-Vandewalle $V$, Temel $Y$, Boon $P$, et al.

J Neurosurg 99: 1094-1100, 2003

\section{CONCLUSION}

105

\section{CONCLUSIE}

109

DANKWOORD

113

LIST OF PUBLICATIONS

117

CURRICULUM VITAE

123 


\section{Introduction}

\section{HISTORY}

A. The pre-DBS era

The first operation in the treatment of movement disorders was performed in 1909 , by Sir Victor Horsley ${ }^{29}$. He performed cortical extirpations to alleviate athetosis. Since then, many extirpations and transsections in various parts of the corticospinal tract have been performed to treat hyperkinesias and Parkinson disease. In 1939. Russel Meyers introduced lesioning of the extrapyramidal system. In these procedures the head of the nucleus caudatus, parts of the putamen and globus pallidus, and the ansa lenticularis were successively dissected or transsected. These operations had a high complication rate, not only because of causing damage to the targeted structure (and its environment), but also because of damage to more superficially located parts of the brain that had to be passed to reach the deep seated structures. For this reason, the first application of a stereotactic device by Spiegel and Wycis in 1947 was a milestone in the history of functional neurosurgery: the intended structure, called the target, could be reached by a small burr hole, thus sparing more superficially located structures.

Initially these so-called "closed" functional operations were mainly performed in patients with intractable pain. In 1952, Spiegel and Wycis made lesions in the ansa lenticularis, globus pallidus and dorsomedial nucleus of the thalamus in patients with hyperkinetic phenomena.

In 1953 Cooper discovered by chance that ligation of the anterior choroidal artery resulted in an improvement in symptoms in a patient with Parkinson disease (PD) ${ }^{29}$. The effect was caused by softening of the globus pallidus and its efferents. Subsequently pallidal lesions, or "pallidotomies", were performed in larger series of PD patients. The changeover from pallidal to thalamic lesions was initiated by Hassler who not only performed thalamotomies in patients with tremor, but later also in patients with Tourette syndrome ${ }^{10}$. In 1969, Spiegel and $\mathrm{W}$ ycis were the first to create lesions in the subthalamus in patients with $\mathrm{PD}^{27}$. 
They limited their lesions to the fibres located ventral to the subthalamic nucleus, (STN) thereby avoiding this nucleus itself because of fear of evoking hemiballism.

By 1969 the results of more than 37,000 stereotactic operations had been published ${ }^{26}$. The vast majority of these had been performed in patients with PD, in an attempt to alleviate tremor and rigidity. At this time, levodopa became generally available. This medication seemed to have a spectacular effect on all parkinsonian symptoms, including akinesia, and consequently the number of stereotactic operations declined dramatically. However, as a result of the shortcomings of levodopa therapy in the long-term treatment of PD, the thalamotomy gradually regained its place, and in 1992, pallidotomies were reintroduced by Laitinen ${ }^{16}$

It was in the field of intractable pain that deep brain stimulation (DBS) was used for the first time. In 1973, a report appeared on chronic thalamic stimulation in five patients with anaesthesia dolorosa ${ }^{12}$.

In 1987, Benabid introduced DBS of the ventral intermediate thalamic nucleus (VIM) in the treatment of tremor. In patients with bilateral Parkinson tremor, a VIM thalamotomy was performed contralateral to the more disabled side, and chronic VIM stimulation on the other side 5 .

\section{B. DBS from 1987 to 2003}

Since 1987, unilateral and bilateral thalamic DBS has been performed on a wide scale in patients with tremor. In 1991 Benabid stated that "this reversibility and adaptability, allowing control of side effects, make thalamic stimulation preferable to thalamotomy, especially when treatment of both sides of the brain is needed". ${ }^{+}$In a lange series of patients with Parkinson disease and essential tremor with a follow-up of more than 8 years, a $85 \%$ reduction in tremor was obtained. ${ }^{21}$

A recent double-blind study by Schuurman et al compared the efficacy and safety of unilateral and bilateral thalamotomy versus thalamic DBS ${ }^{24}$. Both procedures provided a significant improvement in tremor, but adverse effects were much more common in the thalamotomy-treated group. The study concluded that thalamic DBS is better tolerated and provides a greater functional improvement than thalamotomy in PD patients with severe tremor.

Thalamic DBS has an almost exclusively anti-tremor effect with no improvement in other cardinal features of PD or levodopa-induced dyskinesias. 
In 1992, Siegfried introduced DBS of the ventroposterolateral globus pallidus internus $(\mathrm{GPi})$ as a new therapeutic approach for alleviating all parkinsonian symptoms ${ }^{25}$. Although these positive preliminary results had been confirmed by others in short-term follow-up studies, large studies with long-term follow-up review are lacking.

The discovery that primates treated with MPTP (1-methyl-4-phenyl-1, 2, 3, 6-tetrahydropyridine) provided an almost perfect animal model for idiopathic $\mathrm{PD}$, shed new light on the pathophysiology of the disease. An important discovery was that striatal dopamine deficiency led to an electrical hyperactivity of the $\mathrm{STN}^{2}$

After promising results of STN DBS in MPTP-treated primates? Benabid performed the first STN DBS in a PD patient in $1993^{20}$. Nowadays, the STN is considered to be the target of choice for patients with advanced PD, with a good effect on all cardinal motor symptoms.

\section{AIM AND OUTLINES OF THIS STUDY}

In this study the role of DBS in advanced PD is re-evaluated and new indications in the field of movement disorders are explored.

The benefit of thalamic stimulation to tremor patients has been broadly established since its first application $1,3,4,6,8,11,13,14,15,17,18,19,23,24$. For PD, however, the situation seems to be different: starting with DBS of the thalamus, surgeons moved to the GPi aiming to reduce all Parkinson symptoms, and eventually ended up at the STN.

This study commenced in January 1996. Unilateral pallidal stimulation was performed in selected patients with idiopathic PD with unilateral or asymmetric distribution of symptoms and, despite optimal pharmacological treatment, severe response fluctuations and/or dyskinesias. In chapter 1, we analyze the long-term motor effect of unilateral pallidal stimulation in 26 patients.

Between June 1997 and September 1998, patients were selected for STN DBS if they had clinical findings consistent with idiopathic PD with bilateral and/or axial symptoms. Many reports have been published on the long-term benefits of STN DBS in PD, but all with limited follow-up. Chapter 2 presents the literature on the long-term effects of bilateral STN DBS in PD and the outcome of our own 
series of 32 patients with a follow-up of 4 years. The beneficial as well as the unwanted effects of bilateral STN stimulation at long term are discussed.

In chapter 3, we describe the effects of STN DBS in multiple system atrophy-parkinsonism (MSA-P). MSA-P is a highly incapacitating disease with a short life-expectancy and very few treatment options. Only two patients with MSA-P who underwent bilateral STN stimulation have been reported in the literature. Because of short-term unsatisfactory results, the electrodes were removed in one patient. We present the long-term effects of bilateral STN stimulation in four patients with MSA-P and compare these to the effect of natural disease progression by evaluating the patients when both stimulators are switched off.

Whereas PD and MSA-P are mainly characterized by hypokinesia, we explored the possible role of DBS in a hyperkinetic disorder, namely Tourette syndrome (TS). TS is a chronic neurological disorder with onset in early childhood and characterized by tics. Tics are sudden, brief, intermittent, involuntary or semivoluntary movements (motor tics) or sounds (phonic or vocal tics). Frequently, TS is found to be a self-limiting disorder as the patient reaches adulthood whereas in a small proportion of the patients the tics continue into adult life and require long-term medication. Behavioral therapy has not been proven to be effective at long term. In chapter 4 we present an extensive review of procedures

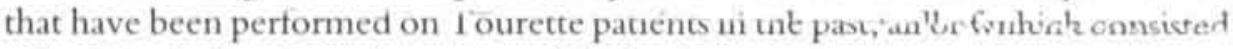
of making lesions in various parts of the brain.

In chapter 5, we introduce DBS as a new therapeutic approach in intractable TS. We performed the first DBS in a patient with intractable TS $^{28}$ in 1997. In this last chapter, we present the long-term outcome of bilateral thalamic stimulation in three patients with TS.

\section{REFERENCES}

1. Alesch F, Pinter MM, Helscher RJ, et al. Stimulation of the ventral intermediate thalamic nucleus in tremor dominated Parkinson's disease and essential tremor. Acta Neurochir (Wien) 1995;136(1-2):75-81

2. Aziz TZ, Peggs D, Sambrook MA., et al. Lesion of the subthalamic nucleus for the alleviation of 1-methyl-4-phenyl-1, 2, 3, 6-tetrahydropyridine (MPTP) - induced Parkinsonism in the primate. Mov Disord 1991: 6 (No 4): 288-292

3. Benabid AL, Pollak P. Gao D, et al. Chronic electrical stimulation of the ventralis intermedius nucleus of the thalamus as a treatment of movement disorders.

J Neurosurg 1996: 84(2): 203-14 
4. Benabid AL, Pollak P, Gervason C, et al. Long-term suppression of tremor by chronic stimulation of the ventral intermediate thalamic nucleus. Lancet 1991 Feb 16;337(8738): 403-6

5. Benabid AL, Pollak P, Louveau A, et al. Combined (thalamotomy and stimulation) stereotactic surgery of the VIM thalamuc nucleus for bilateral Parkinson disease. Appl Neurophysiol 1987; 50(1-6): 344-6

6. Benabid AL, Pollak P, Seigneuret E, et al. Chronic VIM thalamic stimulation in Parkinson's disease, essential tremor and extra-pyramidal dyskinesias. Acta Neurochir (Wien) 1993:58: $39-44$

7. Benazzouz A, Gross C, Feger J. Reversal of rigidity and improvement in motor performance by subthalamic high-frequency stimulation in MPTP-treated monkeys.

Eur J Neurosc 1993: 5: 382-389

8. Caparros-Lefebvre D, Blond S, Vermersch P. Chronic thalamic stumulation improves tremor and levodopa induced dyskinesias in Parkinson's disease. I Neurol Neurosurg Psychiatry 1993 Mar; 56(3): 268-73

9. Guridi J en Obeso JA. The role of the subthalamic nucleus in the origin of hemiballism and parkinsonism. In: The basal gangla and new surgical approaches for Parkinson's Disease. Advances in Neurology, Vol 74, Ed by Obeso JA, Delong MR, Ohye C and Marsden D. Lippincott-Raven Publishers, Philadelphia (1997

10. Hassler R, Dieckmann G. Relief of obsessive-compulsye disorders, phobias and tics by stereotactic coagulations of the rostral intralaminar and medial-thalamic nuclei. In: Laitinen LV. Livingoton (eds): Surgical approaches in psychiatry. Proceedings of the Third Intermational Congress of Psychosurgery, Cambridge UK, Garden City Press, Letchworth. 1973: 206-212.

11. Hooper J, Taylor R, Pentland B. A prospective study of thalamic deep brain stimulation for the treatment of movement disorders in multiple sclerosis. Br J Neurosurg $2002 \mathrm{Apr}$; 16(2): 102-9

12. Hosobuchi Y. Adams JE en Rutkin B. Chronic thalamic stimulation for the control of facial anesthesia dolorosa. Arch Neurol 1973; 29:158-161

13. Koller WC, Pahwa PR, Lyons KE. Deep brain stimulation of the Vim nucleus of the thalamus for the treatment of tremor. Neurology 2000; 55 (12 Suppl 6): S29-33

14. Kumar K, Kelly M, Toth C. Deep brain stimulation of the ventral intermediate nucleus of the thalamus for control of tremors in Parkinson's disease and essential tremor. Stereotact Funct Neurosurg. 1999: 72(1): 47-61

15. Krauss JK, Simpson RK Jr, Ondo WG, et al. Concepts and methods in chronic thalamic stimulation for treatment of tremor: technique and application. Neurosurgery $2001 \mathrm{Mar}$; 48(3): 535-41; discussion 541-3

16. Laitinen LV, Bergenheim T. Hariz M. Leksell's posteroventral pallidotomy in the treatment of Parkinson's disease. J Neurosurg 1992; 76: 53-61

17. Lozano AM. Vim thalamic stimulation for tremor. Arch Med Res 2000 May-Jun; $31(3): 266-9$ 
18. Pahwa R, Lyons K, Koller WC. Surgical treatment of essential tremor. Neurology 2000; 54(11 Suppl 4): S39-44

19. Pollak P, Benabid AL, Gervason CL, et al. Long-term effects of chronic stimulation of the ventral intermediate thalamic nucleus in different types of tremor. Adv Neurol 1993; 60:408-13

20. Pollak P, Benabid AL, Gross C. Effets de la stimulation du noyau sous-thalamique dans la maladie de Parkinson. Rev Neurol Paris 1993 ; 149(3):175-176

21. Pollak P, Benabid AL, Limousin P, et al. Chronic intracerebral stimulation in advanced Parkinson's disease. Adv Neurol 1997; 74:213-220

22. Pollak P, Benabid AL, Limousin P. Subthalamic nucleus stimulation alleviates akinesia and rigidity in parkinsonian patients. Adv Neurol, Vol 69, ed by Battistin L, Scarlato G, Caraceni T, and Rugieri S. Lipincott-Ravne Publishers, Philadelphia@1996

23. Rehncrona $\mathrm{S}$, Johnels $\mathrm{B}$, Widner $\mathrm{H}$, et al. Long-term efficacy of thalamic deep brain stimulation for tremor: double-blind assessments. Mov Disord 2003 Feb; 18(2): 163-70

24. Schuurman PR, Bosch DA, Bossuyt PM., et al. A comparison of continuous thalamic stimulation and thalamotomy for suppression of severe tremor. N Engl J Med $2000 \mathrm{Feb}$ 17: $342(7): 461-8$

25. Siegfried J en Lippitz B. Bilateral chronic electrostimulation of ventroposterolateral pallidum: a new therapeutic approach for alleviating all parkinsonian symptoms. Neurosurgery 1994; 35 (No 6): 1126-1130

26. Speelman JD, Bosch DA. Resurgence of functional neurosurgery for Parkinson's disease: a historical perspective. Mov Disord 1998 May: 13(3): 582-8

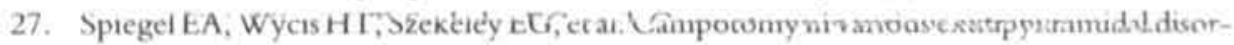
ders. J Neurosurg 1963; 20: 871-884

28. Vandewalle V, van der Linden Chr, Groenewegen HJ, et al. Stereotactic treatment of Gilles de la Tourette syndrome by high frequency stimulation of thalamus. Lancet $1999 ; 353(9154): 724$

29. Van Manen J. Stereotactic methods and their applications in disorders of the motor system. Royal VanGorcum, Publishers, Assen. The Netherlands. Charles C Thomas, Publisher, 1967 
CHAPTER 1

\section{Long-term motor effects of unilateral pallidal stimulation in 26 patients with advanced Parkinson disease}

Veerle Visser-Vandewalle, Chris van der Linden, Yasin Temel, Fred Nieman, Halime Celik, Emile Beuls.

J Neurosung 99: 701-707, 2003 


\begin{abstract}
Object. The aim of this study was to evaluate the long-term effects of unilateral pallidal stimulation on motor function in selected patients with advanced Parkinson disease (PD).
\end{abstract}

Methods. The authors enrolled 26 patients with idiopathic PD in whom there was an asymmetric distribution of symptoms and, despite optimal pharmocological treatment, severe response fluctuations and/or dyskinesias. After the patient had received a local anesthetic agent, a quadripolar electrode (Medtronic model 3387) was implanted at the side opposite the side affected or, if both sides were affected, the side contralateral to the more affected side. No serious complications occurred. After 3 months, the total Unified PD Rating Scale (UPDRS) Part III score decreased by $50.7 \%$ while patients were in the off-medication state (from $26.5 \pm 9.2$ to $13.1 \pm 6.1$ ) and by $55.4 \%$ while they were in the on-medica-

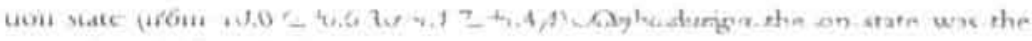
contralateral effect clearly more pronounced. The UPDRS Part IVa score decreased by $75 \%$ (from $3.7 \pm 2.5$ to $0.9 \pm 1.1$ ), and the UPDRS Part IVb score by $54.7 \%$ (from $3.3 \pm 1.3$ to $1.5 \pm 1.3$ ).

At long-term follow-up review $(32.7 \pm 10.7$ months), there was an $8.3 \%$ increase in the UPDRS Part III score while patients were in the off state (from 26.5 \pm 9.2 to $28.7 \pm 7.6)$. and $a 40.2 \%$ increase in this score while patients were in the on state (from 10.6 \pm 6.3 to $14.9 \pm 5.1$ ). The UPDRS Part IV a score decreased by $28.1 \%$ (from $3.7 \pm 2.5$ to $2.7 \pm 2.3$ ), and the UPDRS Part IVb score increased by $3.5 \%$ (from $3.3 \pm 1.3$ to $3.4 \pm 1.6$ ).

Conclusions. Based on these unsatisfactory results at long-term review, the authors conclude that unilateral pallidal stimulation is not an effective treatment option for patients with advanced PD. 
The GPi has been of interest to neurosurgeons in the treatment of PD since the middle of the $20^{\text {th }}$ century ${ }^{23}$. Initially, the target was located in the anterior and mediodorsal portion of the nucleus, but these medial pallidotomies only had an effect on rigidity, and not on tremor. In 1956, Leksell moved the target toward the ventroposterolateral portion of the $\mathrm{GPi}$, and equal effects on tremor, rigidity and bradykinesia were reported. In 1992, Laitinen and colleagues ${ }^{24}$ published the results of a large series of ventroposterolateral pallidotomies, which had been undertaken over an extended period of time. The results showed that this procedure gave long-lasting relief from akinesia and rigidity; other authors have since confirmed the relevance of the lesion.

After the discovery that high frequency DBS has the same effect on symptoms as lesions but with fewer complications, the possibility of adjusting the effect over time and the chance of performing bilateral surgery led Siegfried to become the first to perform chronic pallidal electrostimulation in $1994^{34}$.

Several reports have appeared on the effect of pallidal stimulation. As shown in a recent study ${ }^{26}$, it is difficult to interpret the results because of several factors, and large studies with long-term follow-up review are lacking. In general, the reports agree that there is a strong postoperative drug dependency, whereas drug-related side effects, more specifically dyskinesias, are directly counteracted by the stimulation.

In January 1996 we embarked on a technique of stereotactic surgery performed in patients with advanced PD. Because authors of several studies had reported beneficial effects of unilateral pallidotomy on parkinsonian symptoms $7,8,23,24$ and because DBS had proved to have fewer complications ${ }^{35}$, we decided to start with unilateral pallidal stimulation in selected patients. In previous studies we reported on cognitive outcomes ${ }^{41}$ and changes in the quality of life ${ }^{40}$ following unilateral pallidal stimulation in patients with PD.

In this report we prospectively analyse the long-term effects of unilateral pallidal stimulation on motor function.

\section{CLINICAL MATERIAL AND METHODS}

Patient population

Between January 1996 and June 1997 patients were selected for unilateral pallidal stimulation if they had clinical findings consistent with idiopathic PD accompa- 
nied by asymmetric distribution of symptoms and, despite optimal pharmacological treatment, severe response fluctuations and/or dyskinesias. Good initial response to levodopa was an absolute criterion. The one exception to this was the inclusion of patients who demonstrated levodopa-resistant rest tremor. Exclusion criteria included significant atrophy, multiple white matter lesions, or other focal brain abnormalities on MR images; parkinsonism due to known causative factors, Hoehn and $Y$ ahr stage $V$ at the best moment of the day; a score less than 24 on the Mini-Mental State Examination; psychosis;and general contraindications for surgery such as severe hypertension or blood coagulation disorders.

\section{Surgery}

Stereotactic surgery was performed using local anesthesia and the Leksell $G$ frame after overnight withdrawal of antiparkinsonian drugs. The target was chosen in the external segment of the GPi with the following coordinates: 18 to $22 \mathrm{~mm}$ lateral to the AC-PC line, $4 \mathrm{~mm}$ anterior to the midcommissural point, and $2 \mathrm{~mm}$ inferior to the intercommissural line. In the first 10 patients the target was defined using both CT scanning and ventriculography. It became clear that target calculation performed using ventriculography added no extra value to target calculation performed using computerized tomography alone, and we therefore decided to omit the ventriculography measurement in the remaining patients.

After making a precoronal burr hole, a rigid monopolar test- stimulation electrode (diameter $1.8 \mathrm{~mm}$ with a $2 \mathrm{~mm}$ naked tip, model 3101; Radionics, Ghent, Belgium) was introduced $6 \mathrm{~mm}$ above the presumed target. Stimulation was initiated with a frequency of $100 \mathrm{~Hz}$ and a stimulus duration of $0.1 \mathrm{~ms}$, and it was continued stepwise every $2 \mathrm{~mm}$, until $4 \mathrm{~mm}$ below the target. At each step the stimulus intensity was increased at increments of $0.5 \mathrm{~V}$ until the desired response was achieved or until unwanted side effects occurred. At each point of the test stimulation, the clinical response was evaluated by one neurologist (C.v.d.L.) blinded to the presence of the stimulation. The following clinical parameters were assessed using the UPDRS: tremor (if present) and rigidity in all four extremities; rapid finger movements; closing and opening of the hands; and dorsiflexion and plantar flexion of the feet and leg movements. If a clinical response was not present at or several millimeters below the target, the electrode was withdrawn and a second target through a different trajectory $-2 \mathrm{~mm}$ anterior, posterior, medial or lateral to the initial target-was chosen. If necessary, additional adjacent trajectories were selected. After determination of the optimum stimulation site, the monopolar electrode was replaced by the final quadripolar electrode (model 3387; Medtronic, Kerkrade. The Netherlands), with the second deepest pole at the level of the best clinical result. At the level of the burr hole, the electrode was fixed with methyl metacrylate and connected to an extension cable, which was 
externalized about $7 \mathrm{~cm}$ from the burr hole and connected to an external pulse generator (model 3625; Medtronic). If 1 week of evaluation with test stimulation had shown a clear effect on parkinsonian symptoms, a second operation was performed while the patient was in a state of general anesthesia for the subcutaneous implantation of the pulse generator (Itrel 2 model 7425 in 13 patients, and Itrel 2 model 7424 in the other 13 [Medtronic]).

\section{Clinical evaluation}

Motor performance was evaluated using part III, dyskinesias using part IVa, and motor fluctuations using part IVb of the UPDRS ". Preoperative UPDRS Part III assessments were conducted in the best on-medication state (on state) and the practically defined off-medication state (off state), as described in the Core Assessment Program for Intracerebral Transplantations in patients with PD (CAPIT-PD $)^{25}$. Postoperative UPDRS Part III scores were evaluated during the best on and the practically defined off states with the stimulator on. For motor subscores the following questions from Part III were used: for rest tremor, Question 20 (maximum score 26); for rigidity, Question 22 (maximum score 20); for bradykinesia, Question 31 (maximum score 4); for akinesia, Questions 23 through 26 (maximum score 32); for gait, Question 29 (maximum score 4): and for freezing, Question 14 of Part II (maximum score 4). Dyskinesias and daily appearance and predictability of off periods were evaluated using UPDRS Part IVa (dyskinesias; maximum score 13) and Part IVb (motor fluctuations; maximum score 7) scores both preoperatively and postoperatuvely with the stumulator on.

\section{Medication use}

Medication intake was defined by the levodopa equivalent dose (LED), which equals $100 \mathrm{mg}$ levodopa or $133 \mathrm{mg}$ of levodopa modified-release preparations, or $1 \mathrm{mg}$ pergolide, $10 \mathrm{mg}$ bromocryptine, $1 \mathrm{mg}$ cabergoline, $6 \mathrm{mg}$ ropinirole, $1 \mathrm{mg}$ lisuride, or $20 \mathrm{mg}$ apomorphine.

\section{Statistical analysis}

Data are presented as mean values \pm SDs. Changes between preoperative baseline, 3-month follow-up, and long-term follow-up were analysed using the paired Student t-test and the Wilcoxon signed-rank test.

This was repeated for both off and on states and for both sides (contralateral and ipsilateral) in each clinical parameter. Differences in follow-up values, compared with baseline values in the off state were compared with the same differences in the on state by applying repeated-measures analysis of variance, in which double paired $t$-tests are performed. Triple paired $t$-tests are also performed in this way. when the difference between contralateral and ipsilateral sides were compared 
over time in both the off and on state. Along with all these paired t-tests a more comprehensive analysis was performed in which the patient's linear changes over time were expressed as one overall parameter. The calculation of the ordinary linear slope over time was complicated by the variable moment at which long-term follow-up results were measured: this could vary between 6 and 49 months after the operation. Weights found in unequal-distances first-order orthogonal polynomials were used to calculate individual linear slopes over time. Next, mean linear slopes in contralateral measurements, averaged for both the off and on states of the patients, were compared with those in ipsilateral measurements by means of the paired Student $t$-test and also by the Wilcoxon signed-rank test. To assess the relationship between preoperative differences in contralateral and ipsilateral scores and linear-slope differences between the same scores the Pearson correlation coefficient was used. To control for both age and sex, a regression analysis was performed to test the statistical significance of this relationship by means of its partial standardized regression or $\beta$ coefficient. A probability value less than 0.05 is considered to be statistically significant. All data were analyzed using a commercially available statistical software program(SPSS-pc, version 11.0.1; SPSS Inc., Chicago, IL).

\section{RESULTS}

Twenty-six patients ( 20 men and six women) were included in this study. The mean age of these patients at the time of diagnosis was $43.1 \pm 10.5$ years and the mean age at the time of surgery was $56.2 \pm 8.6$ years. Patient profiles are listed in Table 1. The side chosen for stimulation was either contralateral to the side affected or, if both sides were affected, contralateral to the more affected side.

The mean number of trajectories necessary to find an optimal clinical result during test stimulation was 2.44 (range 1-9 trajectories). No incidence of bleeding or serious side effects was encountered. Four patients displayed confusion for a maximum of 3 days after the electrode implantation. One patient suffered pain due to traction on the extension cable after implantation of the pulse generator; the pain disappeared after an Itrel augmentation procedure.

Results are presented 3 months after surgery and at long-term follow-up review, which occurred at a mean of 32.7 months (range 6-49 months). 
Table 1 Charactenstics of 26 patients receving unilateral GP1 stumulation.

\begin{tabular}{|c|c|}
\hline Characteristic & Value \\
\hline \multicolumn{2}{|l|}{ Sex (no. of patients) } \\
\hline male & 20) \\
\hline female & 6 \\
\hline \multicolumn{2}{|l|}{ Age $(y \mathrm{ri})$ at disease onset } \\
\hline mean $\pm S D$ & $43.1 \pm 10.5$ \\
\hline range & $20-60$ \\
\hline \multicolumn{2}{|l|}{ Age (yn) at surgery } \\
\hline mean $\pm S D$ & $56.2 \pm 8.6$ \\
\hline range & $38-67$ \\
\hline \multicolumn{2}{|l|}{ Disease duration (yn) } \\
\hline mean $\pm S D$ & $13.1 \pm 5.0$ \\
\hline range & $5-21$ \\
\hline No: of pattents with tremor & 18 \\
\hline No, of patients with dyskinevias & 21 \\
\hline \multicolumn{2}{|l|}{ Most affected side (no, of patients) } \\
\hline left & 11 \\
\hline right & 15 \\
\hline \multicolumn{2}{|l|}{ Follow-up (mos) } \\
\hline mean \pm SD & $32.7 \pm 10.7$ \\
\hline range & $6-49$ \\
\hline No. of patients with follow-up $>24 \operatorname{mos}$ & 21 \\
\hline
\end{tabular}

Overall effect on motor function

At 3 months postoperatively, significant improvements were found in global lateral motor symptoms, as well as in bodv bradykinesia and gait, during off and on states. Freezing did not improve significantly. For all these symptoms, with the exception of akinesia, the improvement was significantly more pronounced while the patient was in the on state than in the off state $(0.001<p<0.014)$. The total UPDRS Part III score did decrease by $50.7 \%$ (from $26.5 \pm 9.2$ to $13.1 \pm 6.1$ ) in the off state, and by $55.4 \%$ (from $10.6 \pm 6.3$ to $4.7 \pm 4.4$ ) in the on state ( $\mathrm{p}$ $<0,001)$. These differences in effect between the off and on states were most pronounced for body bradykinesia ( $\mathrm{p}<0.001$; difference was $65.2 \%$ [ from $2.7 \pm 0.8$ to $0.9 \pm 0.7]$ in the off state and $-81 \%$ [from $0.6 \pm 0.7$ to $0.1 \pm 0.3]$ in the on state). and for gait $(\mathrm{p}=0.005$; difference was $-49.3 \%$ [from $2.6 \pm 1.1$ to $1.3 \pm 0.6$ ] in the off state and $-57.2 \%$ [from $1.1 \pm 0.8$ to $0.5 \pm 0.6]$ in the on state).

There was a pronounced improvement in dyskinesias, with a decrease of $75 \%$ (from $3.7 \pm 2.5$ to $0.9 \pm 1.1$ ) in the UPDRS Part IVa score and a clear reduction in 
Table 2 Companison of motor scores and medication use in 26 patients who recerved umilateral stimulation of the GPi

\begin{tabular}{|c|c|c|c|c|c|c|c|c|}
\hline \multirow[b]{2}{*}{ Scoring Factor } & \multirow[b]{2}{*}{ Bascline score } & \multicolumn{3}{|c|}{ 3-mo Follow-up } & \multicolumn{3}{|c|}{ Long-Term Follow-up } & \multirow[b]{2}{*}{ 3-Mo/LTp Value } \\
\hline & & Score & "XChange" & P Value & Score & 8 Change" & p Value & \\
\hline \multicolumn{9}{|l|}{ OFF STATE } \\
\hline UPDRS Part III tocal score & $26.5 \pm 9.2$ & $13.1 \pm 6.1$ & -50.7 & $<0.001$ & $28.7 \pm 76$ & +8.3 & 0.244 & $<0.001$ \\
\hline tremor & $3.5 \pm 3.6$ & $1.4 \pm 2.2$ & -62.0 & $<0,001$ & $3.1 \pm 3.1$ & -120 & 0.453 & $<0.001$ \\
\hline rigrdity & $5.5 \pm 30$ & $3,0 \pm 2.0$ & -45.5 & $<0,001$ & $6.0 \pm 27$ & +9.1 & 0,416 & $<0,001$ \\
\hline akineria & $12.3 \pm 7.2$ & $6.5 \pm 4.3$ & -47.2 & $<0.00$ & $145 \pm 4.5$ & +17.8 & 0.099 & $<0.001$ \\
\hline bradykinesia & $2.7 \pm 0.8$ & $0.9 \pm 0.7$ & -65.2 & $<0.001$ & $2.3 \pm 0.8$ & -14.5 & 0.096 & $<0.001$ \\
\hline freczing & $20 \pm 1.1$ & $1.4 \pm 0.7$ & .32 .7 & 0,007 & $2.9 \pm 1.1$ & $+\$ 6.2$ & 0.001 & $<0,001$ \\
\hline gat & $2.6 \pm 1.1$ & $1.3 \pm 0.6$ & -49.3 & $<0.00 \mathrm{t}$ & $2.8 \pm 0.6$ & +9.0 & 0.207 & $<0,001$ \\
\hline \multicolumn{9}{|l|}{ ON STATE } \\
\hline UPDRS Part III total score & $10.6 \pm 6.3$ & $47 \pm 4.4$ & $-55+$ & $<0.001$ & $14.9 \pm 5.1$ & +40.2 & $<0,001$ & $<0,001$ \\
\hline tremor & $1.2 \pm 2.3$ & $0.3 \pm 0.8$ & -75.6 & $<0,001$ & $0.6 \pm 10$ & $-50,0$ & 0.088 & 0.043 \\
\hline rigidity & $2.3 \pm 2.0$ & $0.9 \pm 14$ & .65 .2 & $<0,001$ & $2.0 \pm 1.8$ & -13.0 & 0.381 & $<0.001$ \\
\hline akinesiz. & $5.4 \pm 4.3$ & $3.0 \pm 3.1$ & -44.7 & $<0.001$ & $10.3 \pm 3.7$ & +90.8 & $<0,001$ & $<0.001$ \\
\hline bradykinesia & $0.6 \pm 0.7$ & $0.1 \pm 0.3$ & -81.2 & $<0,001$ & $0.4 \pm 0.7$ & -31.3 & 0.232 & 0.029 \\
\hline freezing: & $0.4 \pm 0.8$ & $0.2 \pm 0.4$ & .45 .5 & 10.170 & $1.2 \pm 0.9$ & +172.7 & 0.001 & $<0.001$ \\
\hline gaie & $1.1 \pm 0.8$ & $0.5 \pm 0.6$ & -57.2 & $<0,001$ & $1.5 \pm 0.6$ & +39.3 & 0.005 & $<0.001$ \\
\hline UPDRS Part IVa score & $3.7 \pm 2.5$ & $0.9 \pm 1.1$ & -75.0 & $<0.0001$ & $2.7 \pm 2.3$ & -28.1 & 0.036 & $<0,001$ \\
\hline UPDRS Part IVb score & $3.3 \pm 1.3$ & $1.5 \pm 1.3$ & -54.7 & $<0,001$ & $3.4 \pm 1.6$ & +3.5 & 0.713 & $<0.001$ \\
\hline \multicolumn{9}{|l|}{ MEDICATION } \\
\hline LED (me & $788 \pm 262$ & $821 \pm 408$ & +42 & 0223 & $1212 \pm 409$ & +53.8 & 0.001 & $<0.001$ \\
\hline
\end{tabular}

-Values are expreased as means \pm SD; 'Percentages of change with respect to baseline value ( $+=$ increase, $-=$ decrease

Abbrevation: 3 -mo/LT = results at long-term follow-up compared with resultx at 3-month follow-up 
Table 3 Outcome scores of lateral motor symptoms in 26 patients who received unilateral GPi stamulation: companson of effects contra- and ipsilateral to the side of stimulation

\begin{tabular}{|c|c|c|c|c|c|c|c|c|}
\hline \multirow[b]{2}{*}{ Scoring Factor } & \multirow{2}{*}{$\begin{array}{l}\text { Bascline Score } \\
\text { (contralat/ipsilat) }\end{array}$} & \multicolumn{3}{|c|}{ 3-Mo Follow-Up (contralat/ipulat) } & \multicolumn{3}{|c|}{ Long-Term Follow-up (contralat/rpulat) } & \multirow{2}{*}{$\begin{array}{l}\text { 3-mo/LT } \\
\text { P Value }\end{array}$} \\
\hline & & Score & \%o Change & p Value & Score & \$Change & P Value & \\
\hline \multicolumn{9}{|l|}{ OFF STATE } \\
\hline UPIDRS Part III total & $18.5 \pm 4.9 / 13.0+5.7$ & $9.5 \pm 3.8 / 5.8 \pm 34$ & $-48.6 /-55.8$ & $<0,001 /<0,0011$ & $189 \pm 46 / 147 \pm 41$ & $+21 /+127$ & $0.718 / 0.150$ & $<0,001 /<0,001$ \\
\hline tremor & $2.5 \pm 2.3 / 0.7 \pm 1.4$ & $1.1 \pm 1.7 / 0.2 \pm 0.7$ & $-56.1 /-68.4$ & $<0,001 /<0.030$ & $2.4 \pm 2.2 / 0.7 \pm 1.1$ & $-76 /-5.3$ & $0.593 / 0.857$ & $0.001 /<0.001$ \\
\hline ngidity & $3.2 \pm 1.7 / 24 \pm 1.6$ & $20 \pm 1.2 / 1.0 \pm 1.0$ & $-36.1 /-68.4$ & $<0,001 /<0001$ & $3.4 \pm 1.4 / 2.6 \pm 1.6$ & $-4.8 /+9.8$ & $0.703 / 0513$ & $<0.001 /<0,001$ \\
\hline akineua & $7.6 \pm 3.7 / 4.7 \pm 3.8$ & $4.2 \pm 2.5 / 2.4 \pm 2.2$ & $-552 /-50.4$ & $<0,001 /<0) 001$ & $8.2+2.7 / 6.4 \pm 41$ & $+76 /+342$ & $0.427 / 0.022$ & $<0.001 /<0.001$ \\
\hline \multicolumn{9}{|l|}{ ON STATE } \\
\hline UPIDRS Part III total & $78 \pm 3.8 / 46 \pm 3,4$ & $20 \pm 2.1 / 3.3 \pm 3.0$ & $-74.4-27.7$ & $<0,001 /<00 .(n) 1$ & $7 \pm \pm 27 / 94 \pm 3.3$ & $-4.9 /+104.2$ & $0.469 /<0001$ & $<0.001 /<0001$ \\
\hline tremor & $10 \pm 1.6 / 0.2 \pm 0.7$ & $0.1 \pm 0.40 .2 \pm 0.6$ & $-88.0 /-16.7$ & $0.007 / 0.327$ & $02 \pm 0.5 / 0.4 \pm 0.7$ & $-80.0 /+66.7$ & $0.015 / 0212$ & $0.161 / 0.134$ \\
\hline ngedity & $1.7 \pm 1.2 / 0.7 \pm 1.1$ & $0,1 \pm 0,4 / 0,7 \pm 1,0$ & $-93.2 /+5.6$ & $<0,001 / 0.574$ & $0.2 \pm 0.5 / 18 \pm 1.4$ & $-86.4 /+155.6$ & $<0.001 /<0.001$ & $0.185 /<0.001$ \\
\hline akinesia & $35 \pm 24 / 20 \pm 22$ & $1.2 \pm 1.6 / 1.8 \pm 19$ & $-65.5 /-7.8$ & $<0001 / 01+63$ & $5.1 \pm 20 / 53 \pm 2.0$ & $+46,7 /+168.6$ & $<0.001 /<0001$ & $<0,001 /<0,001$ \\
\hline
\end{tabular}


motor fluctuations, with a decrease of $54.7 \%$ (from $3.3 \pm 1.3$ to $1.5 \pm 1.3$ ) in the UPDRS Part IVb score.

At long-term follow-up review, there was a significant worsening of lateral symptoms, body bradykinesia, freezing, and gait when scores were compared with 3 -month follow-up scores. Compared with baseline, the only significant change in the off state was a worsening of the score for freezing: $46.2 \%$ (from $2 \pm 1.1$ to $2.9 \pm 1.1)$. Also in the on state there was no significant improvement in any item compared with baseline scores. On the contrary, there was a significant worsening of the UPDRS Part III total score ( $40.2 \%$ [from $10.6 \pm 6.3$ to $14.9 \pm 5.1])$ and, specifically, in akinesia $(90.8 \%$ from $[5.4 \pm 4.3$ to $10.3 \pm 3.4])$ and freezing $(172.7 \%$ [from $0.4 \pm 0.8$ to $1.2 \pm 0.9])$. The improvement in dyskinesias (UPDRS Part IV a) was significantly less pronounced $(p<0.001)$ than the improvement at 3 months ( $-28.1 \%$ [ from $3.7 \pm 2.5$ to $2.7 \pm 2.3$ ]). Motor fluctuations (UPDRS Part IVb) did not show any change compared with baseline.

\section{Comparison of contralateral and ipsilateral effects of stimulation}

At 3 months postoperatively, there was a statistically significant change between contralateral and ipsilateral improvements in motor function in the off state (Table 3). During the off state the change in the UPDRS Part III score was $-48.6 \%$ (from $18.5 \pm 4.9$ to $9.5 \pm 3.8$ ) on the contralateral side and $-55.8 \%$ (from $13 \pm 5.7$ to $5.8 \pm 3.4)$ on the ipsilateral side $(\mathrm{p}=0.009)$. During the on state, the improvements were clearly more pronounced on the side contralateral to the stimulation, with a decrease of $74.4 \%$ (from $7.8 \pm 3.8$ to $2.0 \pm 2.1$ ) in the contralateral UPDRS Part III score, and $27.7 \%$ (from $4.6 \pm 3.4$ to $3.3 \pm 3.0$ ) in the ipsilateral score $(p=0.001$ for the difference between on and off states).

At long-term follow-up review, this difference in sides in the on state was even more pronounced, with a decrease in the contralateral UPDRS Part III score of $4.9 \%$ (from $7.8 \pm 3.8$ to $7.4 \pm 2.7$ ), and an increase in the ipsilateral UPDRS Part III score of $104.2 \%$ (from $4.6 \pm 3.4$ to $9.4 \pm 3.3$ ). The poor effect in the contralateral UPDRS Part III score in the on state was mainly due to a worsening of contralateral akinesia ( $46.7 \%$ [ from $3.5 \pm 2.4$ to $5.1 \pm 2$ ]). At long-term follow-up review there was no significant improvement in any lateral motor symptom, either ipsilaterally or contralaterally.

Table 4 shows the means. SDs, and score ranges for the linear slopes in the UPDRS Part III for both contralateral and ipsilateral sides for both off and on states in the 26 patients. Using the paired t-test in both the off and on state, patients scored preoperatively higher on the contralateral side than on the ipsilateral one 
Table 4 Means, SDs and score tanges for UPDRS III preoperative scores and linear sope acores in 26 patients who received uniluteral pallidal stamulation of the Gpi*

\begin{tabular}{|c|c|c|c|c|c|}
\hline \multirow{2}{*}{\multicolumn{2}{|c|}{ Side \& Chnical Condition }} & \multicolumn{2}{|l|}{ Preop Scores } & \multicolumn{2}{|c|}{ Linear Slope Scores } \\
\hline & & Mean \pm SD & Range & Mean \pm SD & Range \\
\hline \multirow[t]{2}{*}{ Contrabteral } & off state & $18.54 \pm+.86$ & 8 to 27 & $3.23 \pm 3.81$ & -4.17 to +13.43 \\
\hline & on state & $7.81 \pm 3.77$ & 1 to 17 & $1.66 \pm 1.82$ & -1.56 to +4.96 \\
\hline \multirow[t]{2}{*}{ Ipsilateral } & off state & $13.04 \pm 5.73$ & 2 to 24 & $3.75 \pm 3.76$ & -2.75 to +13.18 \\
\hline & on state & $4.58 \pm 3.43$ & 0 to 12 & $4.31 \pm 2.30$ & -0.09 to +8.15 \\
\hline
\end{tabular}

- The slopes are calculated through three measuremenst in time (preoperatively, at 3 months postoperatively and at long-term follow-up review). A lower slope score stands for a relative umprovement in the shucal condition, a rero slope stands for "no change," and a higher Jope for a clinical deterioration.

$(\mathrm{p}<0.001)$. Averaging over both states there was still a statistically significant difference in the contralateral side, compared to the ipsilateral side, in baseline UPDRS Part III scores $(p<0.001)$. The mean difference between sides for all patients was $4.37 \pm 2.95$ (range $-0.50-11.5$ ).

Using the paired t-test there was no significant difference between the slopes of the contralateral and ipsilateral sides in the off state $(p=0.321)$, but there was a difference in the on state $(p<0,001)$. Averaging over both states there was still a statistically significant difference between the contralateral and ipsilateral sides in UPDRS Part III progression in time $(p<0.001)$ : on the contralateral side the patient fared better over time due to stimulation.

Regression analysis can be used to investigate the possible predictive power of the preoperative UPDRS Part III scores for the individual linear slope progression in these scores.

Calculating the Pearson correlation coefficient between slope progression and the preoperative difference between contralateral and ipsilateral scores gave a statistically significant negative correlation coefficient of $-0.421 \quad(p=0.016)$.

Standardiszing for age and sex the $\beta$ coefficient of preoperative scores and slope progression scores remained statistically significant $(\beta=-0.389, p=0.049)$. Thus the larger the preoperative difference between scores on the contralateral and ipsilateral sides, the higher the linear progression difference between these sides will be. 


\section{Medication use}

It was not our aim to keep the medication regimen unchanged postoperatively, as described by the CAPIT-PD. In accordance with the patients' clinical condition, we first optimized the stimulation parameters and then adjusted medication use.

The mean LED did not change significantly after 3 months. It increased significantly by $53 \%$ (from 788 to $1212 \mathrm{mg}$ ) at long-term follow-up review.

\section{Stimulation settings}

At 3 months, 14 patients received stimulation delivered in a monopolar manner, compared with 15 patients at long-term follow-up review. At 3 months, the mean voltage was $2.6 \mathrm{~V}$ (range $1-4 \mathrm{~V}$ ), the mean frequency was $141 \mathrm{~Hz}$ (range 130-185 Hz), and the mean pulse width $213 \mu \mathrm{sec}$ (range 120-300 $\mu \mathrm{sec}$ ). At long-term follow-up review, the mean voltage was $3.3 \mathrm{~V}$ (range 2-6 V), with a mean frequency of $135 \mathrm{~Hz}$ (range 130-185 Hz), and a mean pulse width of 234 $\mu \sec$ (range $120-450 \mu \mathrm{sec}$ ).

\section{DISCUSSION}

The results of this study show that there was a clear effect of unilateral pallidal stimulation on contra-and ipsilateral motor function, body bradykinesia, and gait in the off and on states, as well as on dyskinesias and motor fluctuations, at short-term ( 3 months) follow-up review in selected patients. At long-term follow-up, the only improvement worth mentioning was seen in contralateral tremor and rigidity during the on phase.

Our short-term motor results (except for freezing in the off state) are better than those reported in a recently published study in which a 1-year follow-up review of unilateral pallidal stimulation is described ${ }^{26}$. This might be explained by patient selection. The mean preoperative total UPDRS Part III score under off-medication conditions in our study was $26.5 \pm 9.2$ compared with $57.2 \pm 13.7$ in the other study, and the mean preoperative UPDRS Part III score under on-medication conditions was $10.6 \pm 6.3$ compared with $29.1 \pm 6.5$. Moreover, our patients were selected on the basis of an asymmetric distribution of symptoms, which is illustrated by the mean difference between sides, which is $4.37 \pm 2.95$. The higher this score is, the higher the preoperative differences in sides. The statistically significant negative Pearson correlation coefficient of $-0.421(\mathrm{p}=0.016)$, calculated between slope progression and preoperative UPDRS Part III scores, means that the higher the difference between contralateral and ipsilateral UPDRS Part III scores, the larger the difference between the contralateral and ipsilateral effect of 
stimulation will be. In other words, the less the ipsilateral side is affected preoperatively, the more the patient will benefit from the stimulation ipsilaterally.

Our long-term results are worse for any motor item compared with the results of the aforementioned study ${ }^{26}$. The change in the total UPDRS Part III off-medication score at long-term review was $8.3 \%$ in our study, compared with $-38.3 \%$ in the other study, and the respective changes in UPDRS Part III on scores were $40.2 \%$ compared with $-28.6 \%$. The most pronounced difference is seen on the freezing score ontained in the on state: $172.7 \%$ compared with $-16.5 \%$.

These huge differences at long-term review may be explained by the difference in follow-up periods: 21 patients in our study were followed for longer than 24 months (maximum 49 months), compared with 12 months in the other study. These results suggest that the short-term positive motor effect of unilateral pallidal stimulation declines progressively over time. This might be explained as follows. First of all, at short term, there might be a micropallidotomy effect. It seems to us unlikely, however, that this is still the case at 3 months, because in many patients we saw a worsening of symptoms when the stimulator was switched off after 3 months. Furthermore, disease progression might lead to a worsening of symptoms that cannot be counteracted by stimulation. At long-term review, there was a significant increase in the mean stimulation voltage of $23.3 \%$ (2.6 compared with $3.3 \mathrm{~V}$ ) in our study, with an insignificant increase in pulse width. The increase in medication was $53.8 \%$ (LED $821 \mathrm{mg}$ compared with $1212 \mathrm{mg}$ ). This means that the effect of the stimulation was limited, and that an important increase in medication was necessary.

The results of this study confirm that stimulation of the GPi is a safe procedure. In a previous study we reported on cognitive outcome after unilateral pallidal stimulation $^{41}$. No significant deterioration in cognitive status was seen. In the 1-year follow-up study mentioned previously, no changes in cognitive function were reported after 12 months.

In our study no stimulation-dependent behavioral changes were noted. This is in contrast to our experience with bilateral STN stimulation. In a significant number of patients who underwent bilateral STN stimulation for advanced PD in our hospital, voltage-dependent behavioral disinhibition was noticed and was sometimes accompanied by hypersexuality and aggression (report in progress). Comparable behavioral changes have been reported by other groups $9,33,37$. This may lead to the question of whether pallidal stimulation might be preferable in some patients who are prone to behavioral changes, despite the superior effect of STN stimulation on motor symptoms $6.16 .19,21,30,31,39$.

Particularly for patients who have undergone a pallidotomy and in whom motor 
symptoms on the side ipsilateral to the lesion or axial problems like gait freezing develop, the question could arise: would the patient be better off with contralateral unilateral pallidal stimulation or with bilateral STN stimulation? A bilateral pallidotomy bears too many risks, of which speech and psychiatric disturbances are the most frequent $3,5,12,17,28$. A unilateral STN stimulation after pallidotomy is not an option because of conflicting postoperative medication requirements: in general STN stimulation demands a postoperative reduction of medication to avoid dyskinesias ${ }^{29}$, whereas for the side contralateral to the pallidotomy the patient generally remains strongly medication dependent on medication ${ }^{27}$. Moreover, problems with gait freezing and falling have been reported after unilateral STN stimulation in patients with a unilateral pallidotomy ${ }^{36}$. If one has to consider the risks of bleeding, which theoretically increase when more electrodes are implanted, a unilateral pallidal stimulation would be the better option. When the risks of behavioral changes are taken into account, one would again choose unilateral pallidal stimulation. Our results demonstrate that, despite its safety, unilateral pallidal stimulation is not a good treatment option for patients with advanced PD because of the unsatisfactory motor effects at long-term review, even on the side contralateral to the side of stimulation.

It is interesting to note that we found similarities between the long-term effects of unilateral pallidal stimulation and unilateral pallidotomy. Hariz and Bergenheim ${ }^{15}$ reviewed a 10 -year follow-up of patients who underwent the Leksell posterovental pallidotomy for PD. The only symptoms on which the effect was lasting were tremor and dyskinesias. Most patients exhibited a gradual recurrence of axial and akinetic symptoms. Similarly Baron, et $\mathrm{al}^{1}, \mathrm{Pal}$, et $\mathrm{al}^{32}$ and Gregory ${ }^{14}$ demonstrated that initial improvements in contralateral dyskinesia and tremor were preserved after unilateral pallidotomy, whereas the improvements in most other deficits disappeared during follow-up periods lasting 3,2, and 4 years, respectively.

Valldeoriola and colleagues ${ }^{38}$ and Fine, et al., ${ }^{13}$ found that significant early improvements in off-period contralateral signs of parkinsonism were sustained for 4 and 5.5 years, respectively, whereas early benefits observed in axial symptoms and motor fluctuations waned with time.

The underlying mechanism of the effects of pallidal surgery is not clearly understood ${ }^{9}$. Moreover, the effects of stimulation both on parkinsonism and dyskinesias has been shown to vary with the site of stimulation within the pallidal complex: more ventral stimulation has a better effect on dyskinesias at the cost of the effect on akinesia, whereas more dorsal stimulation has a better effect on akinesia at the cost of dyskinesias ${ }^{2,20}$. It seems as if a compromise has to be found concerning which symptoms will be ameliorated and which will not. 
In the case of posteroventral pallidal stimulation, which we performed in this study, this compromise led to favorable results for some time, as long as the akinetic symptoms could be ameliorated by increasing the medication. Levodopa can be increased to higher levels after pallidal surgery because medication-induced dyskinesias are counteracted by the surgery. This rise in medication, however, has its limits, whereas akinetic symptoms progressively decline due to the natural course of the disease.

We consider it unlikely that patient selection led to poor results in our study. A preoperative LED of less than $1000 \mathrm{mg}$ and a good response to levodopa have been shown to be predictive factors for good clinical outcome in pallidotomy. ${ }^{4,18}$ In addition, although this has not been explicitly confirmed in pallidal stimulation studies, we believe that our patients were excellent candidates for good outcome, on the basis of strict selection criteria.

\section{CONCLUSIONS}

Unilateral pallidal stimulation is a safe procedure that conveys a beneficial effect, in the short term, on motor symptoms that are contralateral as well as ipsilateral to the side of the stimulation. Long-term results, however, are unsatisfactory, meaning that this procedure is not a valid treatment option for patients with advanced PD.

\section{REFERENCES}

1. Baron MS, Vitek JL, Bakay RA, et al: Treatment of Parkinson's disease by unilateral posterior GPi pallidotomy: 4-year resuits of a pilot study. Mov Disord 15(2): 230-7. 2000

2. Bejjani B. Amulf I, Bonet AM: Pallidal stimulation for Parkinson's disease. Two targets? Neurology 49: 1564-9, 1997

3. Biousse V. Newman NJ: Morbidity and mortality following pallidotmy in PD. Neurology 59: 1822, 2002 (Letter)

4. de Bie RM, de Haan RJ, Nijssen PC, et al: Unilateral pallidotomy in Parkinson's disease: a randomised, single-blind, multicentre trial. Lancet 354:1665-1669, 1999

5. De Bie RM, Schuurman PR. Esselink RA, et al: Bilateral pallidotomy in Parkinson's disease: a retrospective study, Mov Disord 17(3):533-8, 2002

6. The Deep-Brain Stimulation for Parkinson's Disease Study Group: Deep-brain stimulation of the subthalamic nucleus or the pars interna of the globus pallidus in Parkinson's disease. N Engl J Med 345: 956-963, 2001

7. Dogali M, Fazzini E, Kolodny E, et al: Stereotactic ventral pallidotomy for Parkinson's disease. Neurology 45: 753-761, 1995 
8. Dogali M, Sterio D, Fazzini E, et al: Effects of posteroventral pallidotomy on Parkinson's discase. Adv Neurol 69:585-590, 1996

9. Dostrovsky JO, Hutchison WD, Lozano AM: The globus pallidus, Deep Brain stimulation, and Parkinson's disease. The Neuroscientist 8(3): 284-290, Copyright 2002 Sage Publications.

10. Dujardin K, Defebvre L, Krystkowiak, et al: Influence of chronic bilateral stimulation of the subthalamic nucleus on cognitive function in Parkinson's disease. J Neurol 248(7): 603-611,2001

11. Fahn S: Unified Parkinson's Disease Rating Scale. In Fahn S, Elton R, Calne D, Goldstein M, eds. Recent developments in Parkinson's disease. New Jersey/ Macmillan Healthcare Information, 1987, 153-163, 1987

12. Favre J, Burchiel KJ, Taha JM, et al: Outcome of unilateral and bilateral pallidotomy for Parkinson's disease: patient assessment. Neurosurgery 46(2):344-53; discussion 353-5. 2000

13. Fine J, Duff J, Chen R, et al: Long-term follow-up of unilateral pallidotomy in advanced Parkinson's disease. N Engl J Med 342(23):1708-14, 2000

14. Gregory R: Unilateral pallidotomy for advanced Parkinson's disease. Brain 122: $381-382,1999$

15. Hariz MI, Bergenheim AT: A 10-year follow-up review of patients who underwent Leksell's posteroventral pallidotomy for Parkinson disease. J Neurosurg 94(4): 552-8. 2001

16. Houcto JL, Damier P. Bejani B: Subthalamic stimulation in Parkinson's disease. Arch

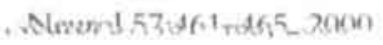

17. Intemann PM, Masterman D, Subramanian I, et al: Staged bilateral pallidotomy for treatment of Parkinson's disease. J Neurosurg 94(3):437-44, 2001

18. Kazumata K, Antonini A, Dhawan V, et al: Preoperative indicators of clinical outcome following stereotaxic pallidotomy. Neurology 49(4):1083-90, 1997

19. Krack P. Pollak P. Limousin P: Subthalamic nucleus or internal pallidum stimulation in young onset Parkinson's disease. Brain 121:451-457, 1998

20. Krack P, Pollak P, Limousin P et al: Opposite motor effects of unilateral pallidal stimulation in Parkinson's disease. Ann Neurol 43(2):180-92, 1998

21. Kumar R, Lozano AM, Kim YJ: Double-blind evaluation of subthalamic nucleus deep brain stimulation in advanced Parkinson's disease. Neurology 51:850-855, 1998

22. Kumar R, Lozano AM, Sime E: Comparative effects of unilateral and bilateral subthalamic nucleus deep brain stimulation. Neurology 53:561-566, 1999

23. Laitinen LV: Pallidotomy for Parkinson's disease. Neurosurg Clin of N Am 6:105-112, 1995

24. Laitinen LV, Bergenheim T, Hariz M: Leksell's posteroventral pallidotomy in the treatment of Parkinson's disease. J Neurosurg 76: 53-61, 1992

25. Langston JW. Widner H, Goetz CG, et al: Core assessment program for intracerebral transplantations (CAPIT). Mov Disord 7:2-13, 1992 
26. Lohrer T], Burgunder JM, Pohle T, et al: Long-term pallidal stimulation in patients with advanced Parkinson's disease: a 1 year follow-up study. I Neurosurg 96:844-853, 2002

27. Merello M: Subthalamic stimulation contralateral to a previous pallidotomy: an erroneous indication? Mov Dis 14:890-892, 1999

28. Merello M, Starkstem S, Nouzeilles MI, et al: Bilateral pallidotomy for treatment of Parkinson's disease induced corticobulbar syndrome and psychic akinesia avoidable by globus pallidus lesion combined with contralateral stimulation.J Neurol Neurosurg Psychiatry 71: 611-614, 2001(Letter)

29. Molinuevo JL, Valldeonola F. Tolosa E, et al: Levodopa withdrawal after bilateral subthalamic nucleus stimulation in advanced Parkinson's disease. Arch Neurol 57: $983-988,2000$

30. Moringlane HR, Ceballos-Baumann AO, Alesch F: Long-term effect of electrostimulation of the subthalamic nucleus in bradykinetic-ngid Parkinson's disease. Min Invas Neurosurg 41:133-136, 1998

31. Moro E, Scerrati M, Romito LM: Chronic subthalamic nucleus stimulation reduces medication requirements in Parkinson's disease. Neurology 53(1): 85-90 1999

32. Pal PK. Samin A, Kishore A, et al: Long-term outcome of unilateral pallidotomy: follow-up of 15 patients for 3 years. J Neurol Neurosurg Psychiatry 69:337-44, 2000

33. Saint-Cyr JA, Trepanier LL, Kumar L, et al: Neuropsychological consequences of chronic bilateral stimulation of the subthalamic nucleus in Parkinson's disease. Brain 123: 2091-108, 2000

34. Siegfried $\mathrm{J}$ and Lippitz B: Bilateral chronic electrostimulation of ventrolateral pallidum: a new therapeutic approach for alleviatang all parkinsonian symptoms. Neurosurgery 35 : 1126-1130, 1994

35. Starr PA: Ablative surgery and deep brain stimulation for PD. Neurosurgery 43: 989-1015, 1998

36. Su CS and Tseng $\mathrm{H}$ : Gait freezing and falling related to subthalamic stimulation in patients with a previous pallidotomy. Mov Dis 16:376-377, 2001(Letter)

37. Trepanier LL, Kumar R, Lozano AM, et al: Neuropsychological outcome of GPi pallidotomy and GPi or STN deep brain stimulation in Parkinson's disease. Brain Cogn $42(3): 32+-347,2000$

38. Valldeoriola F. Martinez-Rodriguez J. Tolosa E, et al: Four year follow-up study after unilateral pallidotomy in advanced Parkinson's disease. J Neurol 249(12): 1671-7, 2002

39. van der Linden C, Vandewalle V, Colle H, et al: Chronic bilateral stimulation of the subthalamic nucleus in advanced Parkinson's disease: a long-term follow-up in 39 patients. Mov Disord 15 (Suppl 3): 62-63, 2000 (Abstract)

40. Vingerhoets $G$, Lannoo $E$, van der Linden $C$, et al: Changes in quality of life following unilateral palhidal stimulation in Parkinson's disease. J Psychosom R es 46: 247-55, 1999

41. Vingerhoets G, van der Linden C. Lannoo E, et al: Cognitive outcome after unilateral pallidal stimulation in Parkinson's disease. J Neurol Neurosurg Psychiatry 66: 297-304, 1999 
CHAPTER 2

\section{Long-term effects of bilateral subthalamic nucleus stimulation in advanced Parkinson disease}

A four year follow-up study

Veerle Visser-Vandewalle, Chris van der Linden, Yasin Temel, Halime Celik, Linda Ackermans, G. Spincemaille, J. Caemaert $J$ Neurosurg (Submitted) 


\section{Abstract}

Objective. In this study we aimed to investigate the effects of bilateral high-frequency stimulation (HFS) of the subthalamic nucleus (STN) in patients with advanced Parkinson disease (PD) at long-term follow-up, with a minimum follow-up of 4 years.

Methods. Patients with idiopathic PD and, despite optimal pharmacological treatment, severe response fluctuations and/or dyskinesias were selected. Surgery was performed under local anesthesia. The target was defined on CT-images. No depth-recordings were performed. UPDRS II(ADL), III(motor performance), IVa (dyskinesias), IVb (motor fluctuations), and Schwab and England scores were evaluated preoperatively during the best on-medication state (on state) and the practically defined off-medication state (off state) at 3 months with the stimulators on, and at 4 years with the stimulatos on and off. Twenty patients (15 men, 5 women) were included in this study with a mean age of $60.9 \pm 8.1$ years. At 3 months follow-up, significant improvements were found in the total UPDRS III score, in the off state (from $42.3 \pm 9.3$ to $19.5 \pm 6.4$ ), as well as in the on state

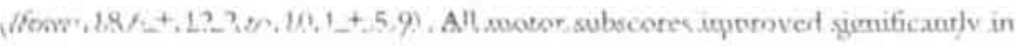
the off state. The UPIORS IVa and IVb scores decreased significantly. At long-term follow-up, there were still significant improvements in the total UPDRS III motor score (from $42.3 \pm 9.3$ to $24.2 \pm 13.2$ ), as well as in all motor subscores, in the off state, during stimulation. In the on state, the only significant improvement was seen in rigidity and akinesia. At 3 months and at long term, there was a significant decrease in the UPDRS II score in the off state as well as in the on state. The Schwab and England scores increased significantly at 3 months and at long-term follow-up. The LED (levodopa equivalent dose) decreased significantly with $47,2 \%$ at the long-term follow-up. Complications included hypounana to mana in four patients. In one, this became apparent only one year after surgery.

Conclusien. Our results indicate that HFS STN results in long-lasting improvement of the motor symptoms, ADL activities and functional performance in patients suffering from advanced PD. The stimulation induced behavioral changes need special consideration. 
Since the beginning of the 19th century, surgery is performed on patients suffering from PD. Lesions of the thalamus had a good effect on contralateral tremor, lesions of the pallidum or Forel's field, had a good effect on contralateral tremor and rigidity. In 1967 oral levodopatherapy was introduced and, in contrast to the results of surgery at that time, seemed to have a good effect not only on tremor and rigidity, but also on akinesia. This led to a drastic reduction of the amount of operations performed on PD patients. After a few years however, complications of chronic levodopa-intake became apparent, mainly dyskinesias and on-off tluctuations. This led to a renewed interest in the surgical treatment. In 1985 the attention was focussed on the globus pallidus. Pallidotomies seemed to have a good effect on contralateral tremor, rigidity, and, dyskinesias. High frequency stimulation became a safer alternative for performing lesions, which led to a reduction of the complication rate. The unsatisfying effects of pallidal stimulations on akinesia however, even when performed bilaterally, motivated researchers and clinicians to search for a better target. The discovery that monkeys treated with MPTP formed an almost perfect animal model for PD, shed new light on the pathophysiology of the disease. An important discovery was that striatal dopamine deficiency led to an overactivity of the STN. In 1991 Aziz' reported on the beneficial effects of lesions of the STN in 2 MPTP-monkeys: there was not only a good effect on tremor and rigidity, but also on posture and spontaneous movements. Both monkeys however developed hemiballism. In 1993 Benazzouz ${ }^{2}$ successfully performed high frequency stimulation (HFS) of the STN in 2 MPTP-monkeys, without the development of hemiballism. In 1993 Benabid $^{21}$ successfully performed the first STN HFS in a patient with advanced PI). Since then many other centers followed, and nowadays the STN is generally considered to be the best target when surgery for patients with advanced PD is considered, improving all cardinal PD symptoms. More and more reports appear on the effects at long term, most of them with a follow-up of 1 to 2 years. In this study we prospectively analyzed the effects of bilateral STN HFS in 20 patients, with a minimum follow-up of 4 years.

\section{CLINICAL MATERIAL AND METHOIDS}

\section{Patient population}

Between June 1997 and September 1998 patients were selected for STN HFS if they had clinical findings consistent with idiopathic PD and, despite optimal pharmacological treatment, severe response fluctuations and/or dyskinesias. Good initial levodopa response was an absolute criterion. The one exception to this was the inclusion of patients who demonstrated levodopa-resistant rest 
tremor. Exclusion criteria consisted of significant atrophy, multiple white matter lesions or other focal brain abnormalities on MR-images, parkinsonism due to known causative factors, Hoehn and Yahr stage 5 at the best moment of the day, a score $<24$ on the Mini-Mental State Examination, psychosis, and general contraindications for surgery such as severe hypertension or blood coagulation disorders.

\section{Surgery}

Stereotactic surgery using the Leksell $G$ frame was performed using local anesthesia, after overnight withdrawal of antiparkinsonian drugs. The target was defined on CT-images with the following coordinates: 11-12 mm lateral to the AC-PC line, at the mid-commissural point, and $4 \mathrm{~mm}$ inferior to the inter-commissural line.

After making a precoronal burr hole, a rigid monopolar test stimulation electrode was introduced with a diameter of $1.8 \mathrm{~mm}$ and a naked tip of $2 \mathrm{~mm}$ (model 3101-2; Radionics, Ghent, Belgium) $6 \mathrm{~mm}$ above the presumed target. Stimulation was initiated with a frequency of $100 \mathrm{~Hz}$ and a stimulus duration of $1 \mathrm{~ms}$ and continued stepwise every $2 \mathrm{~mm}$, until $4 \mathrm{~mm}$ below the target. At each step the stimulus intensity was increased at increments of $0.5 \mathrm{~V}$ until the desired response was achieved or until unwanted side effects occurred. At each point of the test stimulation the clinical response was evaluated by one neurologist (CvdL) blinded to the presence of stimulation. The following clinical parameters using the UPDRS ${ }^{6}$ were scored: tremor (if present) and rigidity in all 4 extremities, rapid finger movements, closing and opening of the hands, dorsi- and plantar flexion of the feet and leg movements. If a clinical response was not present at or several millimeters below the target, the electrode was withdrawn and a second target through a different trajectory, $2 \mathrm{~mm}$ anterior, posterior, medial or lateral to the initial target, was chosen. As much as possible, we led ourselves lead by the clinical result: if an adverse motor effect was found at a low voltage $(<3 \mathrm{~V})$, suggestive for stimulation of the internal capsule, the second trajectory was made more medially, if sensory symptoms occured, we went more anterior. After determination of the optimum stimulation site the monopolar electrode was replaced by the final quadripolar electrode (model 3389; Medtronic, Kerkrade, The Netherlands), with the second deepest pole at the level of the best clinical result. At the level of the burr hole the electrode was fixed with methyl metacrylate and connected to an extension cable, which was externalized about 7 $\mathrm{cm}$ from the burrhole and connected to an external pulse generator (model 3625; Medtronic). When 1 week of evaluation with test stimulation showed a clear effect on parkinsonian symptoms, a second operation was performed under gen- 
eral anesthesia, for the subcutaneous implantation of the pulse generator (Itrel 3 model 7425: Medtronic).

\section{Clinical evaluation}

Activities of daily living (ADL) were evaluated using part II, motor performance was evaluated using part III, dyskinesias using part IVa, and motor fluctuations using part IVb of the UPDRS. Lower scores reflect better performances. Functional performance was evaluated through the Schwab and England score (higher scores correspond with better performances). Preoperative UPDRS II and III assessments and Schwab and England scores were conducted in the best on-medication state (on state) and practically defined off-medication state (off state) as described in the CAPIT-PD 13,4 to 6 weeks before surgery. Postoperative UPDRS III scores were evaluated in the on and off states with the stimulators on at 3 months, and with the stimulators on, and 12 hrs off, at long-term follow-up. For motor subscores the following questions from part III were used: for rest tremor, Question 20 (maximum score 26): for rigidity, Question 22 (maximum score 20); for bradykinesia, Question 31 (maximum score 4); for akinesia, Questions 23 through 26 (maximum score 32); for gait, Question 29 (maximum score 4); for freezing, Question 14 of part II (maximum score 4). Dyskinesias, and daily appearance and predictability of off states were evaluated with UPDRS part IVa (dyskinesias) and IVb (motor fluctuations) with a maximum of 13 and 7. respectively, preoperatively and postoperatively with the stimulators on.

Since all patients kept their stimulators on continuously, postoperative data on ADL (UPDRS II) and functional performance (Schwab and England) were only collected in the stimulation-on condition, in the on and off state.

All postoperative data were collected in the same sequence, and the patient as well as the investigator were aware of the medical and stimulator's status.

\section{Medication}

Medication intake was defined by the LED (levodopa equivalent dose), which equals $100 \mathrm{mg}$ levodopa or $133 \mathrm{mg}$ of levodopa modified release preparations or 1 $\mathrm{mg}$ of pergolide, $10 \mathrm{mg}$ of bromocryptine, $1 \mathrm{mg}$ of cabergoline, $6 \mathrm{mg}$ of ropinirole, $1 \mathrm{mg}$ of lisuride or $20 \mathrm{mg}$ of apomorphine.

Medication was kept stable at least 2 months before surgery. 


\section{Statistical analysis}

Data, which approximated a normal distribution, are presented as mean values \pm SDs. Changes between pre-operative baseline, 3-month, and long-term follow-up were analyzed using the paired Student $t$-test. This was repeated for both states (off and on state) in each clinical parameter. A probability value less than 0.05 is considered to be statistically significant. All were analyzed by SPSS-pc, version 11.0.1 (SPSS inc., Chicago, III., U.S.A.).

\section{RESULTS}

Thirty-two patients met the selection criteria and underwent bilateral STN HFS. Five patients died before 4 year follow-up was reached. One patient became stuporous after diathermia was used on his back musculature, and died soon afterwards, 1 year postoperatively. CT-images revealed a brain stem infarction. One patient committed suicide one year after surgery. The other 3 patients died due to causes clearly not related to surgery. Seven patients were followed by their local neurologist, and are excluded from this study since we have no data with the stimulators being switched off.

Twenty patients ( 15 men, 5 women) were included in this study. Their mean age at time of surgery was $60.9 \pm 8.3$ years (range $45-76$ years). Patient profiles are listed in Table 1. Surgery was started at the side opposite to the most affected side (in 8 patients at the right hemisphere). At this side, the amount of trajectories necessary to obtain the optimal result varied between 1 and 5 , with a mean of $1.7 \pm$ 1.0. At the second side, the amount of trajectories varied between 1 and 4 , with a mean of $1.5 \pm 0.83$. The final coordinates are listed in Table 2 .

Table 3 shows the UPDRS II (ADL), UPDRS III (motor score), UPDRS IVa (dyskinesias), UPDRS IVb (motor fluctuations), and the Schwab and England scores, in the off and on state, preoperatively (baseline) and at 3 months follow-up. At long-term (mean 53.6 \pm 2.6 months), the same scores were assessed in the same conditions, when both stimulators were on, and when both stimulators were switched off for 12 hours.

\section{Overall effect on motor function (UPDRS III)}

At 3 months, significant improvements were found in the total UPDRS III score, in the off state (from $+2.3 \pm 9.3$ to $19.5 \pm 6.4$ ), as well as in the on state (from $18.6 \pm$ 12.2 to $10.1 \pm 5.9$ ). All motor subscores improved significantly in the off state 
Table 1 Charactenstics of the 20 patients receiving bilateral STN.

\begin{tabular}{|c|c|}
\hline Characternstac & \\
\hline Sex (no. of pat & \\
\hline male & 15 \\
\hline fermale & 5 \\
\hline$A_{g e}(y r r)$ at su & \\
\hline mean \pm SD & $60.9 \pm 8.3$ \\
\hline range & $45-76$ \\
\hline Discase duratio & \\
\hline mean $\pm S D$ & $15.0 \pm 4.4$ \\
\hline range & $10-22$ \\
\hline Most affected & \\
\hline left & 8 \\
\hline nght & 12 \\
\hline Follow- Up (m & \\
\hline mean $\pm S D$ & $53.6 \pm 2.6$ \\
\hline range & $49-58$ \\
\hline
\end{tabular}

Table 2 Coondinates of the final electrode in reference to the AC-PC hine in 20 patients who received bilateral stumulation of the STN

\begin{tabular}{|c|c|c|c|c|}
\hline \multirow{2}{*}{$\begin{array}{l}\text { Distance to mid } A C-P C \text {. } \\
X: 13 \mathrm{~mm} \text { lat }\end{array}$} & \multicolumn{4}{|c|}{ Number of patients } \\
\hline & \multicolumn{2}{|c|}{ Rught } & \multicolumn{2}{|c|}{ Left } \\
\hline $\begin{array}{l}\mathrm{X}: 13 \mathrm{~mm} \text { lat } \\
\mathrm{Y}: 0 \mathrm{~mm} \text { post } \\
\mathrm{Z}:+\mathrm{mm} \text { inf }\end{array}$ & I & (16) & 2 & (k.20) \\
\hline $\begin{array}{l}X: 13 \mathrm{~mm} \text { lat } \\
Y: 2 \mathrm{~mm} \text { post } \\
Z: 4 \mathrm{~mm} \text { inf }\end{array}$ & 1 & (9) & 1 & (4) \\
\hline $\begin{array}{l}X: 11 \mathrm{~mm} \text { lat } \\
Y: 0 \mathrm{~mm} \text { post } \\
\mathrm{Z}: 2 \mathrm{~mm} \text { inf }\end{array}$ & 1 & . & & \\
\hline $\begin{array}{l}X: 11 \mathrm{~mm} \text { lat } \\
Y: 2 \mathrm{~mm} \text { post } \\
Z: 4 \mathrm{~mm} \text { inf }\end{array}$ & I & (3) & 4 & $(3,1+, 16,18)$ \\
\hline $\begin{array}{l}\mathrm{X}: 11 \mathrm{~mm} \text { lat } \\
\mathrm{X}: 0 \mathrm{~mm} \text { post } \\
\mathrm{Z}: 4 \mathrm{~mm} \text { inf }\end{array}$ & 12 & $\begin{array}{l}(1,4,6,7,12,13 \\
14,15,17,18,19,20)\end{array}$ & 10 & $\begin{array}{l}(2,5,6,7,10) \\
11,13,15,17,19)\end{array}$ \\
\hline $\begin{array}{l}X: 11 \mathrm{~mm} \text { lat } \\
Y: 0 \mathrm{~mm} \text { post } \\
Z: \quad 6 \mathrm{~mm} \text { inf }\end{array}$ & 1 & (5) & & \\
\hline $\begin{array}{l}\mathrm{X}: 10 \mathrm{~mm} \text { bt } \\
\mathrm{Y}: 0 \mathrm{~mm} \text { post } \\
\mathrm{Z}: 4 \mathrm{~mm} \mathrm{inf}\end{array}$ & 3 & $(8,10,11)$ & 3 & $(1.9 .12)$ \\
\hline
\end{tabular}

$\mathrm{AC}=$ antenor commussure: $\mathrm{PC}=$ postenor commusure, lat=lateral; post=posterior, inf=infenor, Between brackets, patient numbers are given 
Tabel 3 Qutcomie scores and medication in 20 patients who received biliteral stmulation of the STN

\begin{tabular}{|c|c|c|c|c|c|c|c|c|c|c|}
\hline \multirow[b]{3}{*}{ Scoring Factor } & \multirow[b]{3}{*}{ Baseline } & \multirow{2}{*}{\multicolumn{3}{|c|}{$\frac{3 \text { months follow-up }}{\text { Stim ON }}$}} & \multicolumn{6}{|c|}{ Long-tem follow-up } \\
\hline & & & & & \multicolumn{3}{|l|}{ Stum OFF } & \multicolumn{3}{|l|}{$\operatorname{san} O N$} \\
\hline & & Score: & $\%$ & p Value & Srore & $\%$ & P Value & Score & $*$ & p Value \\
\hline \multicolumn{11}{|l|}{ OFF } \\
\hline UPDRS II & $23,9 \pm 72$ & $12.6 \pm 5.2$ & -47.3 & 0,004 & Not evaluated & & & $9.7 \pm 4.0$ & -594 & 0.004 \\
\hline UPDRS III total & $42.3 \pm 9.3$ & $19.5 \pm 6.4$ & -540 & $<0,001$ & $53.6 \pm 20.6$ & +20.0 & 0.160 & $24.2 \pm 13.2$ & $-43,0$ & $<0,001$ \\
\hline tremor & $42 \pm+5$ & $0.7 \pm 1.1$ & -83.0 & 0.001 & $+3 \pm 47$ & +20 & 0.689 & $17 \pm 3.9$ & -60.0 & 0.039 \\
\hline rigidity & $9.1 \pm 3.3$ & $1.7 \pm 2.1$ & -810 & $<0,001$ & $90 \pm+5$ & -1.0 & 0.617 & $2.5 \pm 3.3$ & -73.0 & $<0.001$ \\
\hline akınesiz & $15.0 \pm 4.9$ & $7.7 \pm 3.9$ & -48.7 & $<0.001$ & $20.1 \pm 93$ & $+25,4$ & 0,070 & $11.2 \pm 5.9$ & -253 & 0.046 \\
\hline bradykinesia & $3.1 \pm 0.8$ & $1.5 \pm 0.6$ & -51.6 & $<0.001$ & $2.6 \pm 1.3$ & -16.1 & 0.216 & $19 \pm 1.5$ & -38.7 & 0.015 \\
\hline freezing & $2.6 \pm 0.9$ & $1.0 \pm 0.7$ & -61.5 & $<0.001$ & $1.7 \pm 1.8$ & -34.6 & 0.190 & $1.2 \pm 1.1$ & -53.8 & 0.013 \\
\hline gait & $2.8 \pm 0.8$ & $1.4 \pm 0.7$ & -500 & $<0.001$ & $3.1 \pm 1.1$ & +9.7 & 0.090 & $1.6 \pm 1.2$ & -35.7 & 0.002 \\
\hline Schwab \& England & $230 \pm 11.7$ & $64.5 \pm 10.1$ & & $<0.001$ & Not evaluated & & & $62.3 \pm 14.1$ & & $<0.001$ \\
\hline \multicolumn{11}{|l|}{ ON } \\
\hline UPDRS II & $9.1 \pm 5.3$ & $46 \pm 2.4$ & -49.5 & 0.023 & Not evaluated & & & $3.9 \pm 2.0$ & -571 & 0.040 \\
\hline UPDRS III total & $18.6 \pm 12.1$ & $10.1 \pm 5.9$ & -45.7 & $0.00) 2$ & $383 \pm 185$ & +51.3 & 0.001 & $144 \pm 7.5$ & -22.6 & 0.162 \\
\hline tremor & $1.3 \pm 2.6$ & $0.2 \pm 0.7$ & -84.6 & 0.063 & $40 \pm 5.5$ & +67.5 & 0.039 & $0.2 \pm 0.7$ & -84.6 & 0.079 \\
\hline ngidity & $3.0 \pm 3.3$ & $1.7 \pm 2.1$ & -43.3 & 0,046 & $6.1 \pm 6.0$ & +50.8 & 0.091 & $1.1 \pm 1.8$ & -63.3 & 0.030 \\
\hline akmexia & $6.5 \pm 4.8$ & $3.9 \pm 2.6$ & -400 & 0,007 & $15.7 \pm 8.6$ & +586 & 0.003 & $6.9 \pm 5.0$ & +5.8 & 0.961 \\
\hline bradykinesia & $0.4 \pm 0.6$ & $0.4 \pm 0.6$ & 00 & 1.000 & $2.2 \pm 1.4$ & +81.8 & $<0.001$ & $0.4 \pm 0.5$ & 0.0 & 1.000 \\
\hline freczing: & $0.7 \pm 0.7$ & $0.4 \pm 0.5$ & -42.9 & 0.083 & $1.8 \pm 1.6$ & +61.1 & 0.029 & $0.5 \pm 0.8$ & $-28,6$ & 0.546 \\
\hline gare & $0,6 \pm 0,8$ & $0.4 \pm 0.5$ & -33.3 & 0.171 & $2.5 \pm 1.3$ & +76.0 & $0.00 !$ & $1.3 \pm 1.2$ & +53.8 & 0.039 \\
\hline Schwab \& England & $65.8 \pm 9.3$ & $72.3 \pm 6.6$ & & $<0.001$ & Nor evaluated & & & $74.0 \pm 9.6$ & & $<0,001$ \\
\hline UPDRS IV & $19 \pm 1.8$ & $0.4 \pm 0.8$ & $-79,0$ & 0.004 & & & & $0.4 \pm 0.9$ & -79.0 & 0.009 \\
\hline UPDRS IVb & $3.7 \pm 1.3$ & $0.7 \pm 1.1$ & $-81,0$ & $<0.001$ & & & & $0.8 \pm 1.1$ & -78.4 & $<0.001$ \\
\hline \multicolumn{11}{|l|}{ MEDICATION } \\
\hline [ED (mg) & $1133 \pm 383$ & $439 \pm 237$ & 61.3 & $<0,001$ & & & & $598 \pm 413$ & 47.2 & 0.023 \\
\hline
\end{tabular}

Valuss are expressed as means $\pm \mathrm{SD}$; \%=change in \%(+-increase,- decrease) with respect to baseline 
with a $p<0.001$ for rigidity, akinesia, bradykinesia, freezing and gait, and $p=0,001$ for tremor. In the on state, however, the only motor subscores in which significant changes ( $\mathrm{p} \leq 0.05)$ were seen, were rigidity and akinesia. The UPDRS IV a (dyskinesias) decreased significantly $(\mathrm{p}=0.004$ ) (from $1.9 \pm 1.8$ to $0.4 \pm 0.8$ ), as well as the UPDRS IV b (motor fluctuations) (from $3.7 \pm 1.3$ to $0.7 \pm 1.1$ ) $(\mathrm{p}<0,001)$.

At long-term follow-up review, there were still significant improvements in the total UPDRS III motor score (from 42.3 \pm 9.3 to $24.2 \pm 13.2$ ), as well as in all motor subscores, in the off state, during stimulation, albeit slightly less pronounced compared to the 3 months values. In the on state, the only significant improvement was seen in rigidity (from $3.0 \pm 3.3$ to $1.1 \pm 1.8$ ). For the total UPDRS III score, as well as for all other subscores, improvements were not significant. In gait, there even was a significant increase (from $0.6 \pm 0.8$ to $1.3 \pm 1.2$ ). When both stimulators were switched off, there was an insignificant increase in the total UPDRS III score in the off state. In the on state, there was a significant increase in the total UPDRS III score, as well as in all subscores except for rigidity, when the stimulators were off. The UPDRS IV a and IV b scores decreased significantly (from $1.9 \pm 1.8$ to $0.4 \pm 0.9$, and from $3.7 \pm 1.3$ to $0.8 \pm 1.1$, respectively).

Effect on activities of daily living (UPDRS II), and Schwab and England scores

At 3 months, there was a significant decrease in the UPDRS II score during chronic stimulation, in the off state (from $23.9 \pm 7.2$ to $12.6 \pm 5.2$ ), as wel as in the on state (from $9.1 \pm 5.3$ to $4.6 \pm 2.4$ ). Also at long-term follow-up, decreases were significant in the off state (from $23.9 \pm 7.2$ to $9.7 \pm 4.0$ ), as well as in the on state (from $9.1 \pm 5.3$ to $3.9 \pm 2.0)$. The respective scores were significantly $(\mathrm{p}<0.001)$ lower at long term than at 3 months $(9.7 \pm 4.0$ compared to $12.6 \pm 5.2$ in the off state, and $3.9 \pm 2.0$ compared to $4.6 \pm 2.4$ in the on state).

The Schwab and England scores increased significantly in the off state, at 3 months follow-up (from $23.0 \pm 11.7 \%$ to $64.5 \pm 10.1 \%$ ) and at long-term follow-up (from $23.0 \pm 11.7 \%$ to $62.3 \pm 14.1 \%$ ), as well as in the on state (from $65.8 \pm$ $9.3 \%$ to $72.3 \pm 6.6 \%$ at 3 months, and to $74.0 \pm 9.6 \%$ at long term).

\section{Side effects and complications}

All patients reported weight gain which was most pronounced during the first postoperative year $(\min 3, \max 11 \mathrm{~kg}$ ). In none of the patients epileptic attacks, intracranial hemorhages or infections occurred. Eight patients were confused 
immediately postoperatively. Seven of them recovered after 2 to 3 days. In one patient (a man, 67-yrs-old), this confused state lasted for 3 weeks. In four patients there was a worsening of speech (reduced volume), when the stimulators were on, compared to the stimulation off condition, at long term. One patient suffered from blefarospasms, clearly related to the stimulation. He refused any treatment.

Four patients (all men) presented with hypomanic to manic characteristics. In three of them this became apparent soon after discharge from the hospital. In two of them hyperactivity and verbal aggressiveness were the main symptoms. One patient started to spend an exuberant amount of money. This was however in proportion to his budget, and the psychiatrist judged it to be a "normal" euphoric state, i.e. in proportion to his improved clinical condition. In one patient, changes in behavior were seen only after 1 year. This patient exhibited hypersexuality and started to steel money from his wife for prostitution. Evaluations by a psychologist blinded to variations in voltage bilaterally revealed that these effects were related to stimulation.

\section{Stimulation parameters}

At long-term follow-up review, stimulation was bipolar in 14 patients at the right side, and in 16 at the left. At 3 months, the mean voltage was $1.8 \pm 0.6 \mathrm{~V}$ right and $1.9 \pm 0.9 \mathrm{~V}$ left, with a mean puls width of $333.2 \pm 126.8 \mu \mathrm{sec}$ right and $288.7 \pm$ $139.7 \mu \mathrm{sec}$ left, and frequency $134.5 \pm 14.0 \mathrm{~Hz}$ right, and $141.6 \pm 23.0 \mathrm{~Hz}$ left. At long term, the mean voltage was $2.6 \pm 0.8 \mathrm{~V}$ right and $2.6 \pm 0.9 \mathrm{~V}$ left, with a mean pulse width of $169.3 \pm 62.9 \mu \mathrm{sec}$ right and $177.7 \pm 90.6 \mu \mathrm{sec}$ left and frequency $133.4 \pm 13.8 \mathrm{~Hz}$ right and $136.9 \pm 18.8 \mathrm{~Hz}$ left.

\section{Medication}

The LED decreased significantly with $61.3 \%$ at 3 months (from $1133 \pm 383 \mathrm{mg}$ to $439 \pm 2.37 \mathrm{mg}$ ), and with $47.2 \%$ at long term (from $1133 \pm 383 \mathrm{mg}$ to $598 \pm 413$ $\mathrm{mg})$.

Pulse generator's life duration

Pulse generators had to be changed because of end of life in 22 of 40 implantations, after a mean follow-up of $44.8 \pm 14.1$ months. 
Table 4 Resules of hibteral STN stimulation in PD)

Reference Parients F-U Resules

Complicatiom

Medication

reduction

Limouxum et altes $\quad 20 \quad 12 \quad$ UPDRS 11 off -609

N Engl) Med, 1908 UPDKS III off -6irs

UPDRS III on -TOP

1: antracerebral hematoma wath

$50 m$ in

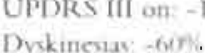

pernatent paralyos and aphasia

(levodopa)

I infectian (pulagenerator and extensson

removed for $6 \mathrm{mos}$

8 transterit changes in mental status

5 evelid-opening apraxia

1. wonenung of hypopthoma and

potrural imstability

I8 weight gats (mean'4 2 kipl

Fraix et al ${ }^{7}$

Neurology, 20000

Volkmann at at ${ }^{12}$

Neurology. 2001.

Krasue et all

INNP. 20001

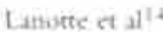

INN!', 2100:

Simumi at alto

1 Neurose, 2002

$12 \quad 12$

UPDRS III off -68

UPDRS III on $16 \%$

Dhokinesus:-93\%

UPDRS III off $-67 \%$

UPIDRS III on "hrtle changes"

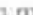

312

(levodopa)

cansent abula: common

ransient anhedom commor

$65 \mathrm{~N}$

(levodopa)

wid hypophoma cotrunot

mild hypersalryation: common

2 infection

1: lead dadodigement

t: kad fracnume

1 intracerchral hematom

I- trong increate in hbido

other mild sim related side effect

UPIBS III off "stat agn mprovement"

UPDRS III on "no ogn change"

Thxinesias: 58:

Fluctuanons 6ats

$\pi, m$

UPDRS III off 50 \%

Dvdanesuas: 738

CPDRS III off -47 .

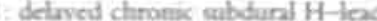

$55 \%$

UPDRS III on: $-2 \mathrm{~N}$ 
Table \& Continued

\begin{tabular}{|c|c|c|c|c|c|}
\hline $\bar{R}$ Reference & $\begin{array}{l}\text { Panents } \\
\text { (no.) }\end{array}$ & $\begin{array}{l}\mathrm{F}-\mathrm{U} \\
\text { (mos) }\end{array}$ & Results & Complicanion: & $\begin{array}{l}\text { Medration } \\
\text { reduction }\end{array}$ \\
\hline & & & UPDRS IV: $-64 \%$ & $\begin{array}{l}\text { 1: single generalized scizure } \\
\text { 1: infection of battery (removed) } \\
\text { 1: transient change in mental status } \\
\text { 2: infection (system removal) } \\
\text { 2: worsening of preop depression/dementia }\end{array}$ & \\
\hline $\begin{array}{l}\text { Vesper et al } \\
\text { Surg Neurol. } 20022\end{array}$ & 34 & 12 & $\begin{array}{l}\text { UPDRS II off } 38 \% \\
\text { UPDSRS III off: } 48 \% \\
\text { UDRS III on } 39 \% \\
\text { UPDRS IV off: } 58 \% \\
\text { UPDRS IV on: } 72 \%\end{array}$ & no serious side effects & $\begin{array}{l}53 \% \\
\text { (levodopa) }\end{array}$ \\
\hline $\begin{array}{l}\text { Oxtergard ot af } \\
\text { Mov Dis, } 2002\end{array}$ & 26 & 12 & $\begin{array}{l}\text { UPDRS III off }-64 \% \\
\text { Dyskinesa duration: }-86 \% \\
\text { Motor fluctuations: } 79 \%\end{array}$ & 2. weight gam $>2 \mathrm{~kg}$ & $\begin{array}{l}22 \% \\
\text { (LED) }\end{array}$ \\
\hline $\begin{array}{l}\text { Spottke et al }{ }^{27} \\
\text { J Neurol. } 2002\end{array}$ & 16 & 12 & $\begin{array}{l}\text { UPDRS II off: } 46 \% \\
\text { UPDRS II on: } 31 \% \\
\text { UPDRS III off: } 66 \% \\
\text { UPDRS III on } 31 \% \\
\text { UPDRS IV: } 86 \%\end{array}$ & transient and usually mild & $\begin{array}{l}51 \% \\
\text { (levodopa) }\end{array}$ \\
\hline $\begin{array}{l}\text { Vingerhoets et all1 } \\
\text { Neurology, } 2002\end{array}$ & 19 & 12 & $\begin{array}{l}\text { UPDRS II off: }-37 \% \\
\text { UPDRS III off: }-45 \% \\
\text { Dyskinesias: }-92 \% \\
\text { Fluctuations: }-95 \%\end{array}$ & $\begin{array}{l}\text { 3: acute agitation (transient) } \\
\text { 3: depression }\end{array}$ & $\begin{array}{l}79 \% \\
\text { (LED) }\end{array}$ \\
\hline $\begin{array}{l}\text { Thobois et } a^{26} \\
\text { J Neurol, } 2002\end{array}$ & 14 & 12 & $\begin{array}{l}\text { UPDRS II off: }-52.8 \% \\
\text { UPDRS III off }-55 \% \\
\text { UPDRS IV }-76 \%\end{array}$ & $\begin{array}{l}\text { 2. Jower limb phjebius } \\
\text { 1: pulmonary embolism } \\
\text { 6: depression } \\
\text { 1: dysarthra and freezing } \\
\text { 1: sialorrhea and drooling }\end{array}$ & $\begin{array}{l}65.5 \% \\
(\mathrm{LED})\rangle\end{array}$ \\
\hline
\end{tabular}


Table 4 Continued

\begin{tabular}{|c|c|c|c|c|c|}
\hline Reterence & $\begin{array}{l}\text { Patients: } \\
\text { (no.) }\end{array}$ & $\begin{array}{l}\mathrm{F}-\mathrm{U} \\
\text { (mos) }\end{array}$ & Rexults & Complacations & $\begin{array}{l}\text { Medication } \\
\text { reduction }\end{array}$ \\
\hline & & & & 1 postural imbalance & \\
\hline $\begin{array}{l}\text { Ronuto et } \mathrm{al}^{24} \\
\text { Neurology, } 2002\end{array}$ & 22 & 12 & $\begin{array}{l}\text { UPDRS II off }-48.2 \% \\
\text { UPDRS III off }-50.2 \%\end{array}$ & 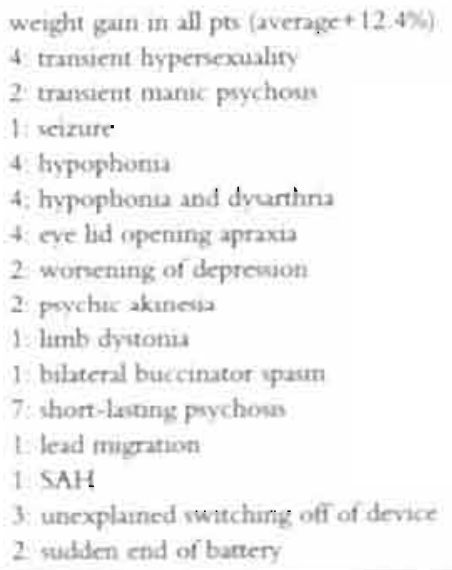 & $\begin{array}{l}6.8 .8 \% \\
\text { (1.ED) }\end{array}$ \\
\hline
\end{tabular}

(15) on - medrcatson

ofil off - medistion

stat stantically

vign. Menuficant

pos patiens

n m sot mentwoned: H hematoma

AH subarachnondal hemorrhage 


\section{DISCUSSION}

This study showed that there was a significant effect of bilateral STN stimulation on ADL (UPDRS II) and motor function (UPDRS III) in the off state, at 3 months and at 4 year follow-up review. The positive effect on motor function was significant for the total UPDRS III score, as well as for all the subscores (tremor, rigidity, akinesia, bradykinesia, freezing and gait). The effect on ADL was significantly better at long term compared to the score at 3 months. The effect on motor functions (total score as well as all subscores), seemed to be less pronounced at long term than at 3 months. All these changes in effects between short and long-term evaluations were, however, not statistically significant.

In the on state, the effect on ADL was again clearly pronounced at 3 months and at long term, with a significantly better effect at long term. The increase in the UPDRS III motor score, and the increase in the rigidity subscore at long term, compared with the 3 months scores, was not statistically significant. The tremor and bradykinesia subscores remained the same. For akinesia, freezing and gait the effect seemed to be worse at long term than at 3 months. This was however only significant for akinesia and gait. The gait subscore was even higher than baseline.

The effects on the UPDRS IV a and IV b were significant, and stable, at 3 months and at long term (the difference in UPDRS IV $b$ values at 3 months compared with long term is not significant).

All ratings were performed by two unblinded investigators, with the patient also being unblinded. It has been discussed before that in blinded studies patients as well as investigators are often aware of the on or off state of the stimulation because of the symptom relief experienced by the stimulation or because of symptoms that occur at the onset of stimulation, like paresthesias ${ }^{26}$.

These results are comparable with other studies with long-term follow-up. Table 4 shows the results of the effects of bilateral STN stimulation in advanced PD in studies with a minimum of ten patients and a minimum follow-up of 1 year for all patients. The average decrease on the UPDRS III is $52 \%$ in the off state. The UPDRS II off score decreases with an average of $42 \%$. Dyskinesias and motor fluctuations improve with an average of $77 \%$. The decrease on the UPDRS III on is better in our study $(45.7 \%$, vs an average of $26 \%)$. This may be due to a difference in postoperative medication reduction. In this study medication could be reduced at 3 months by $61.3 \%$, and at long term by $47.2 \%$. The change in LED reduction at 3 months and at long term is not statistically significant. The average medication reduction in the studies described in Table 4 , is $57 \%$. 
In this study depth recordings were not used during the stereotactic procedure. In a search for better targeting and thus for better results, we have implemented semi-microelectrode recordings after this study, and improved our target imaging by fusing CT-, and MR - images. We are, however, well aware of the fact that the potential advantages (better targeting) and disadvantages (more tracks leading to more bleedings) of depth recordings are still under discussion and have not yet been statistically evaluated in comparative studies.

The increase in voltage from 3 months follow-up to long-term follow-up (from $1.8 \pm 0.6 \mathrm{~V}$ to $2.6 \pm 0.8 \mathrm{~V}$ at the right side, and from $1.9 \pm 0.9 \mathrm{~V}$ to $2.6 \pm 0.9 \mathrm{~V}$ at the left), is counteracted by the decrease in pulse width (from $333.2 \pm 126.8 \mu$ sec to $169.3 \pm 63.0 \mu \mathrm{sec}$ at the right, and from $288.7 \pm 139.7 \mu \mathrm{sec}$ to $177.7 \pm 90.6 \mu \mathrm{sec}$ at the left). It was our policy to reduce pulse widths in the postoperative course of these patients in order to become a more selective effect of stimulation, and thus reduce stimulation induced side effects (mainly speech disturbances and behavioral changes).

The less obvious effect on the UPDRS III in the on state can be, at least partially, explained by the significant increase in the subscores for akinesia and gait compared to the 3 months scores, with even an increase in the gait subscore compared with the baseline score. The difference in effect on the UPDRS II compared with the UPDRS III score is even more pronounced in the on state than in the off state. One possible explanation might be the marked reduction in dyskinesias, which make patients function better during ADL in the on state. On the other hand, the decrease in effect on UPDRS III on, can be explained by progression of symptoms that are not responsive to levodopa, like balance disturbances.

The insignificant change in the UPDRS scores after 4 years when both stimulators were switched off, compared with the baseline scores, might be suggestive for a previously hypothesized neuroprotective effect of bilateral STN stimulation ${ }^{22}$. Nigrostriatal degeneration, which occurs in PD. leads to a electrical hyperactivity of the STN. The dopaminergic part of the substantia nigra (SNc) receives an excitatory input from the STN. This raised the possibility of NMDA-mediated excitotoxic damage to the substantia nigra, pars compacta, as a result of STN hyperactivity. It has been hypothezised through animal studies that "silencing" the STN by HFS, could lead to slowing or even stopping the disease progression ${ }^{3,19,20}$. Upto now, however, no clear clinical evidence has become available supporting this hypothesis.

This study confirms that the implantation of electrodes in the brain is a safe procedure. The stimulation induced behavioral changes, however, need special con- 
sideration. In this study personality changes were obvious in four patients. In one of them, hypomania with hypersexuality became apparent only one year after surgery. This was not preceeded by a change in medication or stimulation parameters. One patient with bilateral STN stimulation for advanced PD was not included in this study because he committed suicide before 4 year follow-up was reached. Of the 221 patients described in Table 4 (the study of Lanotte et al not included, since complications were not mentioned), ten presented with persistent changes in mental and/or psychic functioning. More and more reports appear with special focus on the effects on mood of bilateral STN stimulation $4,5,8,9,10,12,18,23,25,29$. STN stimulation seems to induce euphoria, an increase in motivation, and a decrease in fatigue, anxiety, and tension. Although this effect might be partly secundary to the improved motor-function, PET-studies have shown that STN stimulation directly influences limbic related structures like the anterior cingulate gyrus ${ }^{15}$. Moreover, acute effects on mood with mirthful laughter related to STN DBS have been described that can not be explained by a change in motor function ${ }^{10}$. After STN DBS, not only euphoric states, but also depression is described. Depression after STN DBS might due to three factors. First, it might be caused by the postoperative decrease in levodopa which is known to have a psychotrophic effect. Second, a direct influence of STN DBS on limbic related structures might be responsible, or, current spread to neighbouring structures, like the substantia nigra. The difficulty of these mood changes is that they go mostly hand in hand with the positive motor effect: in several patients (all hypomanic) we tried to change stimulation parameters to maintain the motor benefit and avoid behavioral changes, but these attempts were always unsuccessful. The disappearance of the behavioral changes were probably not secondary to the motor deterioration, since only acute effects were tested, and the after effect for motor function after the stimulators were switched off, was longer than the after effect for behavior.

\section{CONCLUSION}

The conclusion of this study is triple. First, the beneficial effects of bilateral STN stimulation on motor function (UPDRS III), and ADL (UPDRS II), is maintained after four year follow-up. Second, these positive effects can be obtained by a relatively simple technical procedure, with target determination on CT-images, without depth-recordings. Third, stimulation induced behavioral changes after STN DBS need special consideration. They may occur late in the postoperative course. 


\section{REFERENCES}

1. Aziz TZ, Peggs D, Sambrook MA, et al : Lesion of the subthalamic nucleus for the alleviation of 1-methyl-4-phenyl-1,2,3,6-tetrahydropyridine (MPTP)-induced parkinsonism in the primate. Mov Disord 6(4): 288-92, 1991

2. Benazzouz A, Gross C, Feger J, et al: Reveral of rigidity and improvement in motor performance by subthalamic high-frequency stimulation in MPTP-treated monkeys. Eur J Neurosci 5(4): 382-9, 1993

3. Chen L, Liu Z, Tian Z, et al: Prevention of neurotoxin damage of 6-OHDA to dopaminergic nigral neuron by subthalamic nucleus lesions. Stercotact Funct Neurosurg. 75(2-3): 66-75, 2000

4. Doshi PK, Chhaya N, Bhatt MH: Depression leading to attempted suicide after bilateral subthalamic nucleus stimulation for Parkinson's discase. Mov Disord 17(5):1084-5. 2002

5. Dujardin K, Defebvre L, Krystkowiak, et al: Influence of chronic bilateral stimulation of the subthalamic nucleus on cognitive function in Parkinson's disease. J Neurol 248(7): 603-611, 2001

6. Fahn S: Unified Parkinson's Disease Rating Scale. In Fahn S. Elton R, Calne D. Goldstem M. eds. Recent developments in Parkinson's disease. New Jeney/Macmillan Healthare Information, 1987, Vol 2, pp 153-163

7. Fraix V, Pollak P, Van Blercom N, et al: Effect of subthalamic nucleus stumulation on levodopa-induced dyskinesia in Parkinson's disease. Neurology 55(12) 1921-3, 2000

8. Funkiewicz A. Ardouin C. Krack P, et al: Acute psychotropic effects of bilateral subthalamic nucleus stimulation and levodopa in Parkinson's discase. Mov Disord 18(5):524-30, 2003

9. Houeto JL, Mesnage V. Mallet L. et al: Behavioral disorden, Parkinson's disease and subthalamic stimulation. J Neurol Neurosurg Psychıatry 72(6): 701-7, 2002

10. Krack P. Kumar R. Ardouin C, et al: Mirthful laughter induced by subthalamic nucleus stimulation. Mov Disord 16(5): 867-75, 2001

11. Krause M, Fogel W, Heck A et al: Deep brain stimulation for the treatment of Parkinson's disease: subthalamic nucleus versus globus pallidus internus. J Neurol Neurosurg Psychiatry 70(4): 464-70, 2001

12. Kulisevsky J, Berthier ML, Gironell A, et al: Mania following deep brain stumulation for Parkinson's discase. Neurology 59(9): 1421-4, 2002

13. Langston JW. Widner H. Goetz CG, et al Core assessment program for intracerebral transplantations (CAPIT). Mov Disord 7: 2-13, 1992

14. Lanotte MM, Rizzone M. Bergamasco B. et al: Deep brain stimulation of the subthalamic nucleus: anatomical, neurophysiological, and outcome correlations with the effects of stimulation. J Neurol Neurosurg Psychuatry 72(1): 53- - , 20(5)2

15. Limousin P. Greene J. Pollak P. et al: Changes in cerebral activity pattem due to subthalamic nucleus or internal pallidum stimulation in Parkinson's discase. Ann Neurol $42(3)=283-91.1997$ 
16. Limousin P, Krack P. Pollak P et al: Electrical stimulation of the subthalamic nucleus in advanced Parkinson's disease. N Engl J Med 339(16): 1105-11, 1998

17. Ostergaard K, Sunde N, Dupont E, et al: Effects of bilateral stimulation of the subthalamic nucleus in patients with severe Parkinson's disease and motor fluctuations. Mov Disord 17(4): 693-700, 2002

18. Perozzo P, Rizzone M, Bergamasco B, et al: Deep brain stimulation of subthalamic nucleus: behavioral modifications and familiar relations. Neurol Sci 22(1):81-2, 2001

19. Piallat B, Benazzouz A, Benabid AL: Neuroprotective effect of chronic inactivation of the subthalamic nucleus in a rat model of Parkinson's disease. J Neural Transm Suppl 55:71-7, 1999

20. Piallat B, Benazzouz A, Benabid AL: Subthalamic nucleus lesion in rats prevents dopaminergic nigral neuron degeneration after striatal 6-OHDA injection: behavioral and immunohistochemical studies. Eur J Neurosci 8(7): 1408-14, 1996

21. Pollak P, Benabid AL, Gross C, et al: Effets de la stimulation du noyau sous-thalamique dans la maladie de Parkinson. Rev Neurol (Paris) 149(3):175-6, 1993

22. Rodriguez MC, Obeso JA, Olanow CW: Subthalamic nucleus-mediated excitotoxicity in Parkinson's disease: a target for neuroprotection. Ann Neurol 44(3 Suppl 1):S175-88, 1998

23. Romito LM, Raja M, Daniele A, et al: Transient mania with hypersexuality after surgery for high frequency stimulation of the subthalamic nucleus in Parkinson's disease. Mov Disord 17(6): 1371-4, 2002

24. Romito LMA, Scerrati M, Contarino MF, et al: Long-term follow-up of subthalamic nucleus stimulation in Parkinson's disease. Neurology 58: 1546-1550. 2002

25. Saint-Cyr JA, Trepanier LL, Kumar L, et al: Neuropsychological consequences of chronic bilateral stimulation of the subthalamic nucleus in Parkinson's disease. Brain 123(Pt10): 2091-2108, 2000

26. Simuni T, Jaggi JL, Mulholland $\mathrm{H}$, et al: Bilateral stimulation of the subthalamic nucleus in patients with Parkinson disease: a study of efficacy and safety. J Neurosurg 96: $666-672,2002$

27. Spottke EA, Volkmann J, Lorenz D, et al: Evaluation of healtheare utilization and health status of patients with Parkinson's disease treated with deep brain stimulation of the subthalamic nucleus. J Neurol 249(6): 759-66, 2002

28. Thobois S, Mertens P, Guenot M, et al: Subthalamic nucleus stimulation in Parkinson's disease: clinical evaluation of 18 patients. J Neurol 249(5): 529-34, 2002

29. Trepanier L., Kumar R, Lozano AM, et al: Neuropsychological outcome of GPi pallidotomy and GPi or STN deep brain stimulation in Parkinson's disease. Brain Cogn $42(3): 324-347,2000$

30. Vesper J, Klostermann F, Stockhammer F, et al: Results of chronic subthalamic nucleus stimulation for Parkinson's disease: a 1-year follow-up study. Surg Neurol 57(5): 306-11: discussion 311-3, 2002

31. Vingerhoets FJ, Villemure JG, Temperli P,et al: Subthalamic DBS replaces levodopa in Parkinson's discase: two-year follow-up. Neurology 58(3): 396-401, 2002

32. Volkmann J. Allert N, Voges J, Weiss PH, et al: Safety and efficacy of pallidal or subthalamic nucleus stimulation in advanced PD. Neurology 56(4): 548-51, 2001 
CHAPTER 3

Bilateral high-frequency stimulation of the subthalamic nucleus in patients with multiple system atrophy-parkinsonism

A report of four cases

Veerle Visser-Vandewalle, Yasin Temel, Henry Colle,

Chris van der Linden

$J$ Neurosurg, 98:882-887,2003 


\section{Abstract}

The aim of this study was to investigate the effect of high-frequency stimulation (HFS) of the subthalamic nucleus (STN) in patients with a subtype of multiple system atrophy (MSA) in which levodopa-unresponsive MSA parkinsonism (MSA-P) is predominant.

After a local anesthetic was administered, electrodes were stereotactically implanted bilaterally into the STN in four patients with MSA-P and predominantly akinetorigid symptoms. Unified Parkinson's Disease Rating Scale (UPDRS) scores were evaluated preoperatively, at 1 month, and at long-term follow-up. At I month the median decrease in the UPDRS III motor score was 22 on the 56-point scale (decreases of 16, 13, 29, and 15 points compared with baseline for Cases $1,2,3$, and 4, respectively). This was mainly due to an improvement in rigidity and akinesta. The median decrease in the UPDRS II scote was 11 on the 52-point scale (respective decreases of 5, 7, 13, and 9 points). At 2 years (mean follow-up 27 months) there was a median decrease in the UPDRS III score of 12 (respective decreases of 18, 13, 21 and 9 points), and in the UPDRS II score of 5 (with respective decreases of $2,2,17$, and 2), both compared with the stimulation off state.

At long-term follow-up there was an increase in the individual Schwab and England scores of 10 to $15 \%$ in the stimulation on compared with the stimulation off condition.

There was a beneficial effect of STN HFS in these four patients on both a short-term and a long-term basis. A larger prospective study is justified. 
Multiple system atrophy is an adult-onset neurodegenerative disease of unknown origin. It causes parkinsonian, cerebellar, pyramidal, and autonomic/urinary dysfunctions in many combinations, leading to different clinical subtypes! The discovery in 1989 of glial cytoplasmic inclusions in the brains of patients with MSA provided a neuropathological marker and confirmed that MSA is a single clinicopathological entity ${ }^{27}$. In the majority of cases, levodopa-unresponsive parkinsonism is the key clinical feature in what is known as the MSA-P subtype. Although considered a rare disease, MSA-P may account for up to $10 \%$ of patients with parkinsonism ${ }^{18}$ and is one of the most common conditions mistaken for PD. In addition to a poor or absent levodopa response, clinical signs of MSA-P include symmetrical onset of symptoms, relative absence of rest tremor, early instability, and rapid disease progression'.

In contrast to PD, in which there is a purely presynaptic dopaminergic neuronal cell loss, in MSA the degeneration is pre- and postsynaptic ${ }^{12}$. Progressive loss of striatal postsynaptic dopamine $\mathrm{D}_{2}$ receptors is thought to account for levodopa unresponsiveness. An IBZM-SPECT scan can be used to differentiate between MSA-P and PD because it detects a significant loss of striatal dopamine receptors. 20,22

This study presents the short-and long-term effects of bilateral STN stimulation on the symptoms of four patients with MSA-P who were unresponsive to levodopa treatment.

\section{CLINICAL MATERIAL AND METHODS}

\section{Patient population}

Patients were selected based on having poor levodopa responsive parkinsonism of unknown origin, combined with autonomic failure including urinary dysfunction (probable MSA according to the consensus criteria ${ }^{f}$ ) and severity of disease (Hoehn and $\mathrm{Yahr}^{7}$ stage $\geq 3$ and $<5$ in the best condition). The levodopa response was defined as poor when the improvement in the UPDRS III motor score was less than $5 \%$ in patients undergoing antiparkinsonain drug therapy (levodopa plus decarboxylase inhibitor up to $1000 \mathrm{mg} /$ day and pergolide given for $>3$ months). We diagnosed autonomic dysfunctions on the basis of anamnestic data. Orthostatic hypotension was diagnosed on the basis of a symptomatic postural fall in systolic blood pressure of $30 \mathrm{~mm} \mathrm{Hg}$ within 3 munutes of standing upright from the recumbent position. Exclusion criterion for STN HFS was mental dysfunc- 
tion. Patients with poor cardiovascular or pulmonary status or those receiving anticoagulant therapy were also excluded.

All patients underwent IBZM-SPECT scanning when the diagnosis of MSA-P was suspected on clinical grounds. Only patients with a significant decrease in striatal postsynaptic dopamine receptors were included. Patients in whom structural abnormalities were demonstrated on the MR image (including severe supra- or infratentorial atrophy) were excluded.

None of the patients received antiparkinsonian medication for at least 2 months prior to surgery.

The study was approved by the institutional review boards from both hospitals and informed consent was obtained from each participant.

\section{Clinical assessment}

Activities of daily living (ADL) and motor function were studied using the UPDRS Parts II and $\mathrm{III}^{4}$. Maximum scores (52 for UPDRS Part II and 56 for UPDRS Part III) reflect the worst clinical condition. The severity of the disease was assessed using Hochn and Yahr staging ${ }^{7}$ (raging from 0 , no signs of disease, to 5 , wheclchair bound or bedridden unless aided). The level of dependency for ADL was evaluated by means of the Schwab and England Scale ${ }^{21}(0 \%$ is worst and $100 \%$ is best). All postoperative assessments were conducted by two independent investigators who, postoperatively, were blinded for stimulation. Postoperative evaluations were performed when the stimulation was on, and 12 hours off. 1 month postoperatively, and at the long-term follow-up evaluation.

\section{Operative procedure}

The entire procedure was performed using stereotaxy while the patient received a local anesthetic. For patients undergoing surgery at the University Hospital of Ghent, the Leksell G stereotactic frame was used and stereotactic coordinates were determined based on CT scanning. For the other patients undergoing surgery at the St. Lucas Hospital in Ghent, the Cosman Roberts Wells stereotactic frame was used and the coordinates were determined based on fused CT and MR images. The target was defined in the dorsolateral part of the STN.

The following coordinates were used in reference to the AC-PC: 11-12 mm lateral to the AC-PC, mid AC-PC, and $4 \mathrm{~mm}$ beneath the AC-PC. The angle of approach was chosen to be as perpendicular as possible to both coronal and sagittal 
planes, thereby avoiding the lateral ventricle. We began surgery on the right side in all patients. No micro- or semimicroelectrode recording was used. A 2-mm monopolar test electrode with a naked tip (model 3101-2; Radionics, Burlington, MA) was introduced $6 \mathrm{~mm}$ above the target and stimulation began at a frequency of $100 \mathrm{~Hz}$ and a stimulus duration of $100 \mu \mathrm{sec}$. The stimulus intensity was increased in $0.5 \mathrm{~V}$ stages to the desired response or until untoward side effects occurred. Stepwise test stimulation was continued in $2 \mathrm{~mm}$ steps to $4 \mathrm{~mm}$ beneath the target. At each point of test stimulation the clinical response was evaluated by one neurologist (C.v.d.L.) blinded during the stimulation. The following clinical parameters were scored using the UPDRS: rigidity in all four extremities (must be diminished by $\geq 2$ points on the UPDRS), finger tapping, opening and closing of the hands, and flexion-extension of the leg. When a beneficial effect was found without side effects, the test electrode was replaced by the final quadripolar electrode (model 3389; Medtronic), placing the second deepest pole (Pole 1) at the level of the best clinical response in the patients in Cases 1,3 and 4 , and the deepest pole (Pole 0 ) at the level of the best clinical response in the patient in Case 2. In all patients one trajectory on each side was sufficient to achieve a good clinical effect. The position of this final electrode was checked using fluoroscopy. This electrode was fixed in the burr hole with acrylic cement and connected to an externalized extension cable. The same procedure was then performed on the left side in each patient.

After this first operation, the four patients were tested using externalized electrodes connected to a screener (model 3625: Medtronic) for approximately 1 week to evaluate responses based on UPDRS Parts II and III. In all patients a postoperative MR image revealed that the electrodes were positioned well without any bleeding. Once agreement was reached among the neurologist, neurosurgeon and nursing staff on clinical improvement of the patient, we performed a second operation approximately 1 week later to implant two pulse generators infraclavicularly (Itrel III, model 7425; Medtronic).

\section{Statistical comparisons}

Comparisons were performed using the Friedman test, for $k$ related comparisons, and the Wilcoxon signed-rank test for two related comparisons for paired nonparametric data. The level of significance was accepted at a probability value less than 0.05 . 


\section{RESULTS}

Four patients were included in this study (one man and three women, age range 59-66 years at the time of surgery). Patient profiles and clinical characteristics are shown in Table 1. All patients suffered from a severe akineto-rigid syndrome with gait ataxia. In three patients the gait abnormality was partly extrapyramidal (slow shuffling short steps, hastening steps, and propulsion), and partly cerebellar (irregular timing, irregular direction, and irregular length of steps). The patient in Case 4 had a predominantly extrapyramidal gait. No patient had tremor.

The patient in Case 3 died of pneumonia after 6-month follow- up. The other patients were followed for at least 2 years $(29,28$ and 44 months for Cases 1,2 and 4, respectively).

Table 1 Demographic features and clinical characteristics in four patients

\begin{tabular}{|c|c|c|c|c|c|c|c|c|}
\hline $\begin{array}{l}\text { Case } \\
\text { No. }\end{array}$ & Sex & $\begin{array}{l}\text { Age } \\
\text { (yns) }\end{array}$ & $\begin{array}{l}\text { Disease } \\
\text { duration (yn) }\end{array}$ & $\begin{array}{l}\text { UPDRS } \\
\text { part II }\end{array}$ & $\begin{array}{l}\text { UPDRS } \\
\text { part III }\end{array}$ & $\begin{array}{l}\text { H\& } Y^{*} \\
\text { Score }\end{array}$ & Autonomic falure & $\begin{array}{l}\text { ADL } \\
\text { Score }(\%)\end{array}$ \\
\hline 1 & f & 63 & 5 & 19 & 32 & 3 & urinary incontinence & 6) \\
\hline 2 & f & 65 & 7 & 36 & 55 & 4 & urinary retention & 50 \\
\hline 3 & f & 66 & 4 & 33 & 49 & 3 & urinary incontunence & 65 \\
\hline 4 & m & 59 & 6 & 25 & 42 & 3 & $\begin{array}{l}\text { crectile dysfunction/ } \\
\text { orthostatic hypotension }\end{array}$ & 60 \\
\hline
\end{tabular}

$\star H$ and $\mathrm{Y}=$ Hochn and $\mathrm{Yahr}$

\section{Motor examination: UPDRS Part III}

After 1 month of chronic stimulation, the total UPDRS III motor score clearly decreased in all patients (Case 1: from 32 to 16; Case 2: from 55 to 42 ; Case 3: from 49 to 20 ; Case 4 : from 42 to 27$)$, with a significant $(p<0.05)$ change in the median score of 22 (Table 2). This was mainly due to improvements in rigidity (Case 1: from 10 to 4 ; Case 2 : from 15 to 10 ; Case 3 : from 14 to 1 ; Case 4 : from 5 to 2 ), and akinesia (Case 1: from 16 to 4 ; Case 2: from 23 to 20; Case 3: from 18 to 8 ; Case 4 : from 19 to 13). Bradykinesia improved in Cases 2,3 and 4 (from 3 to 2 in each). For the patient in Case 1, who had a low preoperative score (1), there was no change after 1 month of stimulation. There was gait only improvement in Cases 2,3 and 4 (from 3 to 2 , from 2 to 1 , and from 3 to 2 , respectively). For the patient in Case 1, who also had a low preoperative score for gait (1), there was no change.

At long-term follow-up, there was an increase in the UPDRS Part III total score when the stimulators were switched off, in the patients with a follow-up of more than 2 years (Case 1: from 32 to 63: Case 2: from 55 to 60: Case 4 : from 42 to 46 ). 
Table 2 Individual and median scores on the UPDRS Parts II and III in four patients with MSA-P who recerved bilateral STN stamulation.

\begin{tabular}{|c|c|c|c|c|c|}
\hline \multirow[b]{2}{*}{ Sconng factor } & \multirow[b]{2}{*}{ Buscline } & \multicolumn{2}{|c|}{ 1-mo follow-up } & \multicolumn{2}{|c|}{ Long-term follow-up } \\
\hline & & Stam OFF & Stim ON & Stim OFF & Stim ON \\
\hline \multicolumn{6}{|l|}{ UPDRS II } \\
\hline Case 1 & 19 & 18 & 14 & 36 & 34 \\
\hline Case 2 & 36 & 35 & 29 & 37 & 35 \\
\hline Cane 3 & 33 & 32 & 20 & 37 & 20 \\
\hline Case 4 & 25 & 27 & 16 & 3 & 20 \\
\hline median & 29 & 29.5 & $18^{*}$ & $36.5 *$ & $31.5 *$ \\
\hline \multicolumn{6}{|l|}{ UPDRS III } \\
\hline Case 1 & 32 & 29 & 16 & 6.3 & 45 \\
\hline Case 2 & 55 & 53 & 42 & 6) & 47 \\
\hline Case 3 & 49 & +4 & 20 & 41 & 20 \\
\hline Case 4 & 42 & 40 & 27 & thi & 37 \\
\hline median & 455 & 42 & $23.5 *$ & 53 & $41^{*}$ \\
\hline \multicolumn{6}{|l|}{ Rigidity } \\
\hline Case 1 & 10 & 9 & 4 & 14 & 4 \\
\hline Case 2 & 15 & 14 & 10 & 16 & 7 \\
\hline Case 3 & 14 & 11 & 1 & 8 & () \\
\hline Case 4 & 5 & 6 & 2 & 4 & 2 \\
\hline median & 12 & 10 & $3 *$ & 11 & $3 *$ \\
\hline \multicolumn{6}{|l|}{ Akinesia } \\
\hline Case 1 & 16 & 18 & 4 & 26 & 19 \\
\hline Case 2 & 23 & 24 & 20 & 27 & 23 \\
\hline Case 3 & 18 & 14 & 8 & 15 & $y$ \\
\hline Case 4 & 19 & 19 & 13 & 16 & 11 \\
\hline median & 185 & 18.5 & $11^{\circ}$ & 21 & $15^{\circ}$ \\
\hline \multicolumn{6}{|l|}{ Bradykinesia } \\
\hline Case 1 & 1 & 1 & 1 & 4 & 3 \\
\hline Case 2 & 3 & 3 & 2 & 3 & 3 \\
\hline Case 3 & 3 & 3 & 2 & 3 & 2 \\
\hline Case 4 & 3 & 3 & 2 & 3 & 2 \\
\hline median & 3 & 3 & 2 & 3 & 2.5 \\
\hline \multicolumn{6}{|l|}{ Gait } \\
\hline Case 1 & 1. & I & 1 & 3 & 3 \\
\hline Case 2 & 3 & 3 & 2 & 3 & 3 \\
\hline Case 3 & 2 & 2 & 1 & 2 & 1 \\
\hline Case 4 & 3 & 3 & 2 & 4 & 4 \\
\hline median & 2.5 & 2.5 & 1.5 & 3 & 3 \\
\hline \multicolumn{6}{|c|}{ Postural stability } \\
\hline Case I & 2 & 2 & 0 & 3 & 3 \\
\hline Case 2 & 2 & 1 & $\theta$ & 3 & 2 \\
\hline Case 3 & 2 & 2 & 2 & 2 & 2 \\
\hline Case 4 & 4 & 5 & 2 & 4 & 4 \\
\hline medran & 2 & 2 & 1 & 3 & 25 \\
\hline
\end{tabular}

* Change in scores was sugnificant (p<10 05) with both stimulator on. compared wrth scores with both stimuLators off 
Table 3 Individual Schwab and England ADL and Hochn and $Y$ ahr scores in four patients who received bilateral STN stumulation.

\begin{tabular}{|c|c|c|c|c|c|}
\hline \multirow[b]{2}{*}{ Sconing factor } & \multirow[b]{2}{*}{ Baseline } & \multicolumn{2}{|c|}{ 1-mo follow-up } & \multicolumn{2}{|c|}{ Long-term follow-up } \\
\hline & & Stim OFF & Stim ON & Stim OFF & Stim ON \\
\hline \multicolumn{6}{|l|}{ ADL Score } \\
\hline Case I & $60 \%$ & $60 \%$ & $80 \%$ & $20 \%$ & $30 \%$ \\
\hline Case 2 & $50 \%$ & $50 \%$ & $75 \%$ & $15 \%$ & $25 \%$ \\
\hline Case 3 & $65 \%$ & $65 \%$ & $80 \%$ & $65 \%$ & $80 \%$ \\
\hline Case 4 & $60 \%$ & $60 \% 6$ & $75 \%$ & $25 \%$ & $35 \%$ \\
\hline \multicolumn{6}{|l|}{ H \& Y Stage } \\
\hline Case I & 3 & 3 & 2 & 5 & 5 \\
\hline Case 2 & 4 & 4 & 3 & 5 & 5 \\
\hline Case 3 & 3 & 3 & 2 & 3 & 2 \\
\hline Case 4 & 3 & 3 & 2 & 5 & 5 \\
\hline
\end{tabular}

In all patients this score clearly decreased when the stimulators were switched on (Case 1: from 63 to 45 ; Case 2: from 60 to 47 ; Case 3: from 41 to 20; Case 4: from 46 to 37$)$, with a significant $(\mathrm{p}<0.05)$ change in the median score of 12 . In all patients there was a decrease in the scores for rigidity (Case 1: from 14 to 4 ; Case 2: from 16 to 7: Case 3: from 8 to 0; Case 4: from 4 to 2) and akinesia (Case 1: from 26 to 19; Case 2: from 27 to 23; Case 3: from 15 to 9; Case 4 : from 16 to 11). Bradykinesia improved in Cases 1, 3 and 4 (from 4 to 3,3 to 2 and 3 to 2, respectively). Gait only improved in Case 3 (from 2 to 1 ) and postural stability only improved in Case 2 (from 3 to 2 ).

\section{Activities of daily living: UPDRS Part II}

At 1-month follow-up, the UPDRS Part II score decreased in all patients with stimulators turned on (Case 1: from 19 to 14; Case 2: from 36 to 29; Case 3: from 33 to 20; Case 4: from 25 to 16). At long-term follow-up, only the patient with the shortest follow-up (Case 3) showed a clear decrease when the stimulator on scores were compared to the stimulator off scores (from 37 to 20).

Hoehn and Yahr scores

After 1 month of stimulation the individual Hoehn and Yahr scores decreased by 1 point for each patient (Table 3).

At long-term follow-up, only Case 3 showed a decrease of 1 point with the stimulators turned on (from 3 to 2 , at 1 month and at 6 months). For the other three patients the score remained at 5 . 
Individual stimulation charactenstio in four patients who received bilateral STN stimulation.*

\begin{tabular}{|c|c|c|c|c|c|c|c|c|c|c|}
\hline \multirow{3}{*}{$\begin{array}{l}\text { Case } \\
\text { No. }\end{array}$} & \multirow{3}{*}{$\begin{array}{l}\text { Electrode } \\
\text { setrings }\end{array}$} & \multirow{3}{*}{ Frequency } & \multicolumn{4}{|c|}{ Amplitude (V) } & \multicolumn{4}{|c|}{ Pulve Wulth (ysec) } \\
\hline & & & \multicolumn{2}{|c|}{$\mathrm{I} \mathrm{MoFU}$} & \multicolumn{2}{|c|}{ IT FU } & \multicolumn{2}{|c|}{ I Mo FU } & \multicolumn{2}{|c|}{ IT FU } \\
\hline & & & Right & Left & Rught & Left & Right & Left & Right & Left \\
\hline 1 & $1-3+$ & 130 & 25 & 25 & 2.2 & $2+$ & 210 & 210 & 210 & 210 \\
\hline 2 & 1-. Cave + & 130 & 2.7 & 2.7 & 2.8 & 30 & 210 & 210 & 210 & 210 \\
\hline 3 & $1-$ Case + & 1.30 & 2.0 & 24 & 24 & 2.8 & 210 & 210 & 210 & 210 \\
\hline 4 & $2-, 3-$ Caset & 130 & 1.8 & 1.8 & 20 & 24 & 270 & 210 & 210 & 210 \\
\hline
\end{tabular}

$\mathrm{FU}=$ follow-up; $\mathrm{LT}=\mathrm{long}-\mathrm{term}$

\section{Schwab and England scale}

After 1 month of stimulation the preoperative ADL scores remained the same when both stimulators were switched off $(60,50,65$, and $60 \%$ for Cases $1,2,3$, and 4 , respectively). With the stimulation on, the scores increased by 15 to $25 \%$ (with scores of $80,75,80$ and $75 \%$ for Cases 1, 2, 3, and 4, respectively). The scores decreased dramatically for the patients with a long-term follow-up of more than 2 years when both stimulators where switched off (Case 1: from 60 to $20 \%$, Case 2: from 50 to $15 \%$, Case 4 : from 60 to $25 \%$ ). With the stimulators turned on. these scores increased by at least 10\% (Case 1: from 20 to $30 \%$; Case 2: from 15 to 25\%; Case 3: from 65 to $80 \%$; Case 4 ; from 25 to $35 \%$ ).

\section{Stimulation characteristics}

The individual stimulation parameters, at 1 month and at long-term follow-up, are given in Table 4.

\section{Adverse effects}

Mild confusion was observed in one patient immediately postoperatively. There were no other adverse effects such as intracranial bleeding. infections, seizures, stimulation-related paresthesias, involuntary movements, or changes in behavior.

\section{Side effects}

Two patients reported significant weight gain $(10$ and $13 \mathrm{~kg})$.

Effects on cerebellar signs and autonomic failure

Gait ataxia (locomotor ataxia: irregular timing, irregular direction, and irregular length of steps), which was clearly present in Cases 1,2 and 3 preoperatively, was unaffected by STN HFS. Subthalamic nucleus HFS also had little effect on 
extrapyramidal gait ataxia (slow shuffling short steps, hastening steps, and propulsion) and no effect on autonomic failure in these four patients.

\section{DISCUSSION}

The results of this study demonstrate a beneficial effect of bilateral STN stimulation on individual total UPDRS Part III scores at 1 month (with a decrease of 16 , 13,29 and 15 points for Cases $1,2,3$, and 4, respectively, on the maximum score of 56), and at long-term follow-up when stimulator on scores were compared with stimulator off scores (decreases of 18, 13, 21 and 9, respectively.). When UPDRS Part III subscores are considered, the effect is most pronounced for rigidity and akinesia.

On the UPDRS Part II there was a decrease at 1 month in all patients (decreases of $5,7,13$ and 9 for all patients, respectively, on the maximum score of 52). At long-term follow-up, there was a clear improvement only in Case 3 (17 points). In the other three patients with long-term follow-up of more than 2 years, there was a decrease of 2 points on the UPDRS Part II.

In all patients there was an improvement on the Hoehn and Yahr score at 1 month. At long-term follow-up, there was no improvement in the three patients with follow-up longer than 2 years.

In all patients there was an improvement on the Schwab and England ADL score at 1 month (15-25\%) and at long-term follow-up (10-15\%).

There was no change in cerebellar or autonomic dysfunction in any of the patients.

The main question is whether these results justify further application of this technique in more patients with MSA-P. We believe they do for a number of reasons. First of all there is the safety of the technique and the lack of other treatment options.

There is no proven effective treatment for MSA-P. One-third of patients with MSA-P show a clinically significant response to levodopa therapy, but this response usually lasts for fewer than 5 years ${ }^{6}$. There is no evidence to endorse other drug treatment options. Surgery has rarely been performed in patients with MSA; only two patients with MSA who underwent surgery have been reported and both underwent HFS of the STN. ${ }^{17,}{ }^{19}$ The first patient ${ }^{17}$ did not show any 
improvement. The second patient met the clinical criteria for PD (including levodopa responsiveness) and showed substantial improvement of motor symptoms after STN HFS ${ }^{19}$.

In these four patients, bilateral STN stimulation has been shown to be a safe technique, On a much wider scale, STN HFS has proven to be a good and safe treatment for alleviating parkinsonian motor symptoms in cases of advanced PD2, $3,8-11.13-16,17,23-25$.

Patients with MSA-P have a relatively short life expectancy; the main disease duration varies between 6.1 year ${ }^{28}$ and 9.5 years $^{26}$.

Our results demonstrate that the effect of stimulation declines over time, although the results in Cases 1,2, and 4 (with follow-up periods of 29,28 and 44 months. respectively) show that there still is an effect at this long-term follow-up. The shorter the disease duration, the more meaningful the effect of treatment at these follow-up periods. It has also been our experience that the effect of STN stimulation during the long term is greatly appreciated by the patient. For patients, a change of $10 \%$ on the Schwab and England ADL scale is a significant gain. Considering the natural, progressive evolution of the disease, for which the scores with the stimulators off are demonstrative, the Schwab and England ADI scores show that the patients are more independent with than without stimulators. Each patient found the operation to have been worthwhile considering the improvement gained.

None of the four patients responded to levodopa therapy. The positive effect of STN stimulation on motor function (most pronounced for rigidity and akinesia) might be explained by a mechanism similar to that in PD, in which GPe hypoactivity leads to STN hyperactivity. In PD, loss of dopaminergic cells leads to enhanced striatal inhibitory outflow towards GPe (indirect pathway), with hypoactivity of GPe and hyperactivity of the STN as a consequence. Increased excitation of GPi by the STN leads to reduced thalamocortical drive, which is thought to account for motor symptoms of PD. Loss of dopamine leads to reduced striatal inhibitory outflow towards GPi (direct pathway), also leading to hyperactivity of the $\mathrm{GPi}$, and reduced thalamocortical outflow. In MSA, an autoradiographic postmortem study suggested that disease progression may initially affect the indirect striatal pathway, and subsequently, with increasing disease duration, the direct striatopallidal pathway ${ }^{27}$. The degenerative change appears to be more marked in the GPe than in the GPi. Subthalamic degeneration is uncommon and, if present, rarely severe. This hypothesis of STN hyperactivity due to GPe degeneration could explain the (partial) beneficial effect of STN HFS in these four 
patients, whereas levodopa therapy had no effect, due to loss of striatal $\mathrm{D}_{2}$ receptors.

The poor effect on postural instability and gait disturbances in these four patients might be explained by the involvement of cerebellar pathways in the degenerative process of MSA-P that, together with basal ganglia pathways, regulates gait and balance. Cerebellar and basal ganglia pathways both project to the motor-related thalamus, upstream from the STN, but remain separated ${ }^{5}$. Also the absence of effect on autonomic functions might be explained through degeneration of parts of the central nervous system, not connected to the STN. like the intermediolateral columns. The absence of effect on cerebellar and autonomic dysfunctions explains why the effect on UPDRS Part II scores is less pronounced than on UPDRS Part III.

\section{CONCLUSIONS}

Subthalamic nucleus HFS in these four patients with probable MSA-P had a positive effect on UPDRS Part II and UPDRS Part III scores. The effect declines over time, but at long-term follow-up, the patients' motor score and ADL scores were still clearly better with stimulation than without. We believe that these results justify a larger, prospective study.

\section{Acknowledgement}

We are grateful to ms. Halime Celik for her help with the statistical analyses, mrs. Brenda Vollers for the grammatical corrections, dr. W. Weber for his constructive criticism, and to prof. E. Beuls and dr. G. Spincemaille for their kind support.

\section{REFERENCES}

1. Albanese A, Colosimo C. Bentivoglio AR, et al: Multiple system atrophy presenting as parkinsonism: clinical features and diagnostic criteria, J Neurol Neurosurg Psych $59: 144-151,1995$

2. Burchiel KJ. Anderion VC. Favre J. et al: Comparison of pallidal and subthalamic nucleus deep brain stimulation for advanced Parkinson's disease: results of a randomised, blinded pilot study. Neurosurgery 45: 1375-1384, 1999

3. The Deep-Brain stimulation for Parkinson's Disease Study Group: Deep-brain stimulation of the subthalamic nucleus or the pars interna of the globus pallidus in Parkinson's disease. N Engl ] Med 345: 956-963, 2001 
4. Fahn S, Elton R. Members of the UPDRS Development Committee: Unified Parkinson's Disease Rating Scale, in Fahn S, Marsden CD, Goldstein M, et al (eds) Recent developments in Parkinson's disease. Florham Park, NJ: Macmillan Healthcare Information, 1987. Vol 2, pp 153-163

5. Flaherty WF, Graybiel AM: The anatomy of the basal gangha. In Marsden \& Fahn eds. Movement Disorders 3. Oxford: Butterworth-Heinemann, 1994, pp 3-27

6. Gilman S, Low PA, Quinn N, et al. Consensus statement on the diagnosis of multiple system atrophy. J Auton Nerv Syst 74: 189-192, 1998

7. Hochn MM, Yahr MD: Parkinsonism: onset, progression and mortality. Neurology $17: 427-442,1967$

8. Houeto JL, Damer P, Bejani PB, et al: Subthalamic stimulation in Parkinson's discase: a multidisciplinary approach. Arch Neurol 57:461-465, 2000

9. Krack P, Pollak P, Limousin P, et al: Subthalamic nucleus or internal pallidum stimulation in young onset Parkinson's disease. Brain 121:451-457, 1998

10. Kumar R, Lozano AM, Kim Y], et al: Double-blind evaluation of subthalamic nucleus deep brain stimulation in advanced Parkinson's discase. Neurology 51:850-855, 1998

11. Kumar R, Lozano AM, Sime E, et al: Comparative effects of unilateral and bilateral subthalamic nucleus deep bran stumulation. Neurology 53:561-566, 1999

12. Kume A, Takahashi A. Hashizume $\mathrm{Y}$ : Neuronall cell loss of the striatonigral system in MSA. J Neurol Sci 117: 33-40, 1993

13. Limousin P, Krack P. Pollak P, et al: Electrical stimulation of the subthalamic nucleus in advanced Parkinson's disease. New Engl. J Med 339: 1105-1111, 1998

14. Molinuevo JL, Valldeonola F. Tolosa E. et al: Levodopa withdrawal after bilateral subthalamic nucleus stimulation in advanced Parkinson's disease. Arch Neurol 57 (7):983-988, 2000

15. Moringlane JR, Ceballos-Baumann AO. Alesch F: Long-term effect of electrostimulation of the subthalamic nucleus in bradykinetic-rigid Parkinson's disease. Minim Invasive Neurosurg 41:133-136, 1998

16. Moro E. Scerrati M, Romito LM, et al: Chronic subthalamic nucleus stimulation reduces medication requirements in Parkinson's disease. Neurology 53(1):85-90, 1999

17. Pinter MM: Apomorphine test: a predictor for motor responsiveness to deep brain stimulation of the subthalamic nucleus. J Neurol 246:907-913, 1999

18. Quinn N: Multiple system atrophy: the nature of the beast. J Neurol Neurosurg Psychiatry 52 (Suppl): $78-89.1989$

19. RumiaJ, Valldeoriola C, Marin C, et al: Therapeutic effects of subthalamic nucleus stimulation on multiple system atrophy: case report. Mov Disord 15 (Suppl. 3): 66, 2000 (Abstract)

20. Schulz JB, Klockgether T, Petersen D, et al: Multiple system atrophy: natural history. MRI morphology, and dopamine receptor imaging with 123IBZM-SPECT, J Neurol Neurosurg Psychiatry 57: 1047-1056, 1994 
21. Schwab RS, England AC Jr: Projection technique for evaluating surgery in Parkinson's disease, in Gillingham FJ, Donaldson IML (eds): Third Symposium on Parkinson's Disease, Royal College of Surgeons in Edinburgh, May 20-22, 1968. Edinburgh: E \& S Livingstone, 1969. pp 152-157

22. Schwarz J. Tatsch K, Gasser T, et al: 123-IBZM binding compared with long-term clinical follow-up in patients with de novo parkinsonism. Mov Disord 13, 1: 16-19, 1998

23. Starr PA, Vitek JL, Bakay RA: Ablative surgery and deep brain stimulation for PD. Neurosurgery 43: 989-1015, 1998

24. van der Linden C, Vandewalle V, Colle H, et al: Chronic bilateral stimulation of the subthalamic nucleus in advanced Parkinson's disease: a long-term follow-up in 39 patients. Mov Disord 15 (Suppl 3): 62-63, 2000 (Abstract)

25. Voges J, Volkmann J, Allert $\mathrm{N}$, et al: Bilateral high frequency stimulation in the subthalamic nucleus for the treatment of Parkinson's disease: correlation of therapeutic effect with anatomical electrode position. J Neurosurg 96: 269-79, 2002

26. Wenning GK, Ben Shlomo Y, Magalhaes M, et al: Clinical features and natural history of multiple system atrophy. An analysis of 100 cases. Brain 117: 835-845, 1994

27. Wenning GK, Tison F, Scherfler C: Towards neurotransplantation in multiple system atrophy: clinical rationale, pathophysiological basis, and preliminary experimental evidence. Cell Transplant 9: 279-288, 2000

28. Wenning GK, Tison F, Shlomo B: Multiple system atrophy: a review of 203 pathologically proven cases. Mov Disord 12: 133-147, 1997 
CHAPTER 4

\section{Research Review}

Surgery in Tourette Syndrome

Yasin Temel and Veerle Visser-Vandewalle

Mov Disord (In press) 


\section{Sunmary}

Tourette syndrome (TS) is a neuropsychiatric disorder with onset in early childhood. It is characterized by tics and often accompanied by disturbances in behavior, such as obsessive-compulsive disorder (OCD). In most cases, the disorder is self-limiting or can be treated by medication or behavioral therapy. In a small percentage, however, symptoms are intractable to any conservative treatment. Since 1955, various attempts have been made to treat these patients through neurosurgical procedures.

The target sites have been diverse and include the frontal lobe (prefrontal lobotomy and bimedial frontal leucotomy). the limbic system (limbic leucotomy and anterior cingulotomy), the thalamus and the cerebellum. Combined approaches have also been tried such as anterior cingulotomies plus infrathalamic lesions. The results have often been unsatisfactory or major side effects have occurred, such as hemiplegia or dystonia.

Our review of the literature from 1960 until 2003 revealed 21 reports and 3 descriptions in textbooks covering about 65 patients in total who had undergone ablative procedures for intractable TS, the first being reported in 1962. In 1999. deep brain stimulation (DBS) was introduced as a new approach for intractable TS. To date, 3 patients have been reported who underwent bilateral thalamic stimulation, with promising results on tics and, obsessive-compulsive symptoms. 


\section{INTRODUCTION}

Tourette Syndrome (TS), named after Georges Albert Edouard Brutus Gilles de la Tourette, a French neuropsychiatrist $(1857-1904)^{1.2}$, is a chronic neuropsychiatric disorder characterized by the presence of various tics. Tics are sudden, brief. intermittent, involuntary or semivoluntary movements (motor tics) or sounds (phonic or vocal tics). Tics usually wax and wane in frequency and intensity during the natural course of the disease. At one time, TS was considered a rare syndrome. Nowadays, it is recognized as a relatively common disorder. An estimated worldwide prevalence of 4 to 5 cases per 10,000 individuals has been reported ${ }^{3}$. A recent study ${ }^{4}$, however, revealed a prevalence of 31 to 157 cases per 1,000 individuals in 13 to 14 year-old children attending mainstream secondary schools in the United Kingdom. There is a considerable variation in studies reporting on the prevalence of TS, due most probably to variations in gender, age, diagnostic criteria, and assessment methods 5 .

Throughout the history of this disorder, a variety of theories have been proposed concerning its origin including psychogenic, developmental, and inflammatory mechanisms. Various clinical, neuropathological and neuro-imaging observations suggest that dysfunction of the basal ganglia and related thalamocortical circuits form, at least in part, the pathophysiological basis of TS ${ }^{6-10}$. It is assumed that the basal ganglia play a major role in the "timing and sequencing" of motor and behavioral programs by selecting desired and suppressing unwanted programs to be executed ${ }^{11.12}$. Uncontrolled movements and vocalizations in TS might be the result of defective inhibitory mechanisms at the level of the basal ganglia leading to the expression of simple or more complex motor or behavioral acts. The primary pathology that leads to the defective selection mechanisms is still unknown. Intrinsic striatal or extrinsic factors (e.g. excitatory or dopaminergic afferents at the level of the striatum) might play a role ${ }^{13}$.

The onset of the disease often occurs in childhood with motor and/or vocal tics, the latter usually beginning several years later ${ }^{5}$. TS is associated commonly with symptoms of obsessive-compulsive disorder (OCD) and attention-deficit hyperactivity disorder (ADHD). Although it is frequently self-limited, some patients remain symptomatic and require chronic treatment. The standard treatment is pharmacological involving mainly neuroleptics, $\alpha 2$-adrenergic agonists and sometimes benzodiazepines. In some cases, behavioral treatment may provide temporary control of symptoms but certain patients prove to be medically untreatable or experience unbearable side effects from the medication. It is these patients who have been potential candidates for neurosurgical interventions. 
During the past few decades, many ablative procedures have been carried out in an attempt to treat intractable TS. In total, 65 patients have undergone ablative surgery varying from "tailored" stereotactic operations to more rigorous prefrontal lobotomies, and 3 patients have undergone DBS (see figure 1). In the present review, the various neurosurgical procedures are described chronologically together with their outcome, and the present role of surgery in TS is discussed.

\section{Search strategy}

All articles and textbooks containing descriptions of surgery in TS were reviewed. The reports were found by a Medline search (PubMed) using the key words: Tourette syndrome, TS, Tourette, Gilles de la Tourette, tic, tics and tic disorder in combinations with surgery, neurosurgery, surgical intervention, lobotomy, limbic leucotomy, leucotomy, cingulotomy, campotomy, thalamotomy, dentatotomy, coagulation, ablative, ablative surgery, stereotactic, stereotactic surgery and DBS. Some of the reviewed reports in this article were not Medline indexed. These were found by analysis of the bibliography of all included Medline-indexed articles. Only works published in English, German and French were reviewed.

In total, 21 reports and 3 textbooks were found describing original cases. All data about pacient cnáaracteristucs, medika history, surgery, outcome and śdẻ etrếcts were collected.

\section{ABLATIVE PROCEDURES}

summaries of ablative procedures are shown in Tables 1 and 2

$$
1961-1970
$$

In 1962, Baker ${ }^{14}$ described TS as an "involuntary paroxysmal hyperkinesis involving entire skeletal musculature" and reported the first leucotomy for TS. The patient was a 22-year-old man who had had vocal and somatomotor tics since the age of 9 years, with severe obsessive-compulsive behavior (OCB), and " restlessness, irritability, and distractibility". According to the author, the latter could be associated with brain damage from birth. Pharmacological treatment had no effect on tics and behavioral symptoms. In October 1960, a bimedial leucotomy was carried out. The procedure was complicated by a frontal lobe abscess, which was aspirated. After a follow-up of 1 year, the patient presented with minimal tics and obsessive-compulsive symptoms (OCs), according to the same author. 
Table 1 Patient characteristics of 65 patients who underwent ablative procedures for intractable Tourette Syndrome.

\begin{tabular}{|c|c|c|c|c|c|}
\hline Reference & Patients & $\begin{array}{l}\text { Age at surgery } \\
(y x)\end{array}$ & Gender & $\begin{array}{l}\text { Discase } \\
\text { duration (yt) }\end{array}$ & Indication for sungery \\
\hline Baker $^{14}$ & 1 & 22 & $\mathrm{~m}$ & 13 & tors and $O C s$ \\
\hline \multirow[t]{2}{*}{ Cooper ${ }^{15}$} & 1 & $16-17-22$ & $f$ & 7 & nes \\
\hline & $2-6$ & $n m$ & $\mathrm{n} \cdot \mathrm{m}$ & n.m. & n.m \\
\hline Servens 16 & 1 & 37 & $m$ & 29 & tics and $\mathrm{OC}$. \\
\hline \multirow[t]{5}{*}{ Hassler et al. $19,22,26$} & 1 & 28 & $\mathrm{~m}$ & $\mathrm{n}, \mathrm{m}$. & ness \\
\hline & 2 & n.m. & f & n.m. & tics \\
\hline & 3 & 19 & $\mathrm{~m}$ & 10 & tics \\
\hline & $4-9$ & $\mathrm{n}, \mathrm{m}$ & $n \cdot m$ & n.m. & acs \\
\hline & $10-15$ & $n . m$ & n.m & n.m. & tics \\
\hline Nadvormik et al.20 & 1 & 12 & $m$ & n.m. & tics \\
\hline \multirow[t]{3}{*}{ Beckers $^{21}$} & 1 & 23 & f & 18 & tocs and $\mathrm{OCx}$ \\
\hline & 2 & 31 & m & 21 & tics \\
\hline & 3 & 35 & i & 28 & tics and OCs \\
\hline Moldofsky et al. ${ }^{23}$ & 1 & $\mathrm{n}, \mathrm{m}$. & $m$ & 22 & n.m \\
\hline Wassman et al. 24 & 1 & n.m. & f & 24 & n.m \\
\hline \multirow[t]{2}{*}{ A am et al, 25} & 1 & 14 & $m$ & 5 & tics \\
\hline & 2 & 15 & $\mathrm{~m}$ & 11 & tics \\
\hline \multirow[t]{4}{*}{ Cappabianca et al. 27} & 1 & 20) & $m$ & 13 & $n \cdot m$ \\
\hline & 2 & 19 & $f$ & 9 & o.m \\
\hline & 3 & 24 & m: & 16 & tos and $\mathrm{CC}$. \\
\hline & 4 & 23 & m & 15 & $n m$ \\
\hline Robertson et al. 29 & 1 & 19 & $m$ & 14 & tha and $O C$ : \\
\hline \multirow[t]{2}{*}{ Kurlan et al 30.31} & 1 & 28 & $m$ & 23 & tios and $\mathrm{OC}$; \\
\hline & 2 & $17-22$ & $m$ & 11 & tic and $O \mathrm{OC}_{\text {s }}$ \\
\hline Korren et al. 33 & 1 & 19 & $m$ & 14 & tics and $O C \cdot$. \\
\hline Sawle et al 32 & 1 & 45 & $m$ & 36 & tocs and $O C$ s \\
\hline Leckman et al. ${ }^{34}$ & 1 & 40 & $m$ & 37 & toes and $O C$ s \\
\hline Baer et al 35 & 1 & 33 & m & 30 & tocs and $C \mathrm{C}$ s \\
\hline \multirow[t]{3}{*}{ Rauch et al, 33} & 1 & 34 & f & n.m. & tics and $O C$; \\
\hline & 2 & 40 & $m$ & 37 & tes and $\mathrm{OC}$ is \\
\hline & 3 & n.m. & $m$ & n.m. & tics \\
\hline Korzenev et al. ${ }^{36}$ & $1-4$ & $\mathrm{n} \cdot \mathrm{m}$ & $\mathrm{n} \cdot \mathrm{m}$ & $\mathrm{nm}$ & $n \cdot m$ \\
\hline \multirow[t]{16}{*}{ Babel et al, ${ }^{37}$} & 1 & $+*$ & $m$ & 12 & fucs \\
\hline & 2 & 29 & $f$ & 16 & tics \\
\hline & 3 & 28 & $m$ & 14 & tics \\
\hline & 4 & 21 & $\mathrm{f}$ & 13 & ucs \\
\hline & 5 & 31 & $f$ & 23 & tics \\
\hline & 6 & 34 & i & 12 & tics \\
\hline & 7 & 19 & $\mathrm{~m}$ & 14 & thes \\
\hline & 8 & 40 & $\mathrm{f}$ & 33 & tucs \\
\hline & 9 & 11 & $m$ & 7 & tucs \\
\hline & 10 & 15 & m & 3 & tics \\
\hline & 11 & 20 & m & 9 & tics. AIMHI) and $O C$. \\
\hline & 12 & 23 & $m$ & 17 & tacs \\
\hline & 13 & 21 & $m$ & 15 & tacs \\
\hline & 14 & 23 & $m$ & 19 & tics, $\mathrm{ADHI}$ ) and $O \mathrm{OC}_{\mathrm{s}}$ \\
\hline & 15 & 26 & $m$ & 18 & tics, $\mathrm{ADH}$ ) and $O C$ s \\
\hline & 16 & 19 & $m$ & 13 & tics \\
\hline
\end{tabular}

Superveript numbers correspond to the list of references; These patients were operated by Ruchardum; n.m., not mentioned; OCs: obsessive-compulsve symptoms; $\mathrm{Al}) \mathrm{HI}$, attention-deficit hyperactivity dirorder. 
Table 1 Patient characteristics of 65 patients who underwent ablative procedures for intractable Tourette Syndrome.

\begin{tabular}{|c|c|c|c|c|c|}
\hline Reference & Patients & $\begin{array}{l}\text { Age at surgery } \\
(y x)\end{array}$ & Gender & $\begin{array}{l}\text { Discase } \\
\text { duration (yt) }\end{array}$ & Indication for sungery \\
\hline Baker $^{14}$ & 1 & 22 & $\mathrm{~m}$ & 13 & tors and $O C s$ \\
\hline \multirow[t]{2}{*}{ Cooper ${ }^{15}$} & 1 & $16-17-22$ & $f$ & 7 & nes \\
\hline & $2-6$ & $n m$ & $\mathrm{n} \cdot \mathrm{m}$ & n.m. & n.m \\
\hline Servens 16 & 1 & 37 & $m$ & 29 & tics and $\mathrm{OC}$. \\
\hline \multirow[t]{5}{*}{ Hassler et al. $19,22,26$} & 1 & 28 & $\mathrm{~m}$ & $\mathrm{n}, \mathrm{m}$. & ness \\
\hline & 2 & n.m. & f & n.m. & tics \\
\hline & 3 & 19 & $\mathrm{~m}$ & 10 & tics \\
\hline & $4-9$ & $\mathrm{n}, \mathrm{m}$ & $n \cdot m$ & n.m. & acs \\
\hline & $10-15$ & $n . m$ & n.m & n.m. & tics \\
\hline Nadvormik et al.20 & 1 & 12 & $m$ & n.m. & tics \\
\hline \multirow[t]{3}{*}{ Beckers $^{21}$} & 1 & 23 & f & 18 & tocs and $\mathrm{OCx}$ \\
\hline & 2 & 31 & m & 21 & tics \\
\hline & 3 & 35 & i & 28 & tics and OCs \\
\hline Moldofsky et al. ${ }^{23}$ & 1 & $\mathrm{n}, \mathrm{m}$. & $m$ & 22 & n.m \\
\hline Wassman et al. 24 & 1 & n.m. & f & 24 & n.m \\
\hline \multirow[t]{2}{*}{ A am et al, 25} & 1 & 14 & $m$ & 5 & tics \\
\hline & 2 & 15 & $\mathrm{~m}$ & 11 & tics \\
\hline \multirow[t]{4}{*}{ Cappabianca et al. 27} & 1 & 20) & $m$ & 13 & $n \cdot m$ \\
\hline & 2 & 19 & $f$ & 9 & o.m \\
\hline & 3 & 24 & m: & 16 & tos and $\mathrm{CC}$. \\
\hline & 4 & 23 & m & 15 & $n m$ \\
\hline Robertson et al. 29 & 1 & 19 & $m$ & 14 & tha and $O C$ : \\
\hline \multirow[t]{2}{*}{ Kurlan et al 30.31} & 1 & 28 & $m$ & 23 & tios and $\mathrm{OC}$; \\
\hline & 2 & $17-22$ & $m$ & 11 & tic and $O \mathrm{OC}_{\text {s }}$ \\
\hline Korren et al. 33 & 1 & 19 & $m$ & 14 & tics and $O C \cdot$. \\
\hline Sawle et al 32 & 1 & 45 & $m$ & 36 & tocs and $O C$ s \\
\hline Leckman et al. ${ }^{34}$ & 1 & 40 & $m$ & 37 & toes and $O C$ s \\
\hline Baer et al 35 & 1 & 33 & m & 30 & tocs and $C \mathrm{C}$ s \\
\hline \multirow[t]{3}{*}{ Rauch et al, 33} & 1 & 34 & f & n.m. & tics and $O C$; \\
\hline & 2 & 40 & $m$ & 37 & tes and $\mathrm{OC}$ is \\
\hline & 3 & n.m. & $m$ & n.m. & tics \\
\hline Korzenev et al. ${ }^{36}$ & $1-4$ & $\mathrm{n} \cdot \mathrm{m}$ & $\mathrm{n} \cdot \mathrm{m}$ & $\mathrm{nm}$ & $n \cdot m$ \\
\hline \multirow[t]{16}{*}{ Babel et al, ${ }^{37}$} & 1 & $+*$ & $m$ & 12 & fucs \\
\hline & 2 & 29 & $f$ & 16 & tics \\
\hline & 3 & 28 & $m$ & 14 & tics \\
\hline & 4 & 21 & $\mathrm{f}$ & 13 & ucs \\
\hline & 5 & 31 & $f$ & 23 & tics \\
\hline & 6 & 34 & i & 12 & tics \\
\hline & 7 & 19 & $\mathrm{~m}$ & 14 & thes \\
\hline & 8 & 40 & $\mathrm{f}$ & 33 & tucs \\
\hline & 9 & 11 & $m$ & 7 & tucs \\
\hline & 10 & 15 & m & 3 & tics \\
\hline & 11 & 20 & m & 9 & tics. AIMHI) and $O C$. \\
\hline & 12 & 23 & $m$ & 17 & tacs \\
\hline & 13 & 21 & $m$ & 15 & tacs \\
\hline & 14 & 23 & $m$ & 19 & tics, $\mathrm{ADHI}$ ) and $O \mathrm{OC}_{\mathrm{s}}$ \\
\hline & 15 & 26 & $m$ & 18 & tics, $\mathrm{ADH}$ ) and $O C$ s \\
\hline & 16 & 19 & $m$ & 13 & tics \\
\hline
\end{tabular}

Superveript numbers correspond to the list of references; These patients were operated by Ruchardum; n.m., not mentioned; OCs: obsessive-compulsve symptoms; $\mathrm{Al}) \mathrm{HI}$, attention-deficit hyperactivity dirorder. 
Table 2 Target specification, outcome and complacations in 65 patients who underwent ablative surgery for intractable TS.

\begin{tabular}{|c|c|c|c|c|c|c|c|}
\hline Reference & Patuent & $\begin{array}{l}\text { Surgical } \\
\text { sessions }\end{array}$ & Surgical intervention & $\begin{array}{l}\text { Follow-up: } \\
\text { (mos) }\end{array}$ & $\begin{array}{l}\text { Evaluation } \\
\text { method }\end{array}$ & Result & Side effects \\
\hline Buker! ${ }^{4}$ & 1 & 1 & bimedial frontal leucotony & 12 & otimution & "marked" reduction of tics and OCs & $n . m *$ \\
\hline \multirow[t]{2}{*}{ Cooper ${ }^{15}$} & 1 & 3 & bilateral thalamectomy (left repeated) & 22 & n.m. & "reliet" of tacs & n.m. \\
\hline & $2-6$ & n.m. & bilateral thalamectomy & n.m. & n.m. & n.m & n.m. \\
\hline Stevens ${ }^{16}$ & 1 & 1 & prefrontal fobotomy & I08 & n.m. & $\begin{array}{l}\text { "marked decrease" of tics and } \\
\text { compulsions }\end{array}$ & $\begin{array}{l}\text { no side } \\
\text { effects }\end{array}$ \\
\hline \multirow[t]{5}{*}{$\begin{array}{l}\text { Hassler et al } 19.22 \\
26\end{array}$} & 1 & 2 & $\begin{array}{l}\text { Cosgulations in the intralaminar. medial and } \\
\text { Voi thalamie nucles }\end{array}$ & n.m. & $\mathrm{n} \cdot \mathrm{m}$ & 100 tic reduction & n.m. \\
\hline & 2 & 2 & $\begin{array}{l}\text { coagulations in the intralaminar, medial and } \\
\text { Vos thalamie nucles }\end{array}$ & $\mathrm{nm}$. & n.m. & $90 \%$ tic reduction & $\mathrm{n} \cdot \mathrm{m}$. \\
\hline & 3 & 2 & $\begin{array}{l}\text { coagulations in the intralaminat and medtal } \\
\text { thalamie nucles }\end{array}$ & nim. & $\mathrm{n} \cdot \mathrm{m}$ & $70 \%$ tic reduction & n.m. \\
\hline & $4-9$ & n.m. & $\begin{array}{l}\text { coagulations in the intralaminar, medial and } \\
\text { Vos thalamic nucles }\end{array}$ & n.m. & n.m. & $50-100 \%$ tic reduction & n.m. \\
\hline & $10-15$ & $\mathrm{n} \cdot \mathrm{m}$ & $\begin{array}{l}\text { coagulations in the intralaminar, medial and } \\
\text { Vos thalamic nucles }\end{array}$ & n.m. & n.m. & n.m & n.m. \\
\hline Nadvornik ot al. 20 & 1 & 1 & bilateral dentatotomy & nim. & л.m & $\begin{array}{l}\text { "moverwents decreased, sounds } \\
\text { disappeared" }\end{array}$ & n.m. \\
\hline \multirow[t]{3}{*}{ Beckers et al.21 } & 1 & 2 & vereouctic sungery (target unclear) $(2 \mathrm{x})$ & 24 & $n \mathrm{~m}$ & "dight improvement" & $\begin{array}{l}\text { gait } \\
\text { problems }\end{array}$ \\
\hline & 2 & 2 & bilateral campotomy and prefrontal leucotomy & $\mathrm{n} \cdot \mathrm{m}$. & n.m. & "reduction of symptoms" & n.m. \\
\hline & 3 & 1 & bilateral leucotomy & n.m. & $\mathrm{n} . \mathrm{m}$. & $\mathrm{n} \cdot \mathrm{m}$ & n.m. \\
\hline Moldofiky et al 21 & 1 & 2 & bifrontal leucotony, bilateral thalamotomy & n.m. & n.m. & "no long-term benetir" & $\mathrm{n} \cdot \mathrm{m}$ \\
\hline Waxman et al. ${ }^{24}$ & 1 & n.m. & prefrontal lobotomy & n.m: & n.m. & n.m & n.m. \\
\hline \multirow[t]{2}{*}{ Asam ot al. 25} & 1 & 1 & unlateral stereotactit surgery (target unclear) & 6) & $n . \mathrm{m}$. & "temporal" relief of sics & $\begin{array}{l}\text { spastic } \\
\text { bemiplegia }\end{array}$ \\
\hline & 2 & 2 & bilateral coagulation $\mathrm{ZI}$ & ant & n.m. & "temporal" relief of tics & $\begin{array}{l}\text { pastic } \\
\text { quadriplegia. } \\
\text { dystonia }\end{array}$ \\
\hline \multirow[t]{3}{*}{ Cappabiancs et al.27 } & 1 & 1 & unilateral thalamotomy & several years & n.m. & "temporary improvement" & confusion \\
\hline & 2 & 1 & unilateral thalamotomy & $>12$ & n.m. & "temporary improvement" & n.m. \\
\hline & 3 & 2 & bilateral thalamotomy & $>12$ & $\mathrm{n} . \mathrm{m}$. & "slight reduction" of compulsions & n.m. \\
\hline
\end{tabular}


Table 2 Continued

\begin{tabular}{|c|c|c|c|c|c|c|c|}
\hline Reference & Patient & $\begin{array}{l}\text { Surgical } \\
\text { sessions }\end{array}$ & Surgical intervention & $\begin{array}{l}\text { Follow-up } \\
\text { (mos) }\end{array}$ & $\begin{array}{l}\text { Evaluation } \\
\text { method }\end{array}$ & Resule & Side effects \\
\hline & 6 & n.m & $\begin{array}{l}\text { unilateral coagulation of } \mathrm{Zl} \text { and unilateral } \\
\text { thalamotomy }\end{array}$ & 13 & tic scoring. & $52 \%$ tic reduction & n.m. \\
\hline & 7 & 1 & unilateral thalamotomy & n.m & ic scaring & $52 \%$ tic reduction & $\begin{array}{l}\text { dysarthria, } \\
\text { hemiparevas }\end{array}$ \\
\hline & 8 & n.m & bilareral coagulation of $\mathrm{ZI}$ & $n \cdot m$ & fic scoring & $45 \%$ nic reducrion & n.m. \\
\hline & 9 & $\mathrm{n} . \mathrm{m}$ & bilateral coagulation of $\mathrm{Zl}$ & 7 & dic scoring & $45 \%$ tic reduction & dystomis \\
\hline & 10 & n.m & bilateral coagulation of $\mathrm{Zl}$ & 8.5 & toc scorng & $45 \%$ te reduction & $\begin{array}{l}\text { dystomia, } \\
\text { dysarthria }\end{array}$ \\
\hline & 11 & n.m & bilateral coagulation of 21 & $y .5$ & De scormg & $45 \%$ tic reduction & $\begin{array}{l}\text { dystoma, } \\
\text { dysurthia. } \\
C S\end{array}$ \\
\hline & 12 & 1 & $\begin{array}{l}\text { bilateral coxgulation of } \mathrm{Zl} \text { and bilateral } \\
\text { thalamotomy }\end{array}$ & 55 & nic scoring & $45 \%$ tic reduction & n.m. \\
\hline & 13 & 1 & $\begin{array}{l}\text { bilateral coagulation of } \mathrm{Zl} \text { and bilateral } \\
\text { thalamotomy }\end{array}$ & 3.5 & bic scoring & $45 \%$ tie reduction & $\begin{array}{l}\text { dyarthria, } \\
\text { hemiballism, } \\
\text { CS }\end{array}$ \\
\hline & 14 & 1 & $\begin{array}{l}\text { unilateral cougulation of } \mathrm{ZI} \text { and unalateral } \\
\text { thalamotomy }\end{array}$ & 7 & ac sconing & $52 \%$ tac reduction & $\begin{array}{l}\text { bemuparesis. } \\
\text { CS }\end{array}$ \\
\hline & 15 & 1 & $\begin{array}{l}\text { unilateral coagulation of } \mathrm{ZI} \text { and unilateral } \\
\text { thalamotomy }\end{array}$ & 4.5 & De scoring & $52 \%$ ac reduction & CS \\
\hline & 16 & 1 & $\begin{array}{l}\text { unilateral coxigulation of } \mathrm{ZI} \text { and unilateral } \\
\text { thalamotomy }\end{array}$ & 4.5 & te sconing & $52 \%$ tic refuction & dystonia, CS \\
\hline
\end{tabular}


In the same year. Cooper ${ }^{15}$ published the case of a 16-year-old girl. This patient had a 7-year history of vocal and motor tics and had received various therapies including drugs, hypnosis, and psychoanalysis, without success. A right chemothalamectomy was carried out, followed by a left chemothalamectomy 1 year later. Cooper reported that after the surgery, the patient had a substantial tic reduction and was functioning fully.

Two years later, Stevens ${ }^{16}$ published the long-term follow-up result of a 37 -year old man who had undergone the first prefrontal lobotomy, carried out by James Watts in 1955. At the of age 8, the patient presented with severe motor and vocal tics and OCs. Psychotherapy and pharmacotherapy had no effect on the symptoms. After the operation, there was a marked decrease in the frequency, duration and amplitude of the tics. No specific complications occurred. Stevens concluded that lobotomy, "although an extreme measure", seemed justified in the treatment of intractable TS. As in the report from Cooper, no information is provided regarding the method of tic rating.

Seven years after his first report, Cooper summarized his experience in the treatment of "multiple tics" by bilateral thalamic surgery in 6 patients in his textbook Involuntary Movement Disorders ${ }^{17}$. He described TS as "a syndrome sharing many features of dystonia". The first patient who underwent bilateral surgery was described in detail. This was the same patient previously described in $1962^{15}$. In this report, however, more details were provided with regard to the target (ventrolateral nucleus of the thalamus) and follow-up. In 1966, the left thalamotomy was repeated in this patient because of persistent symptoms on the right side. This had no effect. Cooper described this patient as an illustrative case, without providing details of the other 5 cases.

Four years later Sweet et al ${ }^{18}$ reported briefly on the long-term follow-up of one of the patients in Cooper's series. This was a 26-year -old woman who was operated on in 1963, with partial relief of symptoms.

In 1970 , Hassler and Dieckmann ${ }^{19}$ reported on the results of bilateral thalamotomies in 3 patients with intractable TS. They carried out more than 10 coagulations in the intralaminar and medial thalamic nuclei, and, in case of facial tics, in the nucleus ventrooralis internus (Voi). Only the effects with respect to tics were reported, which improved by $100 \%$ in Patient 1, $90 \%$ in Patient 2, and $70 \%$ in Patient 3. Again, no details about the tic-rating method were provided. 


\section{1-1980}

In the next decade, the first report on the surgical treatment of TS was by Nadvornik et al ${ }^{20}$ describing a case of stereotactic dentatotomy. The patient was a 12 -year-old boy suffering from vocal and motor tics. The motor tics were mainly in the facial and abdominal region. Bilateral dentatotomy was performed transtentorially. The authors reported "a decrease of movements", but did not specify whether they meant motor tics or normal motor function, and "a disappearance of vocal tics". They concluded that bilateral dentatotomy could be an effective treatment for intractable TS. No specification of the tic evaluation was given.

One year later, Beckers ${ }^{21}$ published the outcome of the neurosurgical treatment in 3 TS patients. The patients were 26, 31, and 35 years old with disease onset at the age of 5,10 , and 7 years, respectively. All patients suffered from vocal and motor tics and OCs. Neither psycho- nor pharmacotherapy had any long-term beneficial effects. Two stereotactic operations (target unclear) were carried out in Patient 1 (female) with an interval of 1 year between surgeries. Patient 2 (male) underwent a bilateral campotomy and prefrontal leucotomy in two surgical sessions. A bilateral leucotomy was performed in the third patient (female). The author observed that these stereotactic interventions resulted in partial tic reduction. Nevertheless, surgery was not advocated as a good treatment option for intractable TS because of the side effects, which were not specified. Beckers ${ }^{21}$ did not describe the way tic reduction was assessed.

In the same year, Hassler and Dieckman ${ }^{22}$ wrote a chapter of the textbook Surgical approaches in psychiatry ${ }^{22}$ in which they described their experience in the surgical treatment of OCD, phobias, and tics. In 9 patients suffering from TS, the results after stereotactic coagulation of intralaminar and medial thalamic nuclei were summarized. Unfortunately, they only described the outcome of the surgical intervention without providing detailed information about the patients. Three patients underwent unilateral, and six patients bilateral procedures. The authors reported that 1 patient who had undergone unilateral surgery and three patients with bilateral surgery had a 90 to $100 \%$ improvement in tics. Two unilaterally and 3 bilaterally operated patients experienced a 50 to $80 \%$ tic reduction. No mention was made of duration of follow-up, methods of tic rating or side effects. One year later, Moldofsky et al ${ }^{23}$ reported on 2 patients who had undergone surgery for intractable TS. The first case was the one operated by Baker ${ }^{14}$ as described earlier. In contrast to this first author. Moldofsky et al concluded that no long-term beneficial effects were achieved. The second patient was a 27 -year-old man with vocal and motor tics, the first symptoms appearing at the age of 5 years. The patient 
underwent bilateral frontal leucotomy and later, for unclear reasons, bifrontal thalamotomy. Details of the results and side effects, were not reported.

In 1978 . Wassmann et al $^{24}$ brietly mentioned a female patient who had undergone a prefrontal lobotomy without giving any information about the outcome.

$$
1981-1990
$$

Asam et al ${ }^{25}$ provided a brief (and incomplete) review of the literature on surgical interventions in TS and reported their experience with two TS patients. The patients were both men, 14 and 15 years old, with disease duration of 5 and 11 years, respectively. Their first patient underwent stereotactic surgery (target unclear) with temporary relief of tics. Postoperatively, this patient developed a spastic hemiplegia. Coagulation in the left zona incerta $(\mathrm{ZI})$ was carried out in the second patient, who also had a postoperative hemiplegia. The same patient was operated on 15 months later, for unclear reasons, in the contralateral ZI. Postop eratively, this patient developed hemiplegia on the left side and became quadriplegic. According to the authors, temporary relief of symptoms was achieved in this patient. Later, tics reoccurred in combination with complex dystonic movements. They concluded that surgical intervention in TS may produce temporary improvement of tics and that surgery can be accompanied by severe side effects.

In 1982. Hassler ${ }^{26}$ updated the material on stereotaxic surgery for psychiatric disturbances in Schaltenbrand's textbook and briefly mentioned his experience with thalamic surgery in 15 patients suffering from intractable TS. No details were provided about the outcome.

In 1987. Cappabianca et al ${ }^{27}$ published the long-term results of 3 patients described initially by de Divitiis et $\mathrm{al}^{28}$, and of one new patient. In addition, they provided a review of (all) operated patients. This review was incomplete since the patients described by Nadvornik et al ${ }^{20}$, Cooper ${ }^{15,17}$, and most of those described by $\mathrm{Hassler}^{22}, 26$, were not included. Their operation was based on stereotactic coordinates proposed by Hassler and Dieckmann ${ }^{19}$. The intralaminar and dorsomedian nuclei of the thalamus were coagulated bilaterally in 1 patient and unilaterally in 3. The authors reported temporary tic improvement in 2 patients lasting a few months, a slight reduction of compulsive symptoms in 1 patient, and an almost complete tic regression in the fourth. The follow-up of these patients was several years shorter than one would expect when considering the publication year.

Robertson et al ${ }^{29}$ reported on a 19-year-old man with disease onset at the age of 5.5 years, presenting with a variety of verbal and motor tics. The verbal tics 
included coprolalia: the motor tics involved mainly the head, neck and facial region. Behavioral disturbances, mainly checking, and severe self-injurious behavior, were also present. The tics were treated successfully with the D2 receptor antagonist, sulpiride: the compulsions however, could not be treated. Stereotactic limbic leucotomy was performed involving bilateral lesions in the lower medial quadrants of the frontal lobes and separate lesions in the anterior cingulum (limbic leucotomy). Postoperatively, the compulsions disappeared within 6 weeks. Side effects consisted of apathy, general intellectual impairment, organizational problems, and difficulties in concentration. After 2 years, the patient was socially independent and free from self-injurious behavior. According to the authors, there was a tic-reduction of $75 \%$. This is an interesting remark since the authors reported a "complete resolution" of the tics by medication preoperatively. Postoperatively, the patient continued on drug-therapy with an increased daily dosage. Robertson et al concluded that limbic leucotomy should be considered an effective treatment in TS patients with severe self-injurious behavior, but emphasized that the long-term effects on tics required further assessment. Again, the method of tic evaluation was not mentioned, nor was the impact or the time course of the side effects, nor the criteria for the diagnosis of TS.

Kurlan et al ${ }^{30,31}$ described their neurosurgical therapy in 2 patients with TS and complex OCB. The first patient was a 28 -year-old man with disease onset at the age of 5 years, suffering from OCs. The patient had attempted suicide and subsequently was treated successfully with medication for a bipolar affective disorder. The patient was severely disabled by the tics and OCs, without any effect of pharmacological therapy. A bilateral cingulotomy was performed. The authors reported an improvement of 25 to $30 \%$ in ritualistic behavior without any effect on tics, at long-term follow-up ( 2 years). No side effects were mentioned. The second patient was a 22-year-old man who had undergone bilateral cingulotomy at age 17. Symptoms were reduced for approximately 10 days and later returned to the preoperative state. One year postoperatively, the procedure was repeated and the patient showed a lasting improvement. Kurlan et al proposed that cingulotomy should be considered a valuable treatment option for patients with TS complicated by resistant OCD. The improvements were assessed by the authors without the use of clinical rating scales. The side effects were not mentioned.

1991-2000

In 1993, Sawle et al ${ }^{32}$ reported on the results of bilateral limbic leucotomy in a 45-year-old man suffering from TS. The symptoms consisted of severe self-injurious behavior, obsessions and compulsions, and vocal and motor tics. Long-term trials of pharmacological and behavioral therapy had failed. During limbic 


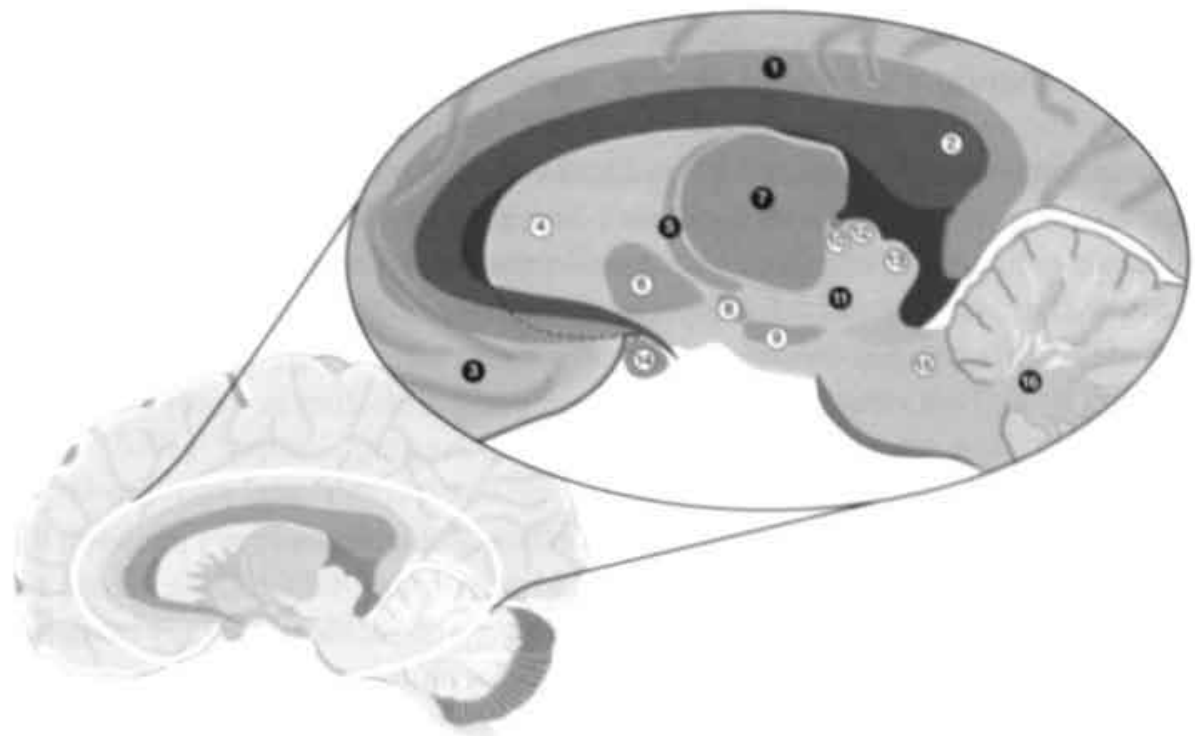

Figure 1. Brain areas that have been tangeted in surgery for TS, and other relevant neuroanatomical structures. The frontal lobe (3) was targeted dunng prefrontal lobotomy and bimedal levcotony. In limbic leucotomy and anterior cingulotomy, the cingulate cortex (1) was fesioned. The thalamus (7) was targeted for lecooning of the madline, intralammar and ventrolateral thalame nucles and for DBS Infrathalamic Ievions were carned out at the level of the $\mathrm{H}$ fields of Forel (11) and the zona incerta (5), Cerebellar surgery involved lesioning of the dentate nucleus (16). The surrounding brain areas include: (2) corpus callosum, (4) caudate-putamen complex, (6) globus pallidus, (8) subthalamic nucleus, (9) substantia nigra, (10) posterior commussure, (12) superior colliculus, (13) inferior colliculus, (15) supenor cerebellar peduncle, and (14) opti chiasm.

leucotomy, bilateral coagulations were carried out in the anterior hypothalamus and cingulate gyrus. However, in a personal communication to Rauch et $\mathrm{al}^{33}$. Sawle remarked that the actual targets were those of conventional limbic leucotomy (cingulotomy plus thermocoagulation of the frontothalamic fibers). According to the authors, the surgery had no direct effect on tics whereas the compulsions were reduced. Nineteen months after surgery, however, there were no longer any signs of tics and the patient reported excellent improvement with regard to his obsessions.

A 40-year-old man suffering from TS and OCD who underwent surgery was reported by Leckman et $\mathrm{al}^{34}$ in 1993 . The disease onset was at the age of 3 years with motor tics. Vocal tics later appeared and checking and cleaning compulsions were present, as was self-injurious behavior. Symptoms failed to respond to medication trials. The patient underwent bilateral stereotactic infrathalamic lesions and anterior cingulotomies. Postoperatively, the obsessive-compulsive symptoms had improved, but the patient continued to experience severe motor and 
vocal tics. Three weeks later, the left infrathalamic and cingulated lesions were repeated. During this second surgical session, the infrathalamic lesion was extended more inferiorly within the borders of the red nucleus and a subsequent coagulation was performed in the $\mathrm{H}$ fields of Forel. The patient had severe neurological deficits postoperatively including dysarthria, dysphagia, handwriting and gait problems, mild hemiparesis, abnormal extraocular movements, axial rigidity, and bradykinesia. The authors suggested that these side effects were due to extension of the infrathalamic lesion. At long term there was a reemergence of tics and OCD. The authors concluded that lesioning brain areas does not only influence pathological, but also destroys physiological functioning.

One year later, Baer et al ${ }^{35}$ reported on the effect of cingulotomy in a patient with TS and OCD. The patient was a 35-year-old man with OCD and associated TS since the age of 5 years. He failed to respond to either behavioral therapy or medication. The patient underwent two sessions of cingulotomy with an interval of 18 months between procedures. After the first and second operation, there was no clear effect on his tics. However, this procedure resulted in an improvement of the OCs. The authors concluded that cingulotomy alone was not an effective treatment for TS.

In 1995, Rauch and co-workers ${ }^{33}$ published a comprehensive review of the neurosurgical treatment of TS. They provided detailed information about the different neurosurgical approaches by summarizing the available literature. In their report, emphasis was placed on the rationale for the different targets. In total, 36 cases were reviewed. Their review was incomplete as the reports by Beckers et $\mathrm{al}^{21}$. Sweet et $\mathrm{al}^{18}$, Moldofsky et $\mathrm{al}^{2.3}$, Wassman $e t \mathrm{al}^{24}$, and Asam et $a^{25}$ were not included. Mention was made, however, of a personal communication from Richardson regarding 3 patients who had undergone a bilateral anterior cingulotomy and infrathalamic lesioning, which had not been published before. The first patient was a 34-year-old woman with severe TS, OCD and bipolar disorders. The patient underwent an anterior cingulotomy plus infrathalamic lesions. Tic-counting on videotapes performed by Rauch et al, revealed a decrease from 18 tics/minute to 2 tics/minute. The second patient was a 40-year-old man suffering from self-injurious motor tics, coprolalia, and OCD. The third patient was not described in detail. The latter 2 patients underwent the same procedure as the first, with poor outcome. Furthermore, the second patient had dysarthria and swallowing, handwriting and gait problems postoperatively. There was only a moderate improvement of tics and OCD. The third patient showed no improvement in symptoms at all. In addition, Rauch et al mentioned a case published in the Russian literature by Korzen in 1991. This involved a 
19-year-old man with TS and associated OCD who had undergone bilateral cryothalamotomy (ventrolateral nuclei) with good results at 1-year follow-up.

Several years later, Korzenev and colleagues ${ }^{36}$ published results of their surgical treatment of 4 intractable TS patients. They concluded that stereotactic surgery was an effective method of treatment for severe incurable TS. However, in their paper no description of the TS patients was provided with respect to patient characteristics, tics, surgical target, or method of evaluation.

\section{1-Present}

Babel and co-workers ${ }^{37}$ reported on results with surgical therapy in 16 intractable TS patients, diagnosed according to the Tourette Syndrome Classification Study Group $^{38}$ (TSCSG) criteria, that were operated on between 1970 and 1998. Long-term evaluations were obtained from 11 patients. Tic severity was evaluated using a tic severity rating scale. All patients suffered from vocal and motor tics. ADHD and OCD were documented in 3 patients. Seven patients were operated unilaterally and 9 bilaterally. Eleven patients underwent coagulations in both the $\mathrm{ZI}$ and thalamus, 4 were operated at the level of the $\mathrm{ZI}$, and 1 patient underwent unilateral thalamotomy. There was a significant reduction in vocal and motor tics immediately postoperatively and at long - term. Almost all patients remained on multidrug therapy. Several patients experienced complications as a result of the intervention, varying from mild hemiparesis to hemiballism. The authors concluded that unilateral ZI and VL/LM (ventrolateral/ lamella medialis of the thalamus) lesioning in patients with asymmetrical symptoms resulted in tic reduction, but that larger prospective random trials were needed to validate the role of surgery in TS. They did not, however, provide any background information as to why the $\mathrm{ZI}$ and thalamus were targeted.

\section{DEEP BRAIN STIMULATION}

In total, 3 patients undergoing DBS for TS have been reported. The first report was in 1999 by Vandewalle et $a^{39}$. At the XVth European Society for Stereotactic and Functional Neurosurgery, the long-term effects of this therapy were presented ${ }^{40}$. The patients were male and were 42,28 and 45 years old. They were selected based on intractable TS with absent comorbidity (except for associated behavioral problems), a diagnosis made according to the criteria of the TSCSG. Other than vocal and motor tics, the patients had compulsive behavior (see Table 3). Psychotherapy had failed in all cases and various drugs were found to have no effect or had to be stopped after prolonged use because of unbearable side effects. The target was at the level of thalamic nuclei as selected by Hassler and 


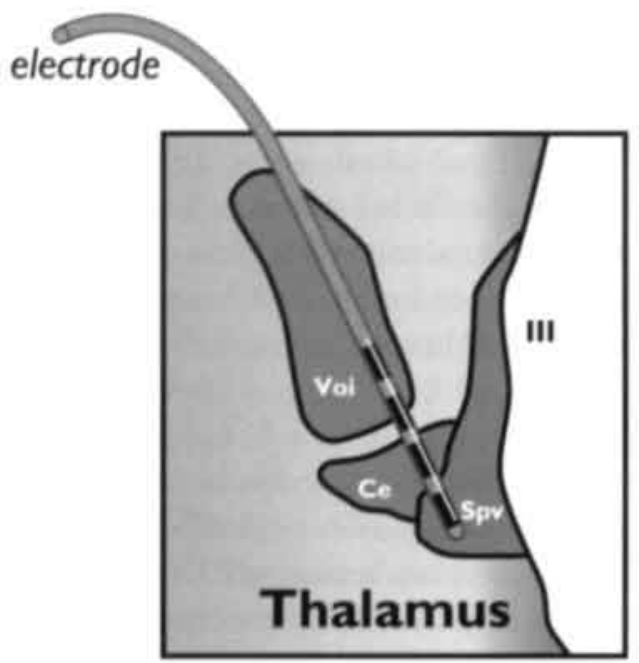

Figure 2. During DBS, stereotactic coordinates were chosen to place the electrodes in this area. Hassler and Dieckmann carried out at least 10 thalamic coagulations on each side. For DBS, a strategic point had to be chosen where the different thalamic nuclei could be influenced through one electrode. According to the target coordinates, the three groups of nuclei that were lesioned by Hassler and Dieckmann are affected through stimulation of the centromedian nucleus (Ce: as part of the intralaminar thalamic nuclei), the substantia periventricularis (Spv; as part of the midline thalamic nuclei), and the Voi.

Dieckmann ${ }^{19}$. DBS was chosen because of its safety, reversibility, and adjustability. Hassler and Dieckmann had successfully performed lesions in the midline and intralaminar thalamic nuclei as a treatment for TS, as described previously. In some patients with facial tics, they additionally carried out lesions of the Voi. Whereas Hassler and Dieckmann performed at least 10 coagulations on each side, in this case a strategic point had to be chosen where the different thalamic nuclei could be influenced through one electrode. According to the target coordinates, the three groups of nuclei that were lesioned by Hassler and Dieckmann are affected through stimulation of the centromedian nucleus (as part of the intralaminar thalamic nuclei), the substantia periventricularis (as part of the midline thalamic nuclei), and the Voi (see figure 2). Each patient was videotaped with both stimulators on and 12 hours off. Two independent and blinded investigators counted the number of tics. At long-term follow-up ( 5 years for Patient 1,1 year for Patient 2 , and 8 months for Patient 3 ), there was a tic-reduction of $90.1 \%$ in Patient 1, 72.2\% in Patient 2 and $82.6 \%$ in Patient $3^{41}$. Neuropsychological evaluations showed no effects of surgery. Patients 1 and 3 , however, reported changes in sexual drive. Laboratory evaluations in stimulation on and off conditions demonstrated that penile erection in response to visual erotic stimuli was increased in Patient 1 and inhibited in Patient 3 during stimulation. Furthermore, all patients described a feeling of "reduced energy" at the stimulus intensity necessary for the best effect on tics. 
Table 3 Patient charactenstice and the outcome of deep brain stimulation in three Touretre Syndrome patients who did not repond to various trals of pharmacological and behavioral therapy.

\begin{tabular}{|c|c|c|c|c|c|c|c|c|c|c|c|c|c|}
\hline Reterence & Patients & $\begin{array}{l}\text { Age at } \\
\text { surgery } \\
(\mathrm{vT})\end{array}$ & Gender & $\begin{array}{l}\text { Disease } \\
\text { duration } \\
\text { (vr) }\end{array}$ & Ties & $\begin{array}{l}\text { Associated } \\
\text { behavioral. } \\
\text { symptoms }\end{array}$ & $\begin{array}{l}\text { Indicarion } \\
\text { for surkery }\end{array}$ & $\begin{array}{l}\text { Sungical } \\
\text { sestioms }\end{array}$ & $\begin{array}{l}\text { Surgacal } \\
\text { atitervennon }\end{array}$ & $\begin{array}{l}\text { Follow-up } \\
\text { (mos) }\end{array}$ & $\begin{array}{l}\text { Evaluation } \\
\text { method }\end{array}$ & $\begin{array}{l}\text { Reaule at } \\
\text { long term }\end{array}$ & Sude effects \\
\hline \multirow[t]{3}{*}{$\begin{array}{l}\text { Viser- } \\
\text { Vandewalle } \\
\text { et al +1 }\end{array}$} & 1 & 42 & $\mathrm{~m}$ & 37 & $\begin{array}{l}\text { vocal and. } \\
\text { motor }\end{array}$ & Compulssons & tacs and $\mathrm{OCs}$ & 1 & $\begin{array}{l}\text { DBS of } \\
\text { thalamus }\end{array}$ & 60 & $\begin{array}{l}\text { blended the } \\
\text { sconnis: }\end{array}$ & $\begin{array}{l}90.196 \mathrm{bc} \\
\text { reduction }\end{array}$ & $\begin{array}{l}\text { increased } \\
\text { sexwal drive, } \\
\text { "reduced } \\
\text { energy" }\end{array}$ \\
\hline & 1 & 28 & $\mathrm{~m}$ & 20 & $\begin{array}{l}\text { vocal and } \\
\text { motor }\end{array}$ & $\begin{array}{l}\text { Automutilation. } \\
\text { compukions. }\end{array}$ & tics and $\mathrm{OC}$, & 1 & $\begin{array}{l}\text { DBS of } \\
\text { thalamus }\end{array}$ & 12 & $\begin{array}{l}\text { bhinded tic } \\
\text { scoring }\end{array}$ & $\begin{array}{l}72.2 \% \text { be- } \\
\text { reduction }\end{array}$ & $\begin{array}{l}\text { reduced } \\
\text { concentration }\end{array}$ \\
\hline & 1 & 45 & $\mathrm{~m}$ & 38 & $\begin{array}{l}\text { vocal and } \\
\text { motor }\end{array}$ & compulsions. & tacr and $\mathrm{OC}$ & 1 & $\begin{array}{l}\text { DBS of } \\
\text { thalemus }\end{array}$ & 8 & $\begin{array}{l}\text { blinded tic } \\
\text { soring }\end{array}$ & $\begin{array}{l}82.6 \% \text { tic- } \\
\text { reduction }\end{array}$ & $\begin{array}{l}\text { reduced } \\
\text { sexual drive. } \\
\text { "reduced } \\
\text { encrigy" }\end{array}$ \\
\hline
\end{tabular}




\section{DISCUSSION}

Many different lesioning procedures have been performed in TS throughout the history of surgical treatment of this disorder. Frontal lobe operations included prefrontal lobotomies and bimedial frontal leucotomies. The limbic system was targeted during limbic leucotomy and anterior cingulotomy. Thalamic operations included lesioning of the medial, intralaminar and ventrolateral thalamic nuclei. Infrathalamic lesions were performed at the level of Forel's fields (campotomies) and the zona incerta. Cerebellar surgery included dentatotomies. In an attempt to achieve total control of symptoms, more complex operations have been carried out, such as combined anterior cingulotomies and infrathalamic lesions.

The question arises of how the authors could be certain of their target localization. Most reports do not mention impedance measurements, depth recordings or postoperative imaging. In some reports, the target is not even mentioned and the only thing we know is that "stereotactic surgery " has been performed $21,25.36$.

Another criticism is the lack of criteria according to which the diagnosis of TS was made. Only Babel et al ${ }^{37}$ mentioned that the diagnosis being made was according to the criteria of the TSCSG. So it may well be that several patients in the other reports were not suffering from typical TS but from TS with prominent and probably more disabling comorbidities, or other tic disorders. Furthermore, most reports lack any specification of tic reduction, let alone the tic evaluation methods adopted, Only Hassler ${ }^{19,22}$, Robertson et al ${ }^{29}$, Kurlan et $\mathrm{al}^{30}$. Leckman et $\mathrm{al}^{34}$, Rauch et $\mathrm{al}^{33}$ and Babel et al ${ }^{37}$ described the outcome in percentages and only Robertson et $a^{29}$, Leckman et $\mathrm{ll}^{34}$, Rauch et $\mathrm{al}^{33}$ and Babel et al ${ }^{37}$ specified the tic evaluation method. The results of these latter reports also have to be interpreted with caution since they lack blinding and independance of the assessors. Moreover, in the postoperative phase many of the patients still used, or were again placed on drug-therapy. All these confounding factors could influence the results. Hence, for many reasons these reports cannot be considered as a body of information on which one can base conclusions about the optimal surgical treatment in intractable TS.

The lack of rationale for choosing specific targets for these ablative procedures is striking and makes most of them hazardous from an ethical point of view, especially when the complications are taken into consideration. These vary from dystonia to even quadriplegia. A possible reason for this lack of rationale might be the uncertainty about the pathophysiology of TS in the past. Through advances in 
genetics, pharmacology, and brain imaging. one now has access to more data on the possible mechanisms underlying TS.

It is also remarkable that very young patients have been included in those selected for surgery. For example, one of the patients described by Babel et al ${ }^{37}$ was only 11 years old. Nadvornik et al ${ }^{20}$ operated on a 12-year-old boy. It is well known nowadays that TS can be a self-limiting disease with symptoms disappearing in early adulthood.

In 1999, the first DBS was carried out for intractable TS, with the target for thalamic stimulation based on the thalamotomies described by Hassler ${ }^{19}, 22.26$. Since then, 3 patients have undergone a bilateral thalamic stimulation with good results. The thalamus seems to be a promising target. The involvement of the thalamus in the pathophysiology of TS is dual in nature: whereas the medial and ventral thalamic nuclei are way stations within the basal ganglia-thalamocortical circuits, the midline and intralaminar nuclei send projections to both the premotor/prefrontal cortex and the striatum. Therefore, the basal ganglia-thalamocortical pathways are influenced strongly, at the level of their major input (the striatum), by excitatory thalamic input.

We conclude that surgery in TS must continue to be considered experimental. If one takes into account the actual knowledge that high-frequency stimulation generally has the same clinical effects as lesioning, apart from its reversibility, carrying out ablative procedures for TS can no longer be justified. It is clear that a study on more patients is required with a strict protocol, including well-defined inclusion, and exclusion criteria, well-defined targets for surgery, and clear specifications of evaluation methods for tics and other symptoms. A single cvaluation of the effect of surgery is most probably not sufficient due to natural fluctuations in symptom severity and their modulation by psychosocial factors. In addition, systematic inquiry into potential adverse effects and careful documentation of the presence and severity of associated behavioral disorders must also be included.

\section{Acknowledgements}

We thank dr. Chris van der Linden for his contribution to the introduction of DBS in TS and are grateful to professor Emile A.M. Beuls for constructive comments, and ms. Lieve Desbonnet for the grammatical corrections. 


\section{REFERENCES}

1. Jankovic J. Tourette syndrome. Phenomenology and classification of tics. Neurol Clin $1997 ; 15(2): 267-275$.

2. Lees AJ. Georges Gilles de la Tourette. The man and his times. Rev Neurol (Paris) 1986;142(11):808-816.

3. Riederer F, Stamenkovic M, Schindler SD, Kasper S. [Tourette's syndrome - a review]. Nervenarzt 2002;73(9):805-819.

4. Hornse $\mathrm{H}$, Banerjee $\mathrm{S}$, Zeitlin $\mathrm{H}$, Robertson $\mathrm{M}$. The prevalence of Tourette syndrome in 13-14-year-olds in mainstream schook. J Child Psychol Psychiatry 2001:42(8):1035-1039.

5. Leckman JF. Tourette's syndrome. Lancet 2002;360(9345):1577-1586.

6. Shapiro AK, Shapiro E, Wayne H. Treatment of Tourette's syndrome with haloperidol, review of 34 cases. Arch Gen Psychiatry 1973;28(1):92-97.

7. Cohen DJ, Shaywitz BA, Young JG, et al. Central biogenic amine metabolism in children with the syndrome of chronic multuple tics of Gilles de la Tourette: norepinephrine, serotonin, and dopamine. J Am Acad Child Psychiatry 1979:18(2):320-341.

8. Singer HS, Butler IJ. Tune LE, Seifert WE, Jr., Coyle JT. Dopaminergic dsyfunction in Tourette syndrome: Ann Neurol 1982;12(4):361-366.

9. Singer HS, Reiss AL, Brown JE, et al. Volumetric MRI changes in basal ganglia of children with Tourette's syndrome. Neurology 1993;43(5):950-956.

10. Braun AR. Stoetter B, Randolph C, et al. The functional neuroanatomy of Tourette's syndrome: an FDG-PET study. I. Regional changes in cerebral glucose metabolism differentiating patients and controls. Neuropsychopharmacology 1993;9(4):277-291.

11. Alexander GE, DeLong MR, Strick PL. Parallel organization of functionally segregated circuits linking basal ganglia and cortex. Annu Rev Neurosci 1986;9:357-381.

12. Marsden CD. The mysterious motor function of the basal ganglia: the Robert Wartenberg Lecture. Neurology 1982;32(5):514-539.

13. Mink JW. Basal ganglia dysfunction in Tourette's syndrome: a new hypothesis. Pediatr Neurol 2001;25(3):190-198.

14. Baker EFW. Gilles de la Tourette syndrome treated by bimedial leucotomy. Canad Med Ass J 1962;86:746-747.

15. Cooper IS. Dystonia reversal by operation in the basal ganglia. Arch Neurol $1962 ; 7: 64-74$.

16. Stevens H. The syndrome of Gilles de la Tourette and its treatment. Med Ann District Columbia 1964;36:277-279.

17. Cooper IS, ed. Involuntary movement disorders. New York: Harper \& Row; 1969:p $274-279$.

18. Sweet RD, Solomon GE, Wayne H, Shapiro E. Shapiro AK. Neurological features of Gilles de la Tourette's syndrome. J Neurol Neurosurg Psychiatry 1973;36(1):1-9. 
19. Hassier R, Dieckmann G. [Stereotaxic treatment of tics and inarticulate cries or coprolalia considered as motor obsessional phenomena in Gilles de la Tourette's disease]. Rev Neurol (Paris) 1970;123(2):89-100.

20. Nadvornik P, Sramka M, Lisy L. Svicka I. Experiences with dentatotomy. Confin neurol 1972; $34(320-324)$.

21. Beckers W. [Gilles de la Tourette's disease based on five own observations]. Arch Psychiatr Nervenkr 1973:217(2):169-186.

22. Hassler R, Dieckmann G. Relief of obsessive-compulsive disorders, phobias and tics by stereotactic coagulations of the rostral intralaminar and medial-thalanuc nuclei. In: Laitinen LV, Livingston K. eds. Surgical approaches in psychiatry. Proceedings of the Third International Congress of Psychosurgery. Cambridge, UK: Garden City Press; 1973:p 206-212.

23. Moldofkky H, Tullis C, Lamon R. Multiple tic syndrome (Giles de la Tourette's syndrome). J Nerv Ment Dis 1974;159(4):282-292.

24. Wassman ER, Eldridge R, Abuzzahab S, Sr, Nee L. Gilles de la Tourette syndrome: clinical and genetic studies in a midwestern city. Neurology 1978:28(3):304-307.

25. Asam U, Karrass W. [Gilles de la Tourette syndrome and psychosurgery] Acta Paedopsychiatr 1981:47(1):39-48.

26. Hassler R. Stereotaxic surgery for psychiatric disturbances. In: Schaltenbrand G. Walker AE, eds Stereotaxy of the human brain New York: Thieme-Stratton Inc 1982:p $570-590$.

27. Cappabianca P, Spaziante R, Carrabs G, de Divitiis E. Surgical stereotactic treatment for Gilles de la Tourette's syndrome. Acta Neurol (Napoli) 1987;9(4):273-280.

28. de Divitus E. D'Emco A, Cerillo A. Stereotactic surgery in Gilles de la Tourette syndrome. Acta Neurochir (Wien) 1977(Suppl 24):73.

29. Robertson M, Doran M, Trimble M, Lees A]. The treatment of Gilles de la Tourette syndrome by limbic leucotomy. J Neurol Neurosurg Psychiatry 1990:53(8):691-694.

30. Kurlan R, Kersun J, Ballantine HT, Jr, Came ED. Neurosurgical treatment of severe obsessive-compulsive disorder associated with Tourette's syndrome. Mov Disord 1990;5(2):152-155.

31. Kurlan R, Caine ED, Lichter D, Ballantine HT, Jr. Surgical treatment of severe obsessive-compulsive disorder associated with Tourette syndrome. Neurology 1988;38 (Suppl.):203.

32. Sawle GV. Lees AJ. Hymas NF, Brooks DJ. Frackowiak RS. The metabolic effects of limbic leucotomy in Gilles de la Tourette syndrome. J Neurol Neurosurg Psychiatry 1993;56(9):1016-1019.

33. Rauch SL, Baer L. Cosgrove GR, Jenike MA. Neurosurgical treatment of Tourette's syndrome: a critical review. Compr Psychiatry 1995:36(2):141-156.

34. Leckman JF, de Lotbiniere AJ, Marek K, Gracco C, Scahill L, Cohen DJ Severe disturbances in speech, swallowing, and gat following stereotactic infrathalamic lesions in Gilles de La Tourette's syndrome. Neurology 1993:43(5):890-894. 
35. Baer L, Rauch SL, Ballantine HT, Jr., et al. Cingulotomy for intractable obsessive-compulsive disorder. Prospective long-term follow-up of 18 patients. Arch Gen Psychiatry 1995;52(5):384-392.

36. Korzenev AV, Shoustin VA, Anichkov AD, Polonskiy JZ, Nizkovolos VB, Oblyapin AV. Differential approach to psychosurgery of obsessive disorders. Stereotact Funct Neurosurg 1997;68:226-230.

37. Babel TB, Warnke PC, Ostertag CB. Immediate and long-term outcome after infrathalamic and thalamic lesioning for intractable Tourette's syndrome. J Neurol Neurosurg Psychiatry 2001;70(5):666-671.

38. Definitions and classification of tic disorders. The Tourette Syndrome Classification Study Group. Arch Neurol 1993;50(10):1013-1016.

39. Vandewalle V, van der Linden C, Groenewegen HJ, Caemaert J. Stereotactic treatment of Gilles de la Tourette syndrome by high frequency stimulation of thalamus. Lancet 1999;353(9154):724.

40. Visser-Vandewalle V, van der Linden C, Temel Y, et al. Chronic high frequency stimulation of the thalamus for Gilles de la Tourette Syndrome; report of three cases. Acta Neurochir (Wien) 2002;144(10):1072 (abstract 1071.1021).

41. Visser-Vandewalle V, Temel Y, Boon P, et al. Chronic bilateral thalamic stimulation: a new therapeutic approach in intractable Tourette syndrome. J Neurosurg 2003;99: $1094-1100$. 


\title{
CHAPTER 5
}

\section{Chronic bilateral thalamic stimulation:}

a new therapeutic approach in intractable Tourette syndrome

\author{
A report of three cases
}

Veerle Visser-Vandewalle, Yasin Temel, Peter Boon, Fred Vreeling, Henry Colle, Govert Hoogland, Henk Groenewegen, Chris van der Linden.

J Neurosurg 99: 1094-1100, 2003 


\begin{abstract}
Based on the results of thalamotomies described by Hassler in 1970, the authors performed bilateral thalamic high frequency stimulation (HFS) in three patients with intractable Tourette syndrome (TS). In this report they describe the long-term effects.

Three male patients $(42,28$, and 45 years of age $)$ had manifested motor and vocal tics since early childhood. The diagnosis of Tourette syndrome was made according to the criteria of the Tourette Syndrome Classification Study Group (TSCSG). Any drug or alternative treatment had been either ineffective or only temporanly effective in all three patients. There was no serious comorbidity. The target for stamulation was chosen at the level of the centromedian nucleus, substantia periventricularis and nucleus ventrooralis internus. After 2 weeks of test stimulation, the pulse generators were implanted.

After a follow-up period of 5 years in the patient in Case 1,1 year in the patient in Case 2, and 8 months in the patient in Case 3, all major motor and vocal tics had disappeared and no serious complications had occurred. When stimulation was applied at the voltage necessary to achieve an optimal result on the tics, a slight sedative effect was noted in all three patients. In the patients in Cases 1 and 3 there were stimulation-induced changes in sexual behavior.

Chronic thalamic HFS may be an effective and safe treatment for medically intractable TS in adult patients. Unwanted stimulation-induced side effects may occur.
\end{abstract}


Tourette syndrome is a chronic neurological disorder with an onset in early childhood that is characterized by tics. These tics are defined as sudden, brief, intermittent, involuntary or semivoluntary movements (motor tics) or sounds (phonic or vocal tics).

They may be abrupt in onset, fast and brief (clonic) or slow and sustained (dystonic or tonic) ${ }^{19}$. Once considered to be a rare and bizarre syndrome, TS is now recognized as a relatively common. biological, genetic disorder with a spectrum of neurobehavioral manifestations that characteristically wax and wane during its natural course. In addition to motor and vocal tics, patients with TS often have a variety of behavioral symptoms, particularly those associated with attention deficit-hyperactivity disorder and obsessive-compulsive disorder $11.19,33$.

Drug treatment of TS consists of neuroleptics and other agents interacting with the dopaminergic system ${ }^{19}$. Side effects such as depression, drowsiness, weight gain and extrapyramidal symptoms are a major drawback for their prolonged use. Frequently, TS is found to be a self-limiting disorder as the patient reaches adulthood, whereas in a small proportion of the patients the tics continue into adult life and require long-term medication. Behavioral therapy has not been proven to be effective at long term.

Surgery has rarely been performed in TS. Hassler and Dieckmann ${ }^{16,17.18}$ carried out bilateral coagulations of the midline and intralaminar thalamic nuclei and the inner part of the ventral oral thalamic nuclei in three TS patients, resulting in partial relief of tics. In 1997, we performed stereotactic bilateral HFS of the thalamic nuclei targeted by Hassler in a patient with intractable $\mathrm{TS}^{41}$. In the present study. we report on the long-term effects of bilateral HFS of the thalamus in three patients with TS. We chose HFS because of its safety and reversibility. We obtained permission from the hospital's ethics committee, and all patients gave their informed consent.

\section{CLINICAL MATERIAL AND METHODS}

\section{Patient characteristics}

Three patients were selected on the basis of intractable TS with absent comorbidity. The diagnosis was made according to the criteria of the TSCSG ${ }^{39}$ Characteristics of tics with their frequencies per patient and per tic are shown in Table 1. The impact of the tics as determined by each patient is presented in Table 2. All three patients suffered from compulsive behavior. None of the patients or their 
partners reported obsessions (such as sexual obsessions). Psychotherapy had failed in all patients and medication, including various dopamine-depleting or dopamine receptor blocking agents and clonidine, either had no effect or had to be withdrawn after prolonged use because of unbearable side effects, depression being the most important.

In all patients blood chemistry, electroencephalography and $\mathrm{MR}$-images were normal. Neuropsychological evaluations were performed in the patients in Cases 1 and 3 .

\section{Evaluation of tics}

One week postoperatively the patients were evaluated by a blinded examiner while the neurosurgeon manipulated the pulse generator. In all patients an assessment of the acute effects of bipolar (poles 0 and 1 negative, 2 and 3 positive) stimulation with a frequency of $125 \mathrm{~Hz}$ and a pulse width of $210 \mu \mathrm{sec}$ was performed. Randomly, the amplitudes of both installed stimulators were set between $0 \mathrm{~V}$ and the maximum voltage, which was defined as the voltage above which the patient felt an unpleasant sensation of dizziness (Case 1: $6 \mathrm{~V}$ bilaterally; Case 2: $4.5 \mathrm{~V}$ for the left and $4 \mathrm{~V}$ for the right; and Case 3:5V for the left and $3 \mathrm{~V}$ for the right). Each evaluation was performed 15 minutes after manipulation of the stimulus intensity. Each session contained two periods during which both stimulators were switched off, and installed at the maximum voltage.

At the long-term follow-up ( 5 years for Case 1,1 year for Case 2 , and 8 months for Case 3), each patient was recorded on videotape for 20 minutes while chronic bilateral stimulation was applied, and for 20 minutes after both stimulators had been switched off for 12 hours. The number of tics displayed on the videotapes was counted by two independent, blinded investigators (Y.T. and G.H.) during a period of 10 consecutive minutes, which showed the greatest variety of tics on the videotape. For tonic tics, the duration was counted in seconds.

The number of tics and compulsions are described in Table 1. Table 2 presents the impact of the symptoms on self-esteem, familial and socio-professional life, as is estimated by the patient.

\section{Surgerical procedure}

The target was defined $5 \mathrm{~mm}$ lateral to the AC-PC line, $4 \mathrm{~mm}$ posterior to the midcommissural point, and at the AC-PC plane. Test stimulation was performed using a rigid monopolar electrode with a 2- mm naked tip (model 3101-2; 


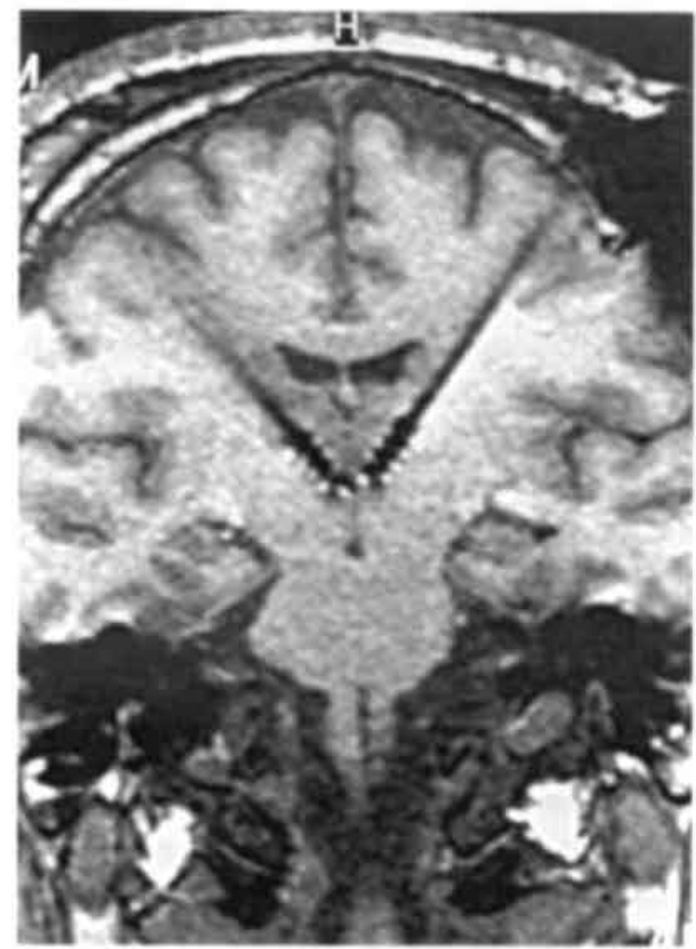

Figure 1. Case 1. Postoperative MR image (coronary slide) obtaned in a patient after implantation of two electrodes demonstrating their position in the medial part of the thalamus.

Radionics, Burlington, MA). After a test stimulation (frequency $100 \mathrm{~Hz}$, pulse width $200 \mu \mathrm{sec}$ ) during which special attention was paid to unwanted effects (except in the patient in Case 2 in whom general anesthesia was induced), the test electrode was replaced with the final, quadripolar electrode (model 3387; Medtronic, Kerkrade, The Netherlands), which was fixed in the burr hole with acrylic cement. In all patients fluoroscopy was used to evaluate the position of the quadripolar electrode before its fixation.

After the stereotactic operation, there was a test period of approximately 2 weeks in all patients when externalized electrodes were used. During this time, a postoperative MR-image was obtained (Fig.1). In all three patients, this MR-image demonstrated a good position of the electrodes, with no abnormalities. 
In the patients in Cases 1 and 2, two Itrel III pulse generators (model 7425, Medtronic) and in the patient in Case 3, a Kinetra pulse generator (model 7428; Medtronic) was implanted infraclavicularly at a second stage.

\section{Illustrative cases}

Case 1. This man was 42 years of age at the time of surgery, which was performed by V.V.V. The first tics had appeared at the age of 5 years and had consisted mainly of eye blinking and grimaces. As a child, he used to hurt himself by cutting his arms with a knife. From the age of 17 years, the most frequent tics consisted of licking objects, including his own shoulders, and making turning movements with his neck. Vocal tics consisted of throat clearing, uttering meaningless sounds, and blowing. Frequently he could not sit still on a chair and made adduction movements of the knees. He suffered from checking compulsions, such as inspecting doors and lights. The patient and his partner confirmed that the tics had a greater impact on their lives than the compulsive behavior.

During surgery, the stereotactic frame (Leksell G frame; Elekta, Linköping, Sweden) was fixed while the patient was sedated with propofol delivered through a laryngeal mask. After defining the target on the CT-scan by using the aforementioned coordinates $(5 \mathrm{~mm}$ lateral to the $\mathrm{AC}$ - $\mathrm{PC}$ line, $4 \mathrm{~mm}$ posterior to the middle of the AC-PC line, and at the AC-PC plane), sedation was tapered and the laryngeal mask was removed. At that time, the patient did not display any tics and was sufficiently cooperative for test stimulation to be performed. We started at his left side because we thought that the dominant hemisphere might have a greater impact on the tics than the nondominant one.

A burr hole was made and the test stimulation initiated. At target minus 6, and target minus 4 , there was no effect following the application of $3 \mathrm{~V}$. At target minus 2 , the patient reported a pleasant feeling at $1.75 \mathrm{~V}$. At target, this pleasant feeling was very intense, and the patient compared it with a feeling of euphoria elicited by drugs and felt that it would have a positive effect on his tics. At target plus 2, this pleasant feeling returned, at $2.25 \mathrm{~V}$, albeit less intense. The test electrode was replaced by the final quadripolar electrode with pole 1 (the second deepest pole) installed at the target.

On his right side we started stimulation at the same point. During stimulation of the target, however, the patient reported an intense sensation of fear and begged us to stop. The test stimulation electrode was reinstalled at a location $2 \mathrm{~mm}$ more medially, and here, at target, the patient again experienced a pleasant feeling of euphoria. The quadripolar electrode was installed at this site, with pole 1 at target. 
On the 1st postoperative day, the patient progressively raised the voltages on the right and left sides, to intensify the pleasant feeling. He increased them very suddenly to $6 \mathrm{~V}$ bilaterally, after which he experienced a sudden intense rebound of tics accompanied by dizziness. We set the voltages at $2 \mathrm{~V}$ bilaterally and instructed the patient not to raise stimulation to more than $3.5 \mathrm{~V}$, after which there was an important reduction of tics.

Case 2. This man was 28 years of age at the time of surgery, which was performed by H.C. His first tics had appeared as grimaces at the age of 8 years. At the time of surgery, the patient's most disabling tics consisted of screaming, head shaking and obscene finger gestures. He performed automutilation by burning his eyelashes with cigarettes. Because of his tics and the compulsion to touch people, he became completely socially isolated and lived with his parents.

The patient was placed under general anaesthesia throughout the stereotactic procedure, for which the Cosman Roberts Wells frame (Radionics) was used. The target was calculated on fused CT and MR images. The quadripolar electrodes on both sides were installed $5 \mathrm{~mm}$ lateral to $\mathrm{AC}-\mathrm{PC}, 4 \mathrm{~mm}$ posterior to the middle of the AC-PC line, and at the AC-PC plane, with pole 1 at target.

Postoperatively, during test stimulation performed by external screeners, the need to touch people and to self-mutilate had completely disappeared.

Case 3. This man was 45 years old at the time of surgery, which was performed by V.V.V. He had suffered from tics from the age of 7 years. The first tics consisted of grimaces and tongue pulling. As an adult, the most disabling tics included pounding the stomach and screaming. Flexion movements of the head and touching the head also had a great impact on the patient's social life. Apart from screaming. vocal tics consisted of throat clearing, coughing and sniffing. The patient's hands were frequently wounded because whenever he saw a glass, he was compelled to break it.

During the stereotactic procedure (for which the Cosman Roberts Wells frame was used), the patient was sedated with clonidine and lorazepam. The target coordinates were calculated on fused CT and MR-images.

We started test stimulation on the right side. From target minus 6 until target, no effect was noticed by the patient or the examiner, up to $3 \mathrm{~V}$. We installed the quadripolar electrode with pole 1 at target. On his left side, the patient showed an eye deviation at target plus 4 , suggesting that the electrode was located in the mesencephalon. We made a second trajectory $2 \mathrm{~mm}$ more medially. Here, there 
was no effect at target minus 6 until target plus 4 up to $5 \mathrm{~V}$, and the quadriploar electrode was installed with pole 1 at target.

Postoperatively, the screaming, stomach pounding, and compulsions to break glass had completely disappeared at $2.5 \mathrm{~V}$. The patient experienced a slight feeling of dizziness at the voltage necessary to reduce his tics, which he compared to the effects of one glass of wine.

\section{RESULTS}

\section{Effect on tics}

One week postoperatively there was a tic reduction of $82.5 \%$ in the patient in Case 1 (from 422 tics $/ 10$ minutes to 74 tics $/ 10$ minutes), $60.5 \%$ in the patient in Case 2 (from 205 tics $/ 10$ minutes to 81 tics $/ 10$ minutes), and of $53.6 \%$ in the patient in Case 3 (from 196 tics $/ 10$ minutes to 91 tics $/ 10$ minutes). In all patients the most disabling tics were absent.

At the long-term follow-up, there was a tic reduction of $90.1 \%$ in Case 1 (from 422 tics $/ 10$ minutes preoperatively to 42 tics / 10 minutes at 5 years), $72.2 \%$ in Case 2 (from 205 tics / 10 minutes to 57 tics/ 10 minutes at 1 year), and $82.6 \%$ in Case 3 (from 196 tics / 10 minutes preoperatively to 34 tics $/ 10$ minutes at 8 months). The results per patient and per tic at the long-term follow-up are presented in Table 1.

The patient in Case 1 still demonstrated minor turning movements of the head, blowing, uttering sounds and leg movements. These tics were clearly reduced in quantity and in intensity.

In the patient in Case 2, the smallest effect was seen on the grimaces. Although preoperatively his entire face had been involved, including the mouth opening widely, postoperatively these grimaces were restricted to the forehead and eye musculature. In the patient in Case 3 a few tendencies to scream were noted during the 20-minute videotape as well as minor flexions of the head and blinking of the eye. In all patients the remaining symptoms had a minimal impact on self-esteem and familial and socioprofessional lives; however, the remaining grimaces in the patient in Case 2 led to moderate problems (Table 2). 
Table 1 Tia nated per 10 - minute period preoperatively and postoperatively (at 5y, Iy and $8 \mathrm{~m}$ resp.) with both stimulator on and off

\begin{tabular}{|c|c|c|c|}
\hline \multirow[t]{2}{*}{ Tic charactenstics } & \multirow[t]{2}{*}{ Bascline } & & Postop stimulation \\
\hline & & On & $O \mathbb{H}$ \\
\hline \multicolumn{4}{|l|}{ Case 1} \\
\hline \multicolumn{4}{|l|}{ Motar tis. } \\
\hline Licking of objects/shoulders & 38 & 0 & 7 \\
\hline Turning movements of head & 42 & 6 & 33 \\
\hline Eye blinking & 0 & 13 & 8 \\
\hline Adduction of knees & 300 & 4 & 35 \\
\hline \multicolumn{4}{|l|}{ Voval nios } \\
\hline Throat clearing & 0 & 0 & 0 \\
\hline Uttering sounds & 24 & 12 & 11 \\
\hline Blowing & 18 & 7 & 12 \\
\hline TOTAL & 422 & 42 & 106 \\
\hline \multicolumn{4}{|l|}{ Case 2} \\
\hline \multicolumn{4}{|l|}{ Moter tio } \\
\hline Head shaking & 56 & 0 & 32 \\
\hline Obscene finger gestures & 2 & 0 & 1 \\
\hline Grumaces & 21 & 35 & 61 \\
\hline Kissing gostures & 105 & 22 & k \\
\hline Flexion movements of body & 3 & 0 & 0 \\
\hline \multicolumn{4}{|l|}{ Vocal tios } \\
\hline Screaming & 13 & 0 & 0 \\
\hline Snuffing & 3 & 0 & 6 \\
\hline TOTAL & 205 & 37 & $10 \mathrm{~K}$ \\
\hline \multicolumn{4}{|l|}{ Case 3} \\
\hline \multicolumn{4}{|l|}{ Motor tics } \\
\hline Pounding stomach & 0 & 0 & 0 \\
\hline Flexion movements of head & 70 & 12 & $4 K$ \\
\hline Grimaces/ Tongue pulling & 44 & 10 & 36 \\
\hline Touching head & 28 & 2 & 11) \\
\hline \multicolumn{4}{|l|}{ Vocal tivs } \\
\hline Screarning & 38 & 6 & 27 \\
\hline Sniffing & 6 & +1 & 5 \\
\hline Coughing & 10 & 2 & 4 \\
\hline TOTAL & 196 & 34 & 13 \\
\hline
\end{tabular}

\section{Neuropsychological effects}

The general intelligence level in both tested patients (Cases 1 and 3) was average to above average (intelligence quotient 108 and 114, respectively.). Preoperatively, these patients showed borderline to low results on verbal memory testing, and the patient in Case 3 performed below average on facial recognition. Postoperatively, the patient in Case 1 showed little or no change on the same tests performed preoperatively. In the patient in Case 3 the results on most timed tasks were lower, including visual reaction time and word fluency, which, seeming 
Table 2 Seventy of tics, obsessions and compulsions per patient and per tic.

Tic characteristics
Case 1
Tics
Licking of objects/shoulden
Turning movements of head
Throat clearing
Uttering sounds
Blowing
Adduction of knees
Eye blinking
Compulsions.
Checking (doon etc)

Preop

Postop

\section{Case 2}

Tis

Head shaking

Screaming

Obscene finger gestures

Girimaces

Kissing gestures

Sniffing

Hitting head

Turnung movements of head

Flexion movements of body

Compulsions

Touching people

Self-injunous hehavior

Automutilation with cigarettes

\section{Case 3}

Tis

Screaming

Pounding stomach

Flexion movements of head

Grimaces/ Tongue pulling

Touching head

Throat clearing

Sniffing

Coughing

Compulsions

Breaking glass

$\begin{array}{ll}+++ & 0 \\ +++ & + \\ ++ & 0 \\ ++ & + \\ ++ & + \\ ++ & + \\ 0 & + \\ ++ & \end{array}$

$\begin{array}{ll}+++ & 0 \\ +++ & 0 \\ +++ & 0 \\ +++ & ++ \\ +++ & + \\ ++ & 0 \\ ++ & + \\ ++ & 0 \\ + & 0 \\ +++ & 0 \\ +++ & 0\end{array}$

$\begin{array}{ll}+++ & + \\ +++ & 0 \\ +++ & + \\ +++ & + \\ +++ & 0 \\ ++ & 0 \\ ++ & 0 \\ ++ & 0 \\ +++ & 0\end{array}$

0: symptoms absent; + symptoms leading to minimal problems in self-esteem, familial or socioprofessional life; ++ symptoms leading to moderate problems in self-esteem, familial or socioprofessional life: +++ very intense symptoms leading to very low self-esteem and social isolation. 
Table 3 Stimulation characterictics at 2 -months and at long-term follow-up in three patients wath TS who received bilateral thalamic stimulation.

\begin{tabular}{|c|c|c|c|c|c|c|c|c|c|c|c|c|}
\hline \multirow[t]{3}{*}{ Pa: } & \multicolumn{4}{|c|}{ Electrode Setting } & \multicolumn{2}{|c|}{ Frequencency } & \multicolumn{4}{|c|}{ Amplitude in Voits } & \multicolumn{2}{|c|}{$\mathrm{PW}$ in microsec } \\
\hline & \multicolumn{2}{|l|}{$2-\operatorname{mos} F U$} & \multicolumn{2}{|l|}{ LTFU } & \multirow[t]{2}{*}{$2-\operatorname{mos} F U$} & \multirow[t]{2}{*}{$\mathrm{LTFU}$} & \multicolumn{2}{|c|}{$2-\operatorname{mos} \mathrm{FU}$} & \multicolumn{2}{|c|}{ LTFU } & \multirow[t]{2}{*}{$2-\mathrm{mos}$} & \multirow[t]{2}{*}{ LTHU } \\
\hline & h & $n$ & It & $\pi$ & & & it & $n$ & it & $\pi$ & & \\
\hline I & $12,1-12+, 3+$ & $0-, 1-12+3+$ & $10-1-1.2+.3+$ & $0+.1-/ 2+.3+$ & 75 & 100 & 25 & 2.5 & 22 & 24 & 210 & 210 \\
\hline 2 & 7- Cuset & 2-,3-/Caset & 7- Caset & $2-, 3-/$ Caxe+ & 65 & 65 & 27 & 2.7 & $2.8 \mathrm{i}$ & 3.0 & 210 & 210 \\
\hline 3 & 4.5 / Case & $0-.1-$ Caset & 5- Cust & 1-/ Caset & 130 & 100 & 20 & 2.4 & 24 & 2.8 & 210 & 210 \\
\hline
\end{tabular}

1. Si ht electrode hax 4 poler with 0 moss ventral and 3 most dorsal, or 4 most ventral and 7 most doral. When case is +, the stimulation is monopolar. In all patients the frequency and the pule width $(\mathrm{PW})$ are the same for the left and nght stde at 2 months and at long-term follow-up. $2 \mathrm{~m}=\mathrm{at} 2 \mathrm{month}$ follow-up; FU=follow-up: $L \mathrm{~T}=$ long term; $\mathrm{R}=\mathrm{nght}$; $\mathrm{L}=$ left; mirfoues= microneconds. 
vulnerable preoperatively, now fell below average in four of five categories. Verbal memory and facial recognition scores increased, indicating a possible retest effect.

\section{Stimulation parameters}

The stimulation parameters for each patient at 2 months and at the long-term follow-up are shown in Table 3.

\section{Side effects and complications}

All patients described a feeling of reduced energy at the stimulus voltage necessary for the best effect on their tics. One patient (Case 1) experienced it as being very pleasant. At the long-term follow-up, however, he reported that he preferred to lower the stimulation intensity during physical exercise, as did the other two patients.

At the long-term follow- up, the patient in Case 1 reported an increased sexual drive, and the patient in Case 3 complained of reduced sexual potency and ejaculation. These functions were examined by a sexologist during stimulation-on and -off conditions (except for ejaculation) and were found to be stimulation-related.

Two patients (Cases 1 and 3) each underwent three revisions of the pulse generator and extension cable because of traction pain.

\section{DISCUSSION}

In all three patients there was clearly a positive effect on the number of tics per 10-minute period before and after chronic bilateral stimulation. The number of tics did not necessarily reflect the impact of the tics on the patient's self-esteem and socio-professional life. Furthermore, not all tics exhibited by the patient during the last month prior to surgery were recorded on the videotape; for example, on the preoperative video of the patient in Case 3 , we did not see him pounding himself in the stomach. It is a well-investigated phenomenon that patients with TS who are videotaped at home exhibit a wider variety of tics than those who are videotaped in the clinician's office ${ }^{12}$. Given that we did not videotape these patients at home, we relied not only on the videotapes recorded in the hospital, but also on anamnestic and heteroanamnestic data. Moreover, the number as well as the intensity of the tics might be different, for example, in the case of the grimaces. For all these reasons, we preferred to present the impact of the tics on the patient's 
life, as shown in Table 2 . In all patients, the remaining symptoms only had a minimal impact on their lives.

After switching the stimulator off for 12 hours, symptoms did not return to baseline (Table 1). We considered this to be an after-effect of stimulation. One might criticize the effect of stimulation and infer that the reduction in symptoms was due to the natural evolution of the disease. We consider it highly unlikely that these patients with TS, which had been refractory to any kind of conservative treatment, would have such a spontaneous reduction in symptoms without presenting new ones. Only in the patient in Case 1 did eye- blinking become apparent after switching the stimulator off.

All three patients suffered from compulsions preoperatively. Compulsions consist of repetitive, seemingly purposeful types of behaviors that are performed to certain rules or in a stereotyped fashion.

Obsessive-compulsive and self-injurious behaviors completely disappeared in all patients (Table 2), even when both stimulators were switched off.

In the past, many different lesioning procedures have been performed on patients with TS. Frontal lobe operations have included prefrontal lobotomies ${ }^{37,42}$ and bimedial frontal leucotomies 5,27 . The limbic system was targeted during limbic leucotomy ${ }^{32,34}$ and cingulotomy ${ }^{4,20,21}$ with or without hypothalamotomy. Thalamic operations have included lesions of the medial, intralaminar and ventrolateral thalamic nuclei ${ }^{3,8-10,16-18,38}$. Infrathalamic lesions were created at the level of Forel's field (campotomies), the zona incerta, and the red nucleus $2,3,6$. ${ }^{22}$. Cerebellar surgery has included dentatotomies ${ }^{28}$. The majority of the reports lack any specification of the tic reduction or any rationale for choosing a specific target. Hassler and Dieckmann ${ }^{16-18}$, however, presented a detailed report of the successful results achieved by creating lesions in the midline and intralaminar thalamic nuclei as a treatment for TS in nine patients. In patients with facial tics, they additionally created lesions of the nucleus ventrooralis internus. Based on these positive results and actual knowledge of the pathophysiological features of $\mathrm{TS}^{25.26}$, we decided to target the same thalamic nuclei in patients with intractable TS. Rather than lesioning these nuclei, however, we applied high- frequency stimulation. In the course of the neurosurgical treatment of Parkinson disease and tremor, HFS has been shown to have effects on symptoms similar to those of lesioning. HFS, however, is safer and has the advantage that its effects can be modulated in accordance with the patient's needs.

Various clinical, neuropathological and neuro-imaging observations indicate that a dysfunctioning of the basal ganglia and related thalamocortical circuits form, at 
least in part, the pathophysiological basis of TS $7,13,14,23,29,30,35,43$. It is assumed that the basal ganglia play a major role in the "timing and sequencing" of motor and behavioral programs by selecting desired and by suppressing unwanted programs to be executed 26,31 . In this way, the basal ganglia "assist" the (pre) frontal cortex in facilitating or by suppressing behavioral or motor responses 1.24 Thus, the uncontrolled movements and vocalizations in TS might be the result of defective inhibitory mechanisms at the level of the basal ganglia, leading to the expression of simple or more complex fragments of otherwise purposeful motor or behavioral act. The thalamic involvement in the aforementioned circuits is dual in nature. Whereas the medial and ventral thalamic nuclei are way stations within these circuits that lead back to the premotor and prefrontal cortices from which the circuits originate, the midline and intralaminar thalamic nuclei send projections to both the premotor and prefrontal cortex and the striatum. Therefore, the basal ganglia-thalamocortical circuits are strongly influenced at the level of their major input (the striatum) by excitatory thalamic input. It has been hypothesized that in this way the midline and intralaminar thalamic nuclei may strongly influence the level of activity in these circuits ${ }^{15}$. The caudal intralaminar thalamic nuclei, the presumptive target of our HFS electrodes in the present study, are thought to play a major role in limbic-motor functions, whereas other, more rostral intralaminar nuclei are thought to be involved in cognitive and attentional functions ${ }^{\text {to }}$. In determining the level of activity of the striatum, the midline and intralaminar thalamic nuclei might play an important role in the gating of the output of the basal ganglia to the thalamocortical system and the brain stem. Lesioning or inhibiting these nuclei by HFS may, at least in part, close the gate.

According to the target coordinates used in our study, we believe that the three groups of nuclei that were lesioned by Hassler and Dieckmann are affected by the stimulation used in our study in the centromedian nucleus (as part of the intralaminar thalamic nuclei), the substantia periventricularis (as part of the midline thalamic nuclei), and the nucleus ventrooralis internus (Fig 2).

Nonetheless, with the amplitudes used and the altered position of the right electrode in the patient in Case 1 (by $2 \mathrm{~mm}$ ), and the left electrode in the patient in Case 3 (also by $2 \mathrm{~mm}$ ), we cannot exclude the possibility that other adjacent nuclei were also influenced.

The reversibility of the effect of stimulation is very important for these patients because of the sedative effect that accompanies the positive effects on the tics. The patient programmer enables them to control the stimulus intensity and hence the level of energy that they prefer based on the situation in which they find themselves. 


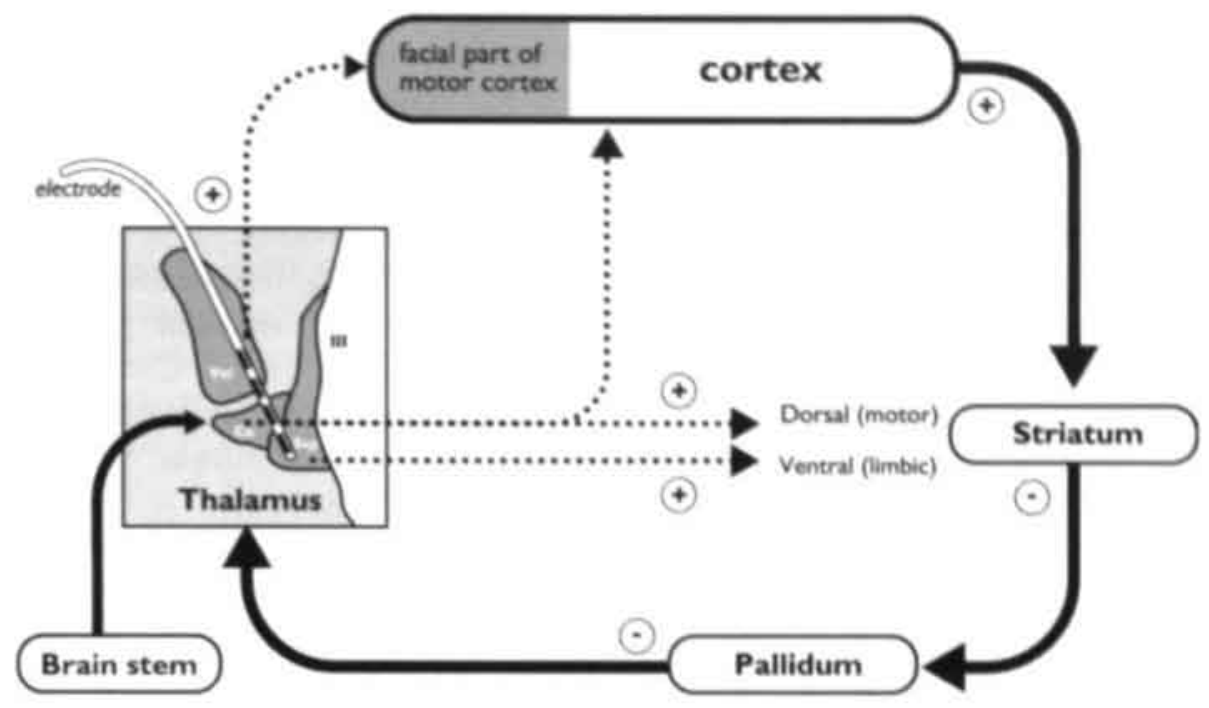

Figure 2. Schematic representation tllustrating the target of stimulation. Donvd limos represent the output: hypothencally reduced by the stumulation. toward the man output structures of the tangeted nuclei. $C e=$ centromedan nucleus, Spv=subsantia periventriculars, Vot=nucleus ventroorals internus, III=third ventricle

The effects on sexual behavior in the patients in Cases 1 and 3 might be explained by stimulation of the caudal intralaminar thalamic nuclei ${ }^{36}$. Thus, data from preclinical studies indicate that the posterior intralaminar thalamic nuclei are possibly involved in processing the sexual outflow from the spinothalamic pathway towards the preoptic area, the temporal lobe and the frontal cortex ${ }^{36}$.

\section{CONCLUSIONS}

Chronic thalamic stimulation could well be an effective and safe treatment for intractable TS. Caution with regard to unwanted stimulation-induced side effects is warranted.

\section{Acknowledgement}

We thank Brenda Vollers-King and Lieve Desbonnet for their editorial assistance. 


\section{REFERENCES}

1. Alexander GE, Delong MR, and Strick PL: Parallel organisation of functionally segregated circuits linking basal ganglia and cortex. Ann Rev of Neurosci 9:357-381, 1986

2. Asam U, Karrass W: Gilles de la Tourette syndrome and psychosurgery. Paedopsychiatr 47(1): 39-48, 1981

3. Babel TB, Warnke PC, Ostertag CB: Immediate and long-term outcome after infrathalamic and thalamic lesioning for intractable Tourette's syndrome. J Neurol Neurosurg Psychiatry 70(5): 666-71, 2001

4. Baer L, Rauch SL, Ballantine HT, Jr., et al: Cingulotomy for intractable obsessive-compulsive disorder. Prospective long-term follow-up of 18 patients. Arch Gen Psychiatry 52(5): 384-92, 1995

5. Baker EFW: Gilles de la Tourette syndrome treated by bimedial leucotomy. Canad Med Ass J 86: 746-747, 1962

6. Beckers W: [Gilles de la Tourette's disease based on five own observations]. Arch Psychiatr Nervenkr 217(2): 169-86, 1973

7. Braun RB, Stoetter B, Randolph C: The functional neuroanatomy of Tourette's syndrome: an FDG-PET study. 1.Regional changes in cerebral glucose metbolism differentiating patients and controls. Neuropsychology 9(4): 277-291, 1993

8. Cappabianca P, Spaziante R, Carrabs G, et al: Surgical stereotactic treatment for Gilles de La Tourette's syndrome. Acta Neurol (Napoli) 9(4): 273-80, 1987

9. Cooper IS: Dystonia reversal by operation in the basal ganglia. Arch Neurol 7:64-74. 1962

10. Cooper IS: Involuntary movement disorders. New York: Harper \& Row: 274-279. 1969

11. Cummings JL, Frankel M: Gilles de la Tourette Syndrome and the neurological basis of obsessions and compulsions. Biol Psychiatry 20: 1117-1126, 1985

12. Goetz CG, Leurgans S, Chmura TA: Home alone: methods to maximize tic expression for objective videotape assessments in Gilles de la Tourette syndrome.

Mov Disord 16(4): 693-7, 2001

13. Graybiel AM, Canales J: The neurobiology of repetitive behaviors: clues to the neurobiology of Tourette syndrome. Adv Neurol 85: 123-131, 2002

14. Graybiel AM, Rauch SL: Toward a neurobiology of obsessive-compulsive disorder. Neuron 28: 343-347, 2000

15. Groenewegen HJ. Berendse HW: The specificity of the non-specific midline and intralaminar thalamic nuclei. Trends Neurosci 17: 52, 1994

16. Hassler R: Stereotaxic surgery for psychiatric disturbances, In: Schaltenbrand G, Walker AE (eds): Stereotaxy of the human brain. Ed. 2. New York: Thieme-Stratton Inc: $570-590,1982$ 
17. Hassler R, Dieckmann G: Relief of obsessive-compulsive disorders, phobias and tics by stereotactic coagulations of the rostral intralaminar and medial-thalamic nuclei. In: Latinen LV, Livingston (eds): Sungical approaches in psychiatry. Proceedings of the Thurd International Congress of Psychosurgery. Cambridge UK. Garden City Press, Letchworth: 206-212, 1973

18. Hassler R, Dieckmann G: Traitement stéréotaxique des tics et cris inarticulés ou coprolaliques considérés comme phénomène d'obsesson motrice au cours de la maladie de Gilles de la Tourette. Rev Neurol, Panis 123 (2): 89-100, 1970

19. Jankovic J. Tourette's syndrome: N Engl J Med 345(16): 1184-1192, 2001

20. Kurlan R, Caine ED, Lichter D, et al: Surgical treatment of severe obsessive-compulsive disorder associated with Tourette syndrome. Neurology 38 (Suppl 1): 203, 1988

21. Kurlan R, Kersun J. Ballantine HT, Jr., et al: Neurosungical treatment of severe obsessive-compulsive disorder associated with Tourette's syndrome. Mov Disord 5(2): $152-5,1990$

22. Leckman JF, de Lotbiniere AJ, Marek K, Gracco C, Scahill L, Cohen DJ Severe disturbances in speech, swallowing, and gait following stereotactic infrathalamic lesions in Gilles de la Tourette's syndrome. Neurology 43(5): 890-4, 1993

23. Leckmann JF, Pauls DL, Peterson BS, et al: Pathogenesis of Tourette syndrome. Clues from the clinical phenotype and natural history. Adv Neurol 58, ed. by T. N. Chase, A. J. Fnedhoff, and D. J. Cohen. Raven Press Ltd, New York c 1992

24. Marsden CD: The mysterious motor functions of the basal ganglia: the Robert Wartenberg Lecture. Neurology 3: 514-539, 1982

25. Mink JW: Basal ganglia dysfunction in Tourette's syndrome: a new hypothesis. Pediatr Neurol 25: 190-8, 2001

26. Mink JW. The basal ganglia: focused selection and inhibition of competing motor programs. Prog Neurobiology 50: 381-425, 1998

27. Moldofsky H, Tullis C, Lamon R: Multiple tic syndrome (Gilles de la Tourette's syndrome). J Nerv Ment Dis 159(4): 282-92, 1974

28. Nadvornik P, Sramka M, Lisy L, et al: Expenences with dentatotomy. Confin Neurol 34: $320-324,1972$

29. Peterson B, Riddle MA, Cohen DJ, et al: Reduced basal ganglia volumes in Tourette's syndrome using three-dimensional reconstruction techniques from magnetic resonance images. Neurology 43 (5): $941-949,1993$

30. Rauch SL, Whalen PJ, Curran T, et al: Probing striato-thalamic function in obsessive-compulsive disorder and Tourette syndrome using neuromaging methods. Adv Neurol 85: 207-24, 2001

31. Redgrave P, Prescott T], Gurney K: The basal ganglia: a vertebrate solution to the selection problem? Neuroscience 89: 1009-1023, 1999

32. Robertson M. Doran M. Trimble M, et al: The treatment of Gilles de la Tourette syndrome by limbic leucotomy. J Neurol Neurosurg Psychuatry 53(8): 691-4, 1990

33. Robertson MM: Tourette syndrome, assoctated conditions and the complexities of the treatment. Brain 123: 425-462, 2000 
34. Sawle GV, Lees AJ, Hymas NF, et al: The metabolic effects of limbic leucotomy in Gilles de la Tourette syndrome. J Neurol Neurosurg Psychiatry 56(9): 1016-9, 1993

35. Singer HS, Butler IJ. Tune LE, et al: Dopaminergic dysfunction in Tourette syndrome. Ann Neurol 12: 361-366, 1982

36. Steers WD: Neural pathways and central sites involved in penile erection: neuroanatomy and clinical implications. Neurosci Biobehav Rev 24(5): 507-1, 2000

37. Stevens H: The syndrome of Gilles de la Tourette and its treatment. Med Amm DC 36: 277-279, 1964

38. Sweet RD, Solomon GE, Wayne H, et al: Neurological features of Gilles de la Tourette's syndrome. J Neurol Neurosurg Psychiatry 36(1): 1-9, 1973

39. The Tourette Syndrome Classification Study Group: Definitions and classification of tic disorders. Arch Neurol 50: 1013-6, 1993

40. Van der Werf YD, Witter MP, Groenewegen HJ: The intralaminar and midline nuclei of the thalamus. Anatomical and functional evidence for participation in processes or arousal and awareness. Brain Res Rev 39: 107-140, 2002

41. Vandewalle V, van der Linden C, Groenewegen HJ, et al: Stereotactic treatment of Gilles de la Tourette syndrome by high frequency stimulation of thalamus. Lancet 353 (9154): 724, 1999

42. Wassman ER, Eldridge R, Abuzzahab S, et al: Gilles de la Tourette syndrome: clinical and genetic studies in a midwestern city. Neurology 28(3):304-7, 1978

43. Wright CI, Peterson BS, Rauch SL: Neuroimaging studies in Tourette syndrome. CNS Spectrums 4:54-61, 1999 


\section{Conclusion}

In the pre-DBS era, unilateral pallidotomies were considered the treatment of choice in advanced Parkinson disease to alleviate all motor symtoms. In chapter 1 we describe the long-term motor effects of unilateral pallidal stimulation in 26 patients with a mean follow-up of 32.7 months (minimum of 24 months). The effects are not good at long term, making unilateral pallidal stimulation an unattractive treatment option for PD patients. Since this long-term effect is not only unsatisfactory on the side ipsilateral to the stimulation and on axial symptoms, but also on the contralateral symptoms, we consider the question: 'would bilateral pallidal stimulation be a favourable option in PD?' to be redundant.

We conclude that the globus pallidus internus is not a favourable target for DBS in advanced $P D$.

Our results described in chapter 2 confirm the beneficial effects of bilateral STN stimulation presented in other studies, all of which, however, have a limited follow-up period. We investigated the effects in 20 patients, each with a minimum follow-up of four years. We found that the positive effect on motor function, ADL, and functional performance is maintained. This strengthens the value of bilateral STN DBS for PD patients who suffer from the complications of chronic levodopa treatment. Moreover, the implantation of electrodes appears to be a safe technique, as shown in our study and in the others reviewed in chapter 2 . One side effect of stimulation of the STN is, however, rather concerning, and that is that the patient's mood, and even personality, can change due to the stimulation. Of the 20 patients described in chapter 2 , four presented with hypomanic to manic features. One patient had to be excluded from this study because he committed suicide before four years of follow-up had been reached.

We conclude that behavioral changes following STN DBS are not rare. We believe that this fact will give an extra impetus to research into alternative treatment options for patients with advanced PD, e.g. transplantation of dopaminergic cells. At this moment in time, there is no alternative, 
For patients who have undergone a pallidotomy and in whom motor symptoms on the side ipsilateral to the lesion or axial problems like gait freezing develop, the question could arise: would the patient be better off with contralateral unilateral pallidal stimulation or with bilateral STN stimulation? A unilateral STN stimulation after pallidotomy is not an option because of conflicting postoperative medication requirements. When the risks of behavioral changes are taken into account, one would choose unilateral pallidal stimulation. The results described in chapter 1 however lead to the conclusion that also in these patients bilateral STN stimulation is the treatment of choice.

In chapter 3 we showed that performing STN DBS in patients with multiple system atrophy-parkinsonism is justifiable. We performed a bilateral STN DBS in four patients with MSA-P. Although the effects were far less pronounced than in patients with PD, we showed that bilateral STN DBS was beneficial to these patients, since, on the one hand, there were no alternatives, and on the other, the patients' functional performance would clearly have been worse without stimulation, as demonstrated by the results with the stimulators being switched off for 12 hours.

While, in our opinion, DBS will probably be replaced by transplantations in the treatment of advanced PD in the future, we believe this technique will remain indispensable for diseases in which there is no chemical deficiency, as in Tourette syndrome (TS). We find this an interesting study object as it lies at the other extreme of the spectrum compared to PD. In PD, a dopamine deficiency accounts for the motor symptoms. In TS, there is probably a dopaminergic hypermetabolism. In the past, there have been numerous attempts to operate on patients with intractable TS, all involving the destruction of various parts of the brain. Frontal lobe operations included prefrontal lobotomies and bimedial frontal leucotomies. The limbic system was targeted during limbic leucotomy and anterior cingulotomy. Thalamic operations included lesioning of the medial, intralaminar and ventrolateral thalamic nuclei. Infrathalamic lesions were performed at the level of Forel's fields (campotomies) and the zona incerta. Cerebellar surgery included dentatotomies. In an attempt to achieve total control of symptoms, more complex operations have been performed such as combined anterior cingulotomies and infrathalamic lesions. We review all of these in chapter 4 . The lack of rationale for choosing specific targets for these ablative procedures is striking and makes most of them hazardous from an ethical point of view, especially when the complications are taken into consideration. These vary from dystonia to even quadriplegia. 
Since we know from the history of surgery for PD that HFS mimics the effects of a lesion, but with far fewer complications, we performed the first DBS in a Tourette patient in 1997. Relying on the beneficial effects of thalamotomies in TS described by Hassler in 1970. we performed a bilateral thalamic stimulation in this patient, with a good result. In chapter 5 , we describe the long-term effects (5yrs, $1 \mathrm{yr}$, and 8 mos, resp.) in three patients with intractable TS, who underwent bilateral thalamic stimulation. The results on the tics are very good, with a tic reduction of $90.1 \%, 72.2 \%$ and $82.6 \%$, respectively. The positive effects on the behavioral disorders, from which approximately $60 \%$ of TS patients suffer, are also very promising. Side effects include a stimulation-induced lower state of arousal in all three, and changes in sexual behavior in two.

After more than fifteen years of experience with DBS, we believe it is important to stay critical and to keep re-evaluating the effects in the long term. Special attention should be paid to side effects which are not apparent at first glance. Teamwork involving not only neurosurgeons and neurologists, but also neuropsychologists and psychiatrists, is of great importance in the field of DBS. We consider this to be even more important than the use of the most sofisticated neurosurgical techniques, since the positive effects of STN stimulation in our study were obtained by a relatively simple technical procedure, with target determination on CT-scan, without depth-recordings.

From our point of view, the safety offered by DBS makes the technique of creating permanent lesions in new indications unethical. Unwanted side effects can occur, and may even appear when the patient is at home ( $\mathrm{f}$. the changes in sexual behavior in the two TS patients) but these can be reversed in the case of DBS.

A final remark is that we believe the advantages and possibilities of DBS should be further exploited. Even in patients with a relatively short life-expectancy with symptoms which react less to DBS than in PD, DBS might be of great value resulting in their functional performance being considerably better than without stimulation. 


\section{Conclusie}

In het pre-DBS tijdperk werd de unilaterale pallidotomie beschouwd als de voorkeursbehandeling voor Parkinsonpatiënten die conservatief waren uitbehandeld, met een gunstig effect op de verschillende motore verschijnselen. In hoofdstuk 1 werden de lang-termijn motorische effecten beschreven van de unilaterale pallidale stimulatie bij 26 patiēnten met een gemiddelde follow-up van 32,7 maanden (met een minimum van 24 maanden). Deze resultaten zijn onbevredigend, niet alleen voor wat betreft de ipsilaterale en axiale symptomen, maar ook voor de contralaterale. Deze bevindingen maken ons inziens de vraag of de bilaterale pallidale stimulatie een goede therapeutische keuze zou kunnen zijn, overbodig.

Wij concluderen dat de globus pallidus internus geen gunstige target is voor DBS bij de ziekte van Parkinson.

De resultaten beschreven in hoofdstuk 2 bevestigen de positieve effecten van bilaterale stimulatie van de nucleus subthalamicus (STN) die in andere studies beschreven zijn. Deze hebben evenwel alle een beperkte follow-up. Wij hebben de lange termijn effecten bestudeerd bij 20 patiënten, elk met een minimum follow-up van 4 jaar. We vonden dat het positieve effect op de motorische functies. het uitvoeren van de dagelijkse activiteiten en het algemeen functioneren, op deze lange termijn behouden blijft. Dit versterkt de waarde van de bilaterale STN stimulatie bij patiënten die lijden onder de complicaties van het chronisch levodopagebruik. Bovendien blijkt de implantatie van electroden in de STN een veilige techniek te zijn, zoals blijkt uit onze studie en andere studies die in hoofdstuk 2 vernoemd worden. Eén neveneffect van de bilaterale STN stimulatie evenwel is onrustwekkend, en dat is dat er postoperatieve stimulatiegebonden stemmings-, en gedragsafwijkingen kunnen optreden. Van de 20 patiënten beschreven in hoofdstuk 2 vertoonden er vier hypomane tot manische kenmerken. Eén patient was geexcludeerd van deze studie omwille van suicide vóór de termijn van vier jaar follow-up was bereikt. 
Wij concluderen dat gedragsveranderingen na bilaterale STN DBS niet zelden voorkomen. Dit zal ons inziens een extra motivatie zijn voor verder onderzoek voor alternatieve behandelingsmethoden voor Parkinsonpatiënten die conservatief zijn uitbehandeld, bijvoorbeeld transplantaties van dopaminerge cellen.

Voor patiènten die in het verleden een pallidotomie hebben ondergaan en die symptomen ontwikkelen ipsilateraal aan de lesie, of gangmoeilijkheden, kan de vraag rijzen of het beter is een contralaterale unilaterale pallidale stimulatie uit te voeren, dan wel een bilaterale STN stimulatie. Een unilaterale STN stimulatie is geen optie omwille van het tegengestelde medicatiebeleid postoperatief na een pallidotomie en een subthalamische stimulatie. Wanneer men de kans op gedragsveranderingen in overweging neemt, zou men voor de contralaterale pallidale stimulatie kiezen. Bovendien is de kans op een bloeding theoretisch kleiner bij een unilaterale, dan bij een bilaterale stimulatie. Toch leiden de resultaten van onze studie tot de conclusie dat ook in deze patiëntengroep een bilaterale STN stimulatie de beste keuze is.

In hoofdstuk 3 hebben wij angetoond dat STN stimulatie een verdedigbare therapeutische optie is voor patiënten met MSA-P ("multiple system atrophy-parkinsonism") Deze operatie werd bij vier MSA-P patiënten uitgevoerd. Alhoewel de effecten minder goed waren dan die van STN stimulatie bij de ziekte van Parkinson, hebben wij aangetoond dat deze patiënten baat hadden bij deze operatie, omdat zij beduidend minder goed functioneerden nadat de stroom uitgezet was gedurende 12 uur, hetgeen respresentatief is voor hun toestand die zij op dat moment zouden vertoond hebben zonder operatie.

Terwijl DBS naar onze mening in de toekomst waarschijnlijk vervangen zal worden door transplantaties van dopaminerge cellen, geloven wij dat deze techniek onvervangbaar zal blijven in de behandeling van aandoeningen waarbij er geen tekort aan neurotransmitters kan worden aangetoond, zoals bij het Tourette syndroom (TS). TS is een interessant studieobject voor DBS omdat het op het andere uiteinde van het spectrum ligt vergeleken met de ziekte van Parkinson. Bij de ziekte van Parkinson ligt een tekort aan dopamine aan de basis van de klinische verschijnselen. In TS is er waarschijnlijk een dopaminehypermetabolisme. In het verleden zijn er multipele soorten operaties uitgevoerd bij patiënten met therapieresistent TS. Ingrepen ter hoogte van de frontaalkwab omvatten prefrontale lobotomieën en bimediale frontale leucotomeën. Er werden lesies uitgevoerd ter hoogte van het limbisch systeem tijdens de limbische leucotomieën en anterieure cingulotomieën. Ingrepen ter hoogte van de thalamus bestonden ondermeer uit het aanbrengen van lesies ter hoogte van de mediaal gelegen, intralaminaire en ventrolaterale kernen. Infrathalamische lesies werden uitgevoerd op het niveau 
van het veld $\mathrm{H}$ van Forel (campotomieèn) en de zona incerta. Ook cerebellaire ingrepen, met name dentatotomieèn, werden uitgevoerd bij Tourettepatiènten. In een poging om alle symptomen te behandelen werden ook complexe operaties uitgevoerd zoals een combinatie van anterieure cingulotomieèn en infrathalamische lesies. Hoofdstuk 4 omvat een samenvatting van al deze ingrepen. Het gebrek aan rationale voor het kiezen van een bepaalde target om een irreversible lesie te maken is frappant. Dit maakt deze ingrepen moeilijk ethisch te verdedigen, vooral wanneer men de complicaties voor ogen houdt. Deze varieerden van dystonie tot quadriplegie.

Omdat HFS hetzelfde klinisch effect heeft als een lesie, maar dan op een reversibele manier, hebben wij in 1997 voor het eerst DBS uitgevoerd bij een patiènt met refractair Tourette syndroom.Gebaseerd op de gunstige effecten van thalamotomieèn die Hassler in 1970 beschreven heeft, hebben wij bij deze patiènt een bilaterale stimulatie uitgevoerd van het mediale gedeelte van de thalamus, met een gunstig resultaat. In hoofdstuk 5 presenteren wij de resultaten van een bilaterale thalamische stimulatie bij 3 patienten met TS, na een follow-up van resp. 5 jaar, 1 jaar en 8 maanden. De effecten op de tics zijn positief, met een ticreductie van resp. $90,1 \%, 72,2 \%$ en $82,6 \%$. Ook op de gedragsafwijkingen, waaran $60 \%$ van de Tourettepatiënten lijdt, was er een gunstig effect. Als nevenwerkingen vermeldden de drie patiènten het gevoel van minder energie te hebben bij die voltage die noodzakelijk was voor een optimaal effect op de tics. Bovendien waren er stimulatiegebonden veranderingen in het sexueel gedrag bij twee patiënten.

Na meer dan 15 jaar ervaring met DBS moeten we kritisch blijven en de patiënten blijven herevalueren, ook op lange termijn. We moeten steeds bedacht blijven op stimulatiegebonden neveneffecten die op-het eerste zicht niet evident zijn. Teamwork, waarbij niet alleen neurologen en neurochirurgen betrokken zijn, maar ook neuropsychologen en psychiaters, is zeer belangrijk voor DBS! Dit vinden wij zelfs belangrijker dan het gebruik van de meest gesofisticeerde operatietechnieken, gezien de positieve effecten van de STN stimulatie in deze studie via een relatief eenvoudige procedure bekomen werden, namelijk met targetbepaling op CT-scan, zonder diepteregistraties. Volgens ons maakt de veiligheid van DBS vandaag de dag het maken van permante lesies bij zogenaamde "nieuwe"indicaties, zoals het Tourette syndroom, nog moeilijk ethisch te verdedigen. Onverwachte neveneffecten kunnen optreden, zelfs relatief laat na de ingreep, wanneer de patiënt ontslagen is uit het ziekenhuis ( $\mathrm{cfr}$ de sexuele veranderingen bij de twee Tourettepatiënten), maar deze zijn reversibel in het geval van DBS. 
Wij geloven dat de voordelen en de mogelijkheden van DBS meer zouden moeten worden benut. Zelfs bij patiënten met een relatief beperkte levensverwachting (zoals MSA-P patiënten), waarbij de effecten van DBS minder spectaculair zijn dan in het geval van de ziekte van Parkinson, kan DBS van grote waarde zijn voor de patiënt omdat hun dagelijks functioneren beter is met stimulatie, vergeleken met de toestand waarin ze zich op dat moment zouden bevinden indien ze niet zouden geopereerd zijn. 


\section{Dankwoord}

De volgende personen wil ik bedanken voor hun hulp bij het tot standkomen van dit boekje.

\section{Prof. J. Caemaert}

Beste Jacques, begin 1996, net na het einde van mijn opleiding, heb ik het ongelooflijke voorrecht gehad om deel te mogen uitmaken van het team dat jij had opgericht om de diepe hersenstimulatie bij Parkinsonpatiënten uit te bouwen. Ik beschouw het als een zeer groot voorrecht dat ik deze technick van jou heb mogen leren en voel diep respect en dankbaarheid voor de manier waarop je me uiteindelijk mijn eigen weg hebt laten gaan.

\section{Prof. E. Beuls}

Beste Emile, jij hebt me alle kansen gegeven om mijn eigen functionele pad uit te stippelen in Maastricht, en om dit proefschrift vorm te geven. Ik kan je niet genoeg bedanken voor je steun.

Prof. A. Bosch

Beste Andries, ik beschouw jou als de "peetvader"van de functionele neurochirurgie in Nederland, met een grote klinische en wetenschappelijke expertise, en beschouw het als een grote eer dat je medepromotor wil zijn van mijn proefschrift. Door onze gesprekken heb je me gestimuleerd om over de toekomst van de diepe hersenstimulatie na te denken. Mijn bijzondere dank ook voor je steun en vertrouwen die ik mag ondervinden bij het uitbouwen van de Tourettechirurgie in Nederland.

\section{Dr. C. yan der Linden}

Beste Chris, begin 1996 is onze samenwerking begonnen, toen we in Gent startten met de pallidale stimulaties. Door jouw niet aflatend enthousiasme konden we veel patienten opereren. Ik heb bijzonder goede herinneringen aan onze gezamenlijke OK-tijd. Ook mijn bijzondere dank voor de eerste Tourettepatiënt 
die je naar me hebt doorverwezen. Ik apprecieer ook zeer de manier waarop je onze patiènten hebt gevolgd.

\section{Dr. G. Spincemaille}

Beste Geert, door de jaren heen heb ik jou leren apprecièren als een bijzonder integer man. Als geen ander weet jij de ogenschijnlijke dagelijkse moeilijkheden die ons professionele leven met zich meebrengt met jouw typische rustige houding te ontmantelen. Jij bent een voorbeeld voor mij. Mijn hartelijke dank voor het kritisch doorlezen van deze manuscripten.

\section{Drs, Y. Temel}

Beste Yasin, jij was ongetwijfeld mijn grootste steun en toeverlaat "op het veld", bij het uitbouwen van de bewegingsstoornissenchirurgie in het azM, en dat ben je nog steeds. Je hebt je echt op een ongelooflijk snelle manier op dit terrein ingewerkt. Mede dankzij jou heb ik de patiëntenzorg kunnen combineren met het schrijven van dit proefschrift. Je hebt ook een grote rol gespeeld in het totstandkomen van dit boekje door jouw niet aflatende ijver om me te helpen bij de datacollectic.

\section{Dr. F. Frocling}

Hese Fred, bedankt voor je hulp en steun bij het uitbouwen van de bewegingsstoomisenchirurgie in het azM.

Dr. Fred Nieman en Mw. Halime Celik

Jullie wil ik hartelijk danken voor jullie hulp bij de statistiek.

Mw Brenda Vollers-King

Beste Brenda, dankzij jou kon ik de artikelen in foutloos engels afleveren.

Mw. Linda Ackermans

Beste Linda, dankzij jou bleef mijn bibliografie steeds up to date!

Mw. K. Foubert

Beste Kris, niemand weet beter dan jij hoe het is om met een Parkinsonpatient te leven. Jouw man is in een vergevorderd stadium van de ziekte door ons geopereerd, en we hebben jou leren kennen als een bijzonder toegewijde vrouw die al onze patiënten op een zeer bijzondere manier heeft bijgestaan. Ze noemen jou niet voor niets "een engel". Jouw goede band met de patiènten heeft me ten zeerste geholpen met de datacollectie voor dit boekje. 
Mijn collega's die ik nog niet vernoemd heb: Erwin Cornips, Jim Dings, Henk van Santbrink. Willem Berfelo, Hubert Defesche. Doordat jullie méér werk verzet hebben in de algemene neurochirurgische kliniek, had ik meer tijd voor mijn aandachtsgebied en voor mijn proefschrift. Ik ben jullie daar zeer erkentelijk voor.

Mirella Waber en Nicole Bakker, case-managers functionele neurochirurgie in het azM. Door jullie bijzonder goede contacten met de patiènten en jullie groot organisatietalent hebben jullie me heel wat werk uit handen genomen!

\section{Geertjan van Zonneveld}

Met jouw creatieve geest heb je hele mooie plaatjes gemaakt voor mijn boekje, waardoor precies werd voorgesteld wat ik bedoelde.

Gijs de Jong

Beste Gijs, samen met José ben je voor Ton en mij het symbool van echte vriendschap. Steeds heb je onbevooroordeeld mijn proefschriftperikelen aanhoord. Ik vind het een eer dat je mijn paranymf wil zijn.

Mijn familie die ik minder aandacht gegeven heb dan ze verdienden omdat mijn boekje op tijd af moest zijn. Vooral mijn zus Ilse en haar familic, mijn schoonouders, en Mark en Dieneke, bedankt voor jullie steun.

\section{Orsolya Semmelweis}

Dear Orsi, thank you so much for taking so good care of Caspertje while Ton and I were (are) working. You often asked me why I worked so hard. Now you'll probably understand it a little bit more.

\section{Ton}

Mijn prins op het witte paard, mijn rots in de branding. Zonder jou was dit boekje er nooit geweest, want niets lukt zonder jou.

\section{Caspertic}

Mijn schattebolletje, je beseft het nog niet, maar je hebt je mama al enorm geholpen door zo $n$ lief en vrolijk jongetje te zijn.

\section{Mijn lieve ouders}

Jullie hebben jarenlang veel geduld met me gehad, en mij geleerd dat je met hard werken en een standvastig vertrouwen veel kan bereiken. Jullie kan ik wel een miljoen keer bedanken. 


\title{
List of publications
}

\author{
ARTICLES
}

De Reuck J, Vanderdonckt P, de Bleeker J, Mareels H, Vandeualle I: Mitotic activity in cerebrospinal fluid cells. Clin Neurol Neurosurg 90: 117-119, 1988

Vingerhoets G, Lannoo E, van der Linden C, Caemaert J, Vandeualle V, van den Abbeele D, Wolters M: Changes in quality of life following unilateral pallidal stimulation in Parkinson's disease. J Psychosom Res 46: 247-55, 1999

Vingerhoets G, van der Linden C, Lannoo E, Vandewalle V, Caemaert J, Wolters $M$, van den Abbeele D: Cognitive outcome after unilateral pallidal stimulation in Parkinson's disease. J Neurol Neurosurg Psychiatry 66: 297-304, 1999

Van Laere K, van der Linden C. Santens P. Vandewalle V, Caemaert J, van den Abbeele D. Dierckx R: 99Tc(m)-ECD SPET perfusion changes by internal pallidum stimulation in advanced Parkinson's disease. Nucl Med Commun $21: 1103-12,2000$

Tavernier R, Fonteyne W, Vandewalle V de Sutter J, Gevaert S: Use of an implantable cardioverter defibrillator in a patient with two implanted neurostimulators for severe Parkinson's disease. Pacing Clin Electrophysiol 23: $1057-9.2000$

Visser-Vandeuralle V, Temel Y. Colle H,van der Linden C: Bilateral high frequency stimulation of the subthalamic nucleus in MSA-P; a study of 4 cases. J Neurosurg 98: 882-887, 2003

Visser-Vandewalle V, van der Linden C, Temel Y, Nieman F, Celik H. Beuls E: Long-term motor effect of unilateral pallidal stimulation in advanced Parkinson disease; a study of 26 patients. J Neurosurg 99: 701-707, 2003 
Visser-Vandewalle $V$, Temel Y, Boon P, Vreeling F, Colle H, van der Linden C, Groenewegen $\mathrm{HJ}$ : Chronic bilateral thalamic stimulation: a new therapeutic approach in intractable Tourette Syndrome. J Neurosurg 99: 1094-1100, 2003

Temel Y, Visser-Vandewalle V, Boon P, Vreeling F, Beuls EAM: Bilaterale hoogfrequente stimulatie van de nucleus subthalamicus bij de ziekte van Parkinson en MSA-P. Tijdschr Neurol Neurochir (In press)

Van der Linden C, Visser-Vandewalle V, Colle H, Foncke E, Temel Y, Bruggeman R: Diepe hersenstimulatie bij het syndroom van Gilles de la Tourette. Tijdschr Neurol Neurochir 104: 228-234, 2003

Temel Y, van Lankveld J, Boon P, Spincemaille GH, van der Linden C, Visser-Vandewalle V: Deep brain stimulation of the thalamus can influence penile erection. Int J Impot Res (In press)

Temel $\mathrm{Y}$ and Visser-Vindewalle V: Surgery in Tourette Syndrome. (Research Review), Mov Disord (In press)

Ackermans L, Temel Y, van Lankveld JJDM, Visser-Vandewalle V: Kan erectie aan- en uitgezet worden? Tijdschr Seksuol (In press)

Leentjes AFG, Visser-Vandewalle V, Temel Y, Verhey FRJ: Manipuleerbare wilsbekwaamheid: een nieuw ethisch probleem bij electrostimulatie van de nucleus subthalamicus voor ernstige ziekte van Parkinson. Ned Tijdschr voor Geneeskunde (In Press)

\section{Submitted}

Visser-Fandewalle V, van der Linden C, Temel Y, Celik H, Ackermans L, Spincemaille GH, Caemaert J: Long-term effects of bilateral subthalamic stimulation in advanced Parkinson disease. J Neurosurg (Submitted)

Temel Y, Ackermans L, Spincemaille GH, Celik H, van der Linden C, Walenkamp GH, van de Kar T. Visser-Vandewalle V: Management of hardware infections following deep brain stimulation. Acta Neurochir (Submitted)

Temel Y, Visser-Vandewalle V, Ackermas L, Beuls E: The role of the thalamus in erection. (Review). Int J Impot Res (Submitted) 
Temel Y, Blokland A, Ackermans L, Boon P, Beuls EAM, Spincemaille GH, Visser-Vandeualle $V$ : Improved motor responding, but central slowing, following bilateral subthalamic nucleus stimulation in patients with advanced Parkinson disease. Brain (Submitted)

\section{NEWSLETTERS}

Vandeualle V, van der Linden C, Groenewegen H J. Cacmacrt J: Stereotactic treatment of Gilles de la Tourette syndrome by high frequency stimulation of the thalamus: case report. The Lancet 353: 724, 1999

\section{BOOK CHAPTERS}

Vandewalle V: De ziekte van parkinson: stimulatie van de nucleus subthalamicus. In: Bewegingsstoornissen, E.Ch. Wolters en T. van Laar (eds). VU uitgeverij. Amsterdam 2002

van der Linden C. Foncke E, Colle H, Bruggeman R. Temel Y. Visser-Vandeualle $V$ : The neurosurgical treatment of Gilles de la Tourette's syndrome. In "handbook of Tourette's syndrome and related tic and behavioral disorders". Kurlan(ed). Dekker. New York, 2nd ed (In press)

\section{ABSTRACTS}

Van Laere K, Goethals I, van der Linden C, Vandewalle I, Caemaert J, Dierckx RA: Pallidal electrostimulation of Parkinson patients: effects on rCBF. Nucl Med 17: 995,1996

Van der Linden C, Caemaert J, Vandewalle V, De Reuck J, Achten R: Unilateral stimulation of the dorsolateral putamen in Parkinson' s disease. Case report. Mov Disord 11: 598, 1996

Van der Linden C, Caemaert J, Vandewalle V. Van den Abbeele D: Chronic unilateral stimulation of the globus pallidus internus (GPi) in advanced Parkinson's disease. Mov Disord 12(suppl): 133, 1997 (poster presentation) 
Van der Linden C, Caemaert J, Vandewalle V, Van den Abbeele D: Chronic unilateral stimulation of the internal globus pallidus $(\mathrm{GPi})$ in advanced Parkinson 's disease: a 3 month follow-up in 9 patients. Neurology 48 (suppl): A430-431, 1997

Vandewalle $V$, Temel Y, Colle $\mathrm{H}$, van der Linden C: Bilateral high frequency stimulation of the subthalamic nucleus in MSA-P, 2001. World society for Stereotactic and Functional Neurosurgery $13^{\text {th }}$ annual meeting Australia (oral presentation) (abstract 125 A). Stereotact Funct Neurosurg 77(1-4): 125, 2001

Vandewalle $V$, van der Linden C, Temel Y, Colle H, Vreeling F: Chronic high frequency stimulation of the thalamus for Gilles de la Tourette syndrome: report of 3 cases, 2002, XVth Congress of the European Society for Stereotactic and Functional Neurosurgery, 9-12 October, Toulouse (France) (oral presentation) (abstract 1.21), Acta Neurochir 144 (10): 1072, 2002

Temel Y, Vandewalle V, Celik H, Ackermans L, van der Linden C: Long-term outcome of unilateral pallidal stimulation in advanced Parkinson's disease. 2002. XVth Congress of the European Society for Stereotactic and Functional Neurosurgery, 9-12 October, Toulouse (France) (oral \& poster presentation) (abstract 1.23), Acta Neurochir 144(10): 1073, 2002

Temel Y, van der Linden, Celik H. Spincemaille G, Visser-Vandewalle V: Long-term effects of bilateral subthalamic nucleus stimulation in advanced Parkinson's disease. 2003 June, $13^{\text {th }}$ meeting of the European Neurological Society, Istanbul, Turkey (poster presentation) (abstract 501a), J Neurol 250:210, 2003

\section{Other poster presentations}

Rijkers K, Vandewalle V, Temel Y, Vanormelingen L, Vandersteen M, Adriaensens P, Gelan J, Beuls EAM: A high field magnetic resonance anatomic analysis of the subthalamic nucleus. The way to the future: direct 3-D visualization of the target. 2002, From Brain Plasticity to Neuronavigation symposium Ghent, Belgium

Ackermans L, Temel Y, Beuls EAM, Van der Linden C, Vreeling F, Visser-Vandewalle V: Deep brain stimulation for movement disorders: Parkinson disease, Multiple System Atrophy-Parkinsonism and Tourette Syndrome. 2003, 7th Maastricht Medical Students Research Conference 
Desbonnet L. Temel Y, Visser-Vandeualle V, van der Wolff M, Steinbusch HWM: Histological damage of bipolar versus unipolar high frequency stimulation in the rat. 2003, $2^{\text {nd }}$ Dutch Endo-Neuro-Psycho meeting, Doorwerth, The Netherlands 


\section{CURRICULUM VITAE}

Veerle Visser-Vandewalle was born on $31^{\text {t }}$ December, 1964, in Sint-Niklaas, Belgium.

She studied medicine at the State University in Ghent. In 1989 she started her training as neurosurgeon consisting of three years in general neurosurgery in the Sint- Jans Hospital. Brugge, followed by a final year at the University Hospital Ghent where Professor Jacques Caemaert was head of department. Subsequently, as staff member in the same department for almost three and a half years, she focussed on functional neurosurgery, more specifically deep brain stimulation, in movement disorders and pain, and psychosurgery. On I"April 1999, she became a member of staff in the Department of Neurosurgery at the University Hospital of Maastricht under Prof. Emile Beuls. She was appointed to expand the area of functional neurosurgery in this hospital, with specific emphasis on surgery for movement disorders and epilepsy. The first two months were spent in Canada, training in epilepsy surgery at the MNI (Montreal Neurological Institute). On returning to The Netherlands, while based in Maastricht, she assisted at and performed operations at the University Medical Centre. Utrecht, under the guidance of Prof. C. van Veelen. In December 1999 the first Parkinson patient was operated on in Maastricht. All this resulted in the University Hospital Maastricht being recognized by the Ministry of Health as the second centre for epilepsy surgery and the sixth centre for movement disorders surgery in The Netherlands, and in an experimental animal project supported by the Dutch Medical Council to investigate the underlying mechanisms of subthalamic nucleus stimulation in Parkinson disease.

In October 1999 she met her husband Ton Visser in the operating theatre of the University Hospital Maastricht (while he was anaesthetizing her first Tourette patient who required a revision of the extension cable!), and in May 2001. Casper was born. 
